CAMILA GREGORUT

\title{
AVALIAÇÃO DO DESEMPENHO DE UMA LÍNGUA ELETRÔNICA NA IDENTIFICAÇÃO DE CULTIVARES DE SOJA
}

\author{
Dissertação apresentada à Escola \\ Politécnica da Universidade de São \\ Paulo para obtenção do título de Mestre \\ em Engenharia.
}

São Paulo 

CAMILA GREGORUT

\title{
AVALIAÇÃO DO DESEMPENHO DE UMA LÍNGUA ELETRÔNICA NA IDENTIFICAÇÃO DE CULTIVARES DE SOJA
}

\author{
Dissertação apresentada à Escola \\ Politécnica da Universidade de São \\ Paulo para obtenção do título de Mestre \\ em Engenharia. \\ Área de Concentração: \\ Microeletrônica \\ Orientador: Prof. Livre-Docente \\ Fernando Josepetti Fonseca.
}

São Paulo 
Este exemplar foi revisado e alterado em relação à versão original, sob responsabilidade única do autor e com a anuência de seu orientador.

São Paulo, 29 de outubro de 2010.

Assinatura do autor

Assinatura do orientador

FICHA CATALOGRÁFICA

Gregorut, Camila

Avaliação do desempenho de uma língua eletrônica na identificação de cultivares de soja / C. Gregorut. -- ed.rev. -- São Paulo, 2010. $105 \mathrm{p}$.

Dissertação (Mestrado) - Escola Politécnica da Universidade de São Paulo. Departamento de Engenharia de Sistemas Eletrônicos.

1. Sensores químicos 2. Soja (Identificação) I. Universidade de São Paulo. Escola Politécnica. Departamento de Engenharia de Sistemas Eletrônicos II. t. 
Dedico este trabalho à minha família. 



\section{AGRADECIMENTOS}

Ao professor Fernando Josepetti Fonseca, pelo suporte e orientação no desenvolvimento deste trabalho.

Ao Leonardo Giordano Paterno, pelo apoio e colaboração na realização deste trabalho.

À Mercedes Concórdia Carrão Panizzi e à Josemeyre Bonifácio da Silva, pela motivação e auxílio nesta pesquisa.

Aos amigos do grupo GEM Marco Roberto Cavallari, Guilherme de Souza Braga, Nadja Karolina Leonel Wiziack, Gerson dos Santos, Sérgio Tonzar Ristori Ozaki e John Paul Hempel Lima por toda a ajuda durante a execução deste trabalho.

Às amigas Adriana, Letícia, Eleonora, Natasha, Karina e Vanessa, pelo companheirismo.

E, finalmente, à minha família, especialmente à minha irmã Vanessa, pelo apoio incondicional e amizade ao longo de minha vida. 

Se queres vencer o mundo inteiro, vence-te a ti mesmo.

(Fiódor Dostoiévski) 



\section{RESUMO}

A soja é um produto de grande importância para a economia brasileira, pois o Brasil é o segundo produtor mundial de soja. Sua aplicação mais conhecida é como óleo refinado, entretanto, a soja é bastante utilizada nas mais variadas indústrias. Do ponto de vista nutricional, a soja se destaca por possuir um alto valor protéico, sendo por isso muito empregada em indústrias alimentícias. Porém, os produtos alimentícios a base de soja ainda enfrentam uma grande resistência por parte dos consumidores. Esta resistência do mercado consumidor tem motivado os produtores de soja e as indústrias a buscarem o desenvolvimento de grãos com características especiais. Este trabalho auxilia nesta busca, pesquisando um método capaz de discriminar cultivares de soja - fornecidos pela Embrapa Soja - através da utilização de uma Língua Eletrônica (LE). A Língua Eletrônica é um sistema multissensorial composto por um conjunto de sensores não-específicos que respondem diferentemente para cada analito, sendo capaz de reconhecer e diferenciar amostras através da obtenção de impressões digitais destas. Neste trabalho, os sensores da Língua Eletrônica foram construídos a partir de filmes automontados de polímeros condutores. Foram realizados testes de repetibilidade e reprodutibilidade, além do estudo de sensibilidade dos sensores que compõem o sistema multissensorial. A Língua Eletrônica construída mostrou-se capaz de diferenciar os cinco cultivares estudados, especialmente aqueles que possuíam características notadamente distintas. Foram observadas variações das medidas ao longo dos dias, o que foi atribuído a uma possível degradação dos grãos de soja e do extrato de soja preparado. Foi proposto ainda um método alternativo de preparação do extrato de soja sem a utilização de tratamento térmico. Devido ao seu bom desempenho nos estudos citados, a Língua Eletrônica se mostrou viável para o emprego em uma pré-seleção de cultivares de soja.

Palavras-chave: Nanotecnologia. Soja. Extrato de soja. Língua Eletrônica. Polímeros Condutores. Automontagem. 



\section{ABSTRACT}

Soy is a commodity of great importance to the Brazilian economy since Brazil is the second biggest producer of soy in the world. Soybeans are usually employed in the production of refined oil for cooking as well as in many other foodstuff industries due to its high protein content. However, foodstuffs based on soy still face some resistance by consumers mainly because of the characteristic soy taste imposed to their respective products. This actual scenario has motivated producers and foodstuff industries to develop new soybeans varieties with improved and more pleasant taste. This work was intended to provide a methodology based on an electronic tongue system (ET) in order to help both producer and industries to develop and identify different soybean cultivars. Different soybeans cultivars developed by Embrapa Soja were evaluated by the ET. The ET is a multisensorial system composed by an array of non-specific, layer-by-layer assembled conducting polymer chemical sensors, which display distinct electrical fingerprints to different samples. The distinct responses make the ET capable to distinguish as well as recognize different samples when previously trained. The sensitivity, repeatability and reproducibility of chemical sensors responses to soybeans liquid extracts were evaluated and confirmed by exhaustive cyclic operation. The ET was indeed able to discriminate 5 different soybeans cultivars, in particular those with pronounced distinct properties. It was observed a systematic variation on the ET responses in a same day of analysis as well as for prolonged days which we have attributed to possible degradation of raw soybeans and its respective liquid extracts. An alternative procedure for soybean extract preparation absent of cooking was developed. The remarkable performance of the ET makes the system of great potential to perform the pre-selection of soybeans cultivars, with reliability and output.

Key-words: Nanotechnology. Soy. Soy Extract. Electronic Tongue. Conducting Polymers. Layer-by-layer films. 



\section{LISTA DE ILUSTRAÇÕES}

Figura 1 - Estrutura química do trans-PAc e da PAni. 29

Figura 2 - Fórmula estrutural da esmeraldina desdopada.

Figura 3 - llustração do processo de fabricação de um filme automontado de 1,10decanodilbisfosfonato de zircônio segundo o mecanismo de adsorção química (PATERNO; MATTOSO; OLIVEIRA Jr., 2001b).

Figura 4 - Ilustração esquemática do processo de fabricação de um filme automontado por meio da atração eletrostática entre polieletrólitos. A - Esquema de soluções poliméricas e de limpeza. B - Evolução da estrutura interna do filme com uma bicamada (DECHER, 1997). 32

Figura 5 - Língua eletrônica. .35

Figura 6 - Fluxograma da Análise Sensorial de cultivares de soja realizada por Silva (2009). 42

Figura 7 - Fluxograma do processamento do extrato de soja. .43

Figura 8 - Fórmulas estruturais (a) PAni, (b) POMA, (c) POEA, (d) PSS, (e) FTC, (f) PEDOT:PSS, (g) PPy e (h) PAH. .48

Figura 9 - Ilustração e dimensões do microeletrodo interdigitado. ..........................49

Figura 10 - Leite de soja Mais Vita Pura Soja da Yoki.........................................49

Figura 11 - Cultivares de soja utilizados neste trabalho. ....................................50

Figura 12 - Procedimento de preparação das amostras: (a) maceração de 0,5 g de grãos de soja em água destilada; (b) trituração dos grãos macerados no liquidificador; (c) filtração do extrato e (d) extrato final analisado...........................52

Figura 13 - Funcionalização do eletrodo de ouro com 3-MPA ..............................53

Figura 14 - Robô para a deposição de filmes por automontagem, Haubenteuer MG 1100 .54

Figura 15 - Ilustração do sistema de medidas da LE. ....................................55

Figura 16 - Condutivímetro portátil Minipa modelo MCD-2000, utilizado nas medições de condutividade elétrica. .56

Figura 17 - Microscópio óptico utilizado. 
Figura 18 - Gráficos de medidas alternadas de capacitância elétrica da água destilada (menores valores) e leite de soja comercial (maiores valores), para os sensores 1 a 4 da LE.

Figura 19 - Gráficos de medidas alternadas de capacitância elétrica da água destilada (menores valores) e leite de soja comercial (maiores valores), para os sensores 5 a 8 da LE

Figura 20 - Gráfico de medidas seqüenciais das capacitâncias elétricas do ar, leite de soja e água destilada sob agitação, para o sensor 1 da LE.

Figura 21 - Gráficos de medidas seqüenciais das capacitâncias elétricas do ar, leite de soja e água destilada sob agitação, para os sensores 2 a 4 da LE.

Figura 22 - Gráficos de medidas seqüenciais das capacitâncias elétricas do ar, leite de soja e água destilada sob agitação, para os sensores 5 a 7 da LE. .63 Figura 23 - Gráfico de medidas seqüenciais das capacitâncias elétricas do ar, leite de soja e água destilada sob agitação, para o sensor 8 da LE. .64 Figura 24 - Gráfico de PCA obtido com a LE a $1 \mathrm{kHz}$, a partir do extrato de soja fornecido por Silva (2009), submetido a um cozimento em autoclave (121 ํ) por 5 minutos.

Figura 25 - Gráfico de PCA obtido com a LE a $1 \mathrm{kHz}$, sem a realização de tratamentos térmicos a partir de $5,0 \mathrm{~g}$ de grãos de soja. .66

Figura 26 - Gráfico de pH dos cultivares de soja estudados.

Figura 27 - Gráfico de condutividade elétrica dos cultivares de soja estudados.

Figura 28 - Impressão digital elétrica dos cinco cultivares de soja estudados, obtida a $1 \mathrm{kHz}$ com a LE.

Figura 29 - Gráfico de PCA obtido com a LE a $1 \mathrm{kHz}$, a partir dos dados apenas do primeiro dia de medida.

Figura 30 - Gráfico de PCA obtido com a LE a $1 \mathrm{kHz}$, a partir dos dados dos três primeiros dias de medida. As setas indicam a separação dos cultivares segundo a sequência: BRS 258, BRS 216, BRS 133, BRS 257 e BRS 267. .70

Figura 31 - Gráfico de PCA obtido com a LE a 1 kHz, a partir dos dados dos 10 dias de medida.

Figura 32 - Gráfico de PCA obtido com a LE a $1 \mathrm{kHz}$, a partir de 5,0 g de grãos de soja e utilizando-se os dados apenas do primeiro dia de medida. 72

Figura 33 - Gráfico de PCA obtido com a LE a $1 \mathrm{kHz}$, a partir de 5,0 g de grãos de soja e utilizando-se os dados dos 3 dias de medidas. 
Figura 34 - Gráficos de 10 dias de medidas de capacitância elétrica da água destilada (menores valores) e dos extratos de soja (maiores valores), para os sensores 1 e 2 da LE.

Figura 35 - Gráficos de 10 dias de medidas de capacitância elétrica da água destilada (menores valores) e dos extratos de soja (maiores valores), para os sensores 3 a 5 da LE.

Figura 36 - Gráficos de 10 dias de medidas de capacitância elétrica da água destilada (menores valores) e dos extratos de soja (maiores valores), para os sensores 6 a 8 da LE. .76

Figura 37 - Imagens obtidas através do microscópio óptico dos sensores 1 e 2 da LE, com ampliação de 8 vezes. .77

Figura 38 - Gráfico de PCA obtido com a LE a $1 \mathrm{kHz}$, a partir de $5,0 \mathrm{~g}$ de grãos de soja e utilizando-se os dados apenas do primeiro dia de medida. As setas indicam a ordem das medições. 79

Figura 39 - Gráfico de PCA obtido com a LE a $1 \mathrm{kHz}$, a partir de 5,0 g de grãos de soja e utilizando-se os dados apenas do terceiro dia de medida.

Figura 40 - Gráficos de PCA obtidos com a LE a $1 \mathrm{kHz}$, a partir de medidas da capacitância elétrica dos extratos de soja dos cultivares BRS 133 e BRS 216, obtidas entre agosto de 2009 e maio de 2010. 81

Figura 41 - Gráficos de PCA obtidos com a LE a $1 \mathrm{kHz}$, a partir de medidas da capacitância elétrica dos extratos de soja dos cultivares BRS 257 e BRS 258, obtidas entre agosto de 2009 e maio de 2010.

Figura 42 - Gráfico de PCA obtido com a LE a $1 \mathrm{kHz}$, a partir de medidas da capacitância elétrica dos extratos de soja do cultivar BRS 267, obtidas entre agosto de 2009 e maio de 2010. .83

Figura 43 - Gráfico de PCA obtido com a LE a $1 \mathrm{kHz}$, onde o cultivar desconhecido $\mathrm{X}$ corresponde ao cultivar BRS 133.

Figura 44 - Gráfico de PCA obtido com a LE a 1 kHz, onde o cultivar desconhecido $X$ corresponde ao cultivar BRS 216. .85

Figura 45 - Gráfico de PCA obtido com a LE a $1 \mathrm{kHz}$, onde o cultivar desconhecido $\mathrm{X}$ corresponde ao cultivar BRS 257.

Figura 46 - Gráfico de PCA obtido com a LE a $1 \mathrm{kHz}$, onde o cultivar desconhecido $\mathrm{X}$ corresponde ao cultivar BRS 258. .86 
Figura 47 - Gráfico de PCA obtido com a LE a $1 \mathrm{kHz}$, onde o cultivar desconhecido X corresponde ao cultivar BRS 267. .86

Figura 48 - Gráfico de PCA obtido com a LE a $1 \mathrm{kHz}$, onde o cultivar desconhecido $X$ corresponde ao cultivar BRS 216.

Figura 49 - Gráfico de PCA obtido com a LE a $1 \mathrm{kHz}$, onde o cultivar desconhecido X corresponde ao cultivar BRS 257. .88

Figura 50 - Gráfico de PCA obtido com a LE a $1 \mathrm{kHz}$, onde o cultivar desconhecido X corresponde ao cultivar BRS 267. .88

Figura 51 - Línguas Eletrônicas utilizadas (a) LE 1 e (b) LE 2. .89

Figura 52 - Impressão digital elétrica dos cinco cultivares de soja estudados, obtida a $1 \mathrm{kHz}$ com a LE 2 . .90

Figura 53 - Gráfico de PCA obtido com a LE 2 a $1 \mathrm{kHz}$, a partir de $0,5 \mathrm{~g}$ de grãos de soja e utilizando-se os dados apenas do primeiro dia de medida. 91 Figura 54 - Gráfico de PCA obtido com a LE 2 a $1 \mathrm{kHz}$, a partir de $0,5 \mathrm{~g}$ de grãos de soja e utilizando-se os dados dos 3 dias de medidas. As setas indicam a separação dos cultivares segundo a sequência: BRS 258, BRS 216, BRS 133, BRS 257 e BRS 267. 


\section{LISTA DE TABELAS}

Tabela 1 - Exemplos de compostos padrões para as cinco sensações de gosto. ....34 Tabela 2 - Composição da soja (EMBRAPA SOJA, 2009) ....................................38

Tabela 3 - Principais características dos cultivares de soja estudados. ..................51

Tabela 4 - Composição dos sensores da LE...............................................54 



\section{LISTA DE ABREVIATURAS E SIGLAS}

$\begin{array}{ll}\text { 3-MPA } & \text { Ácido 3-mercapto propiônico } \\ \text { DMAc } & \text { Dimetil acetamida } \\ \text { FTC } & \text { Ftalocianina de níquel } \\ \text { GEM-EPUSP } & \text { Grupo de Eletrônica Molecular da Escola Politécnica da USP } \\ \text { GMS } & \text { Glutamato monossódico } \\ \text { HCI } & \text { Ácido clorídrico } \\ \text { LE } & \text { Língua Eletrônica } \\ \text { LS } & \text { Lignina sulfonada } \\ \text { PAA } & \text { Poli(ácido acrílico) } \\ \text { PAH } & \text { Hidrocloreto de polialilamina } \\ \text { PAni } & \text { Polianilina } \\ \text { PCA } & \text { Análise das Componentes Principais } \\ \text { PC } & \text { Componente Principal } \\ \text { PEDOT } & \text { Poli(3,4-etilenodioxitiofeno) } \\ \text { PLS } & \text { Regressão por mínimos quadrados parciais } \\ \text { POMA } & \text { Poli(o-metoxianilina) } \\ \text { POEA } & \text { Poli(o-etoxianilina) } \\ \text { PPy } & \text { Polipirrol } \\ \text { PSS } & \text { Poliestireno sulfonado } \\ \text { PVP } & \text { Poli(4-vinil-piridina) }\end{array}$





\section{SUMÁRIO}

1 OBJETIVOS E JUSTIFICATIVAS .............................................. 25

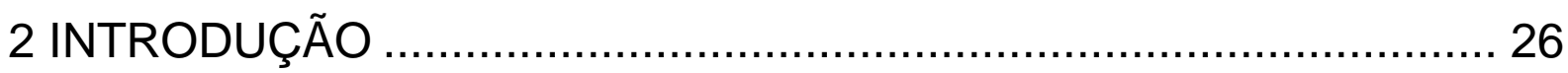

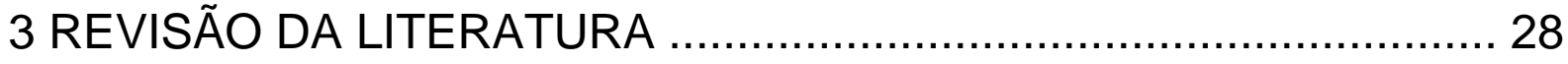

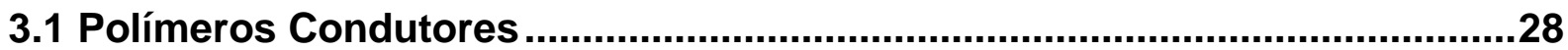

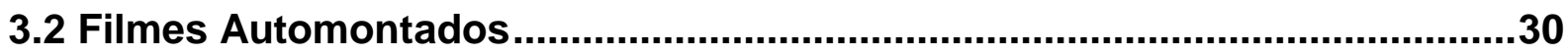

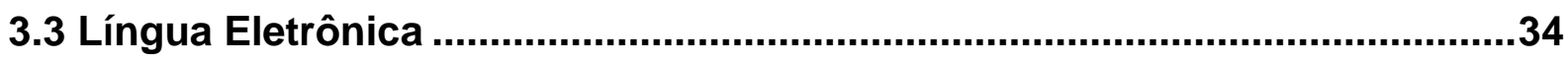

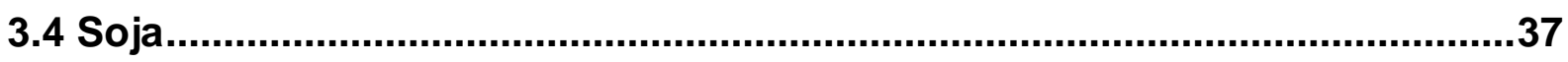

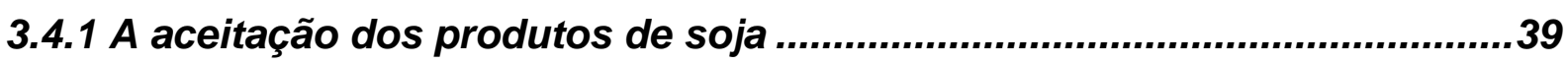

3.4.2 Análise Sensorial de cultivares de soja ..................................................41

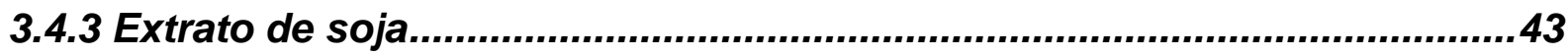

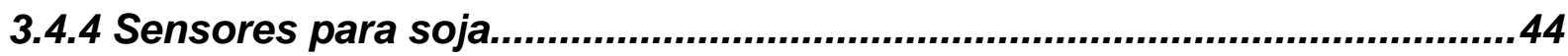

4 MATERIAIS E MÉTODOS ........................................................ 47

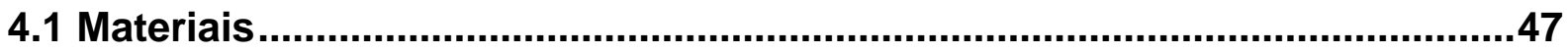

4.1.1 Materiais para a preparação dos sensores..............................................47

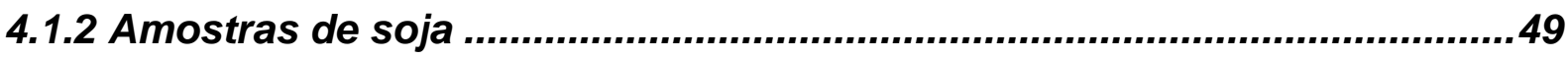

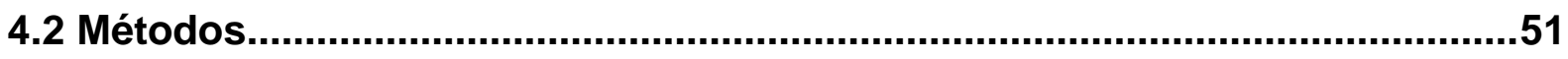

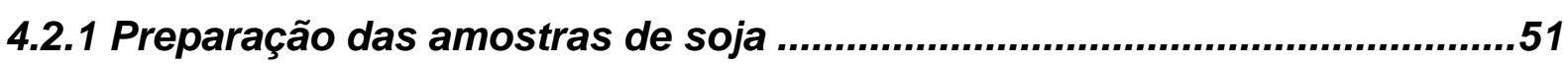

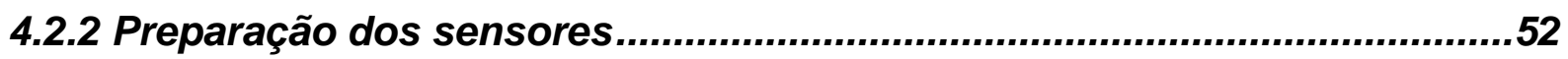

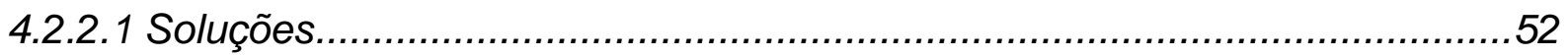

4.2.2.2 Deposição dos Filmes por Automontagem ..............................................53

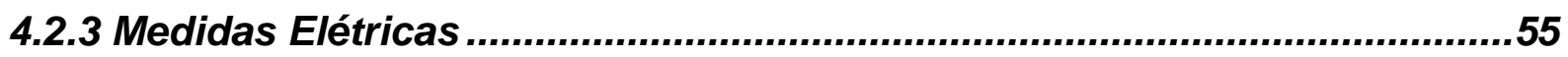

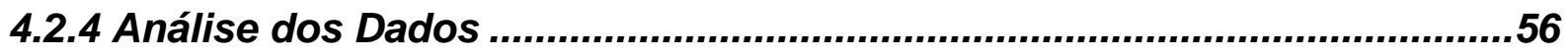

4.2.5 Imagens obtidas por Microscopia Óptica …..........................................57

5 RESULTADOS E DISCUSSÃO ............................................ 59

5.1 Estudo da repetibilidade das medições efetuadas pela Língua Eletrônica .59

5.2 Determinação do tempo de estabilização dos sensores da Língua

Eletrônica

5.3 Comparação dos métodos de preparo do extrato de soja com e sem a utilização de tratamento térmico 


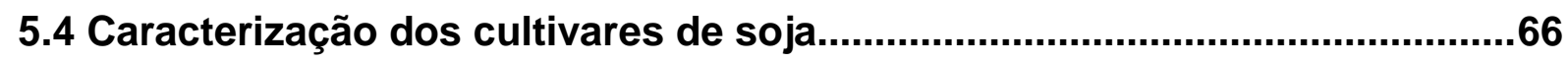

5.5 Discriminação dos cultivares de soja pela Língua Eletrônica ......................69

5.6 Estudo dos sensores da Língua Eletrônica ...................................................73

5.6.1 Avaliação do envenenamento dos sensores da Língua Eletrônica............73

5.6.2 Avaliação microscópica dos sensores da LE........................................77

5.7 Estudo da degradação dos cultivares de soja com a Língua Eletrônica .....78

5.7.1 Degradação dos extratos de soja produzidos ...........................................78

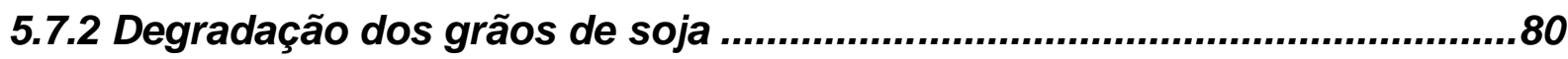

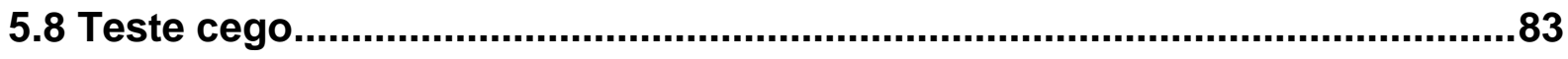

5.9 Avaliação da reprodutibilidade da Língua Eletrônica ...................................89

6 CONSIDERAÇÕES FINAIS ................................................... 93

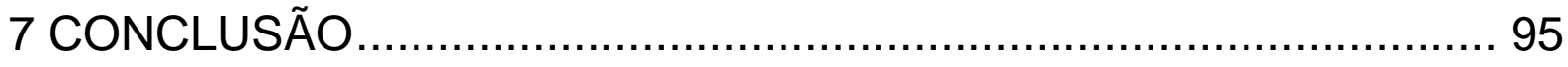

8 SUGESTÕES PARA TRABALHOS FUTUROS .............................. 96 


\section{OBJETIVOS E JUSTIFICATIVAS}

A soja é um alimento de grande importância por possuir alto teor de proteínas (EMBRAPA SOJA, 2009). Porém, os produtos a base de soja existentes no mercado ainda enfrentam resistência por alguns consumidores (TORRESPENARANDA et al., 1998; TORRES-PENARANDA; REITMEIER, 2001). Visando aumentar a aceitação destes produtos, muitas pesquisas estão sendo realizadas a fim de se desenvolver cultivares de soja com características que favoreçam o consumo de soja como alimento (CIABOTTI et al., 2007; DAVIES; NIELSEN; NIELSEN, 1987; FURUTA et al., 1996; SILVA, 2009). Este trabalho auxilia esta busca, estudando a identificação de cinco diferentes tipos de cultivares de soja, com o emprego de uma Língua Eletrônica (LE). O objetivo deste trabalho foi avaliar o desempenho da LE e com isso desenvolver um método simples e de baixo custo capaz de contribuir na identificação dos cultivares de soja. 


\section{INTRODUÇÃO}

A soja é um alimento muito utilizado no Oriente e seu consumo vem aumentando expressivamente no Ocidente. O Brasil é o segundo produtor mundial desta leguminosa, que se destaca pelo grande teor de proteínas em sua composição (EMBRAPA SOJA, 2009).

A soja é um grão muito versátil que dá origem a diversos produtos $\mathrm{e}$ subprodutos muito usados pela agroindústria, indústria química e de alimentos. $\mathrm{Na}$ alimentação humana, a soja entra na composição de vários produtos embutidos, chocolates, temperos para saladas, entre outros produtos. A proteína de soja texturizada é um importante produto da soja, sendo muito utilizada em padarias, massas, produtos de carne, cereais, misturas preparadas, bebidas, alimentação para bebês e alimentos dietéticos. A soja também é usada pela indústria de adesivos, alimentação animal, adubos, formulador de espumas, fabricação de fibras, revestimento e papel e ainda na emulsão de água para tintas (EMBRAPA SOJA, 2009).

No entanto, o uso mais conhecido da soja é como óleo refinado, obtido a partir de seu óleo bruto. Nesse processo, também é produzida a lecitina, um agente emulsificante (substância que faz a ligação entre a fase aquosa e oleosa dos produtos), muito usada na fabricação de salsichas, maioneses, achocolatados, entre outros produtos. Recentemente, a soja vem crescendo também como fonte alternativa de combustível. O biodiesel de soja já vem sendo testado por instituições de pesquisa e em diferentes cidades brasileiras (EMBRAPA SOJA, 2009).

Entretanto, os produtos a base de soja ainda enfrentam resistência por parte dos consumidores. Muitas pesquisas estão sendo desenvolvidas visando melhorar as propriedades dos alimentos de soja, e, portanto, aumentar sua aceitação no mercado. Estes estudos têm por objetivo produzir grãos de soja com sabores e composições distintas, de forma a se adequarem melhor para a produção dos mais variados produtos comerciais (CIABOTTI et al., 2007; DAVIES; NIELSEN; NIELSEN, 1987; FURUTA et al., 1996; SILVA, 2009).

Tradicionalmente, a avaliação do sabor dos grãos de soja é feita por pessoas através do método chamado de análise sensorial. Esta técnica necessita de 
painelistas treinados que requerem um longo período de tempo (DYMINSKI et al., 2006a; SILVA, 2009). Já a composição do grão de soja pode ser obtida a partir de técnicas analíticas de bancada.

Neste contexto, a língua eletrônica (LE) pode ser utilizada para diminuir custos e prazos. Tal sistema sensorial é composto por sensores não-específicos, capazes de reconhecer e identificar uma amostra estudada. Seu funcionamento baseia-se na resposta elétrica obtida pela interação entre seus sensores e 0 analito. Não há a identificação de uma substância específica. O reconhecimento de uma amostra é possível através da obtenção de uma impressão digital característica do líquido analisado (TOKO, 1996). Em comparação com as análises tradicionais, a LE é de grande interesse para o controle de qualidade nas indústrias por ser um método rápido, de baixo custo e com possibilidade de ser amigável na sua operação. A LE tem sido empregada na classificação de diferentes tipos de bebidas, tais como café (LVOVA et al., 2003), água (MORENO et al., 2006), suco de frutas e vinho (LEGIN et al., 1999, 2003; RIUL Jr. et al., 2003b, 2004). Neste trabalho, iniciou-se o desenvolvimento deste sistema sensorial visando a identificação de cinco diferentes tipos de cultivares de soja. 


\section{REVISÃO DA LITERATURA}

\subsection{Polímeros Condutores}

Os polímeros conjugados são formados por uma cadeia principal conjugada, com ligações simples (ligações sigma, $\sigma$ ) e duplas (ligações pi, $\pi$ ) alternadas. Esses polímeros podem tornar-se condutores de eletricidade mediante dopagem, processo químico (ou físico) sob o qual portadores de carga são introduzidos na cadeia polimérica (MEDEIROS; PATERNO; MATTOSO, 2006). Diferentes trabalhos mostram que os polímeros conjugados são bastante promissores para aplicação em sensores químicos. O comportamento elétrico destes polímeros pode variar em função do ambiente ao qual são expostos e esta variação pode ser precisamente medida e correlacionada com as substâncias presentes no ambiente em estudo. Além disso, estes polímeros podem ser empregados tanto como transdutores quanto suporte para o ancoramento de moléculas sensitivas e/ou indicadoras (p. ex. proteínas, enzimas, corantes, etc) (MEDEIROS; PATERNO; MATTOSO, 2006).

O primeiro polímero condutor foi sintetizado por Shirakawa e Macdiarmid (CHIANG et al., 1977) por meio da dopagem com iodo do polímero conjugado transpoliacetileno. Após a dopagem, a condutividade elétrica do polímero aumentou em 10 ordens de grandeza, chegando a $10^{3} \mathrm{~S} / \mathrm{cm}$. Entretanto, devido à instabilidade, insolubilidade e infusibilidade do poliacetileno, outros polímeros condutores baseados em monômeros aromáticos ou heteroaromáticos como os polifenilenos, polipirróis, politiofenos e polianilinas têm sido amplamente pesquisados (MATTOSO, 1996; RIUL Jr. et al., 2003a). Esses polímeros apresentam vantagens como estabilidade em condições ambientais, processabilidade, facilidade de polimerização e dopagem, além de baixo custo de obtenção (MATTOSO, 1996). A Figura 1 apresenta a estrutura química do trans-poliacetileno e da polianilina. 


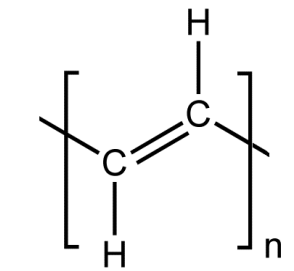

Trans-poliacetileno trans-PAc<smiles>CCCNc1ccc(C(F)(F)F)cc1</smiles>

Polianilina

PAni

Figura 1 - Estrutura química do trans-PAc e da PAni.

Os polímeros conjugados apresentam características especiais, pois combinam as propriedades mecânicas e a processabilidade dos polímeros convencionais com o comportamento elétrico, óptico e magnético dos metais e semicondutores inorgânicos.

Para um polímero conjugado se tornar condutor elétrico, diferentemente da dopagem dos semicondutores inorgânicos, são necessárias grandes quantidades de dopante. Adicionalmente, a dopagem desses polímeros não implica na substituição de átomos da sua rede cristalina. As reações de oxi-redução são extensivamente empregadas na dopagem, onde o polímero neutro é convertido em um íon polimérico e sua carga é balanceada pela carga do contra-íon do dopante (MEDEIROS; PATERNO; MATTOSO, 2006). Logo, a presença de insaturações nas cadeias do polímero conjugado é fundamental, pois as ligações $\pi$, por serem mais fracas em comparação com as ligações $\sigma$, possuem elétrons menos localizados, e, portanto, mais fáceis de serem removidos (oxidação) ou adicionados (redução). A remoção ou adição dos elétrons $\pi$ forma um íon polimérico estável, onde não é necessária a destruição da cadeia principal do polímero (MEDEIROS; PATERNO; MATTOSO, 2006).

A Polianilina (PAni), entretanto, possui um mecanismo de dopagem peculiar em relação aos outros polímeros. Sua dopagem é realizada via reação ácido-base, onde os átomos de nitrogênio da cadeia são protonados por uma solução ácida aquosa. É interessante notar que, por não se tratar de uma reação de oxi-redução, não há alteração do número de elétrons da cadeia polimérica. Além disso, a PAni também se destaca por apresentar diferentes graus de oxidação, que variam 
conforme o número de unidades das espécies reduzidas e oxidadas presentes na cadeia do polímero. Seu estado de oxidação mais importante é chamado de esmeraldina (Figura 2), quando a PAni se apresenta $50 \%$ reduzida (nitrogênios do tipo amina) e 50\% oxidada (nitrogênios do tipo imina). A PAni depois de dopada, neste estado de oxidação, alcança os maiores valores de condutividade, entre 1 e 5 S/cm (PATERNO, 1999).

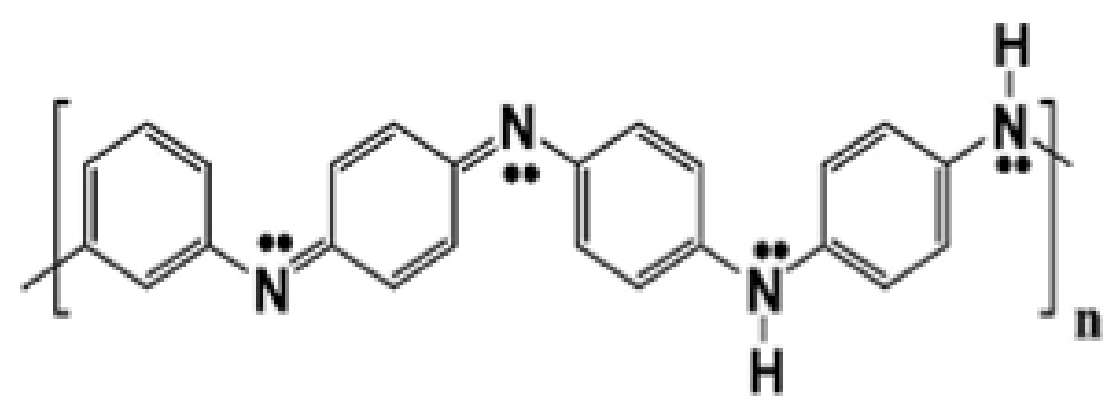

Figura 2 - Fórmula estrutural da esmeraldina desdopada.

\subsection{Filmes Automontados}

A técnica de automontagem (do inglês Self-Assembly) é um método que possibilita a produção de filmes ultrafinos organizados em um nível nanométrico, a partir de diferentes tipos de materiais, de maneira simples e a baixo custo. Esta técnica consiste na adsorção espontânea, química ou física, de camadas ultrafinas (10-100Á) sobre a superfície de um suporte sólido (substrato), a partir de soluções (ou dispersões) de diferentes materiais de interesse. O tipo de adsorção depende da afinidade entre o substrato e o material, o que está diretamente relacionado com a estrutura química dos materiais empregados (DURÁN; MATTOSO; MORAIS, 2006).

$\mathrm{Na}$ adsorção química, as camadas são adsorvidas sobre o substrato pela formação de ligações covalentes. Portanto, o material depositado deve ter afinidade pelo substrato e ainda manter funcionalidades disponíveis para adsorção da nova camada subseqüente (DURÁN; MATTOSO; MORAIS, 2006). Sagiv (1980) propôs um método onde era utilizado um substrato quimicamente modificado em uma solução de moléculas bifuncionais, como fosfanatos metálicos e organossilanos. 
Estas moléculas são capazes de estabelecer uma ligação química com o substrato e, por serem bifuncionais, sua outra extremidade serve como sítio de ancoragem para a adsorção da monocamada subseqüente. A repetição deste procedimento, ilustrado na Figura 3, resulta em um filme fino com multicamadas.

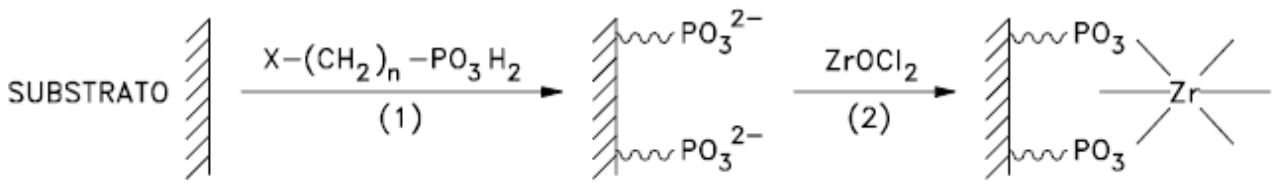

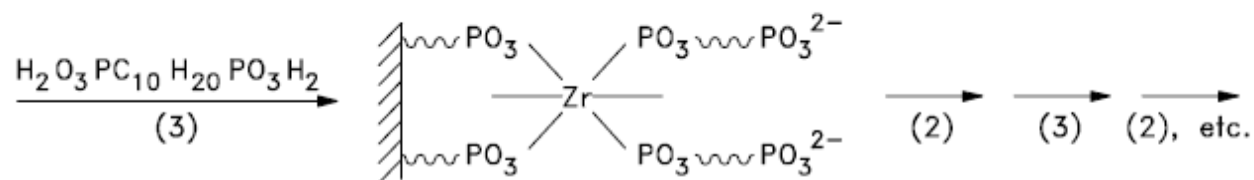

Figura 3 - llustração do processo de fabricação de um filme automontado de 1,10decanodilbisfosfonato de zircônio segundo o mecanismo de adsorção química (PATERNO; MATTOSO; OLIVEIRA Jr., 2001b).

O método proposto por Sagiv et al. continua sendo utilizado, como por exemplo, na formação de filmes finos de alcanotióis sobre substratos de ouro, prata e cobre, dialquil sulfetos e dissulfetos sobre ouro, álcoois e aminas sobre platina e ácidos carboxílicos sobre óxido de alumínio e prata (PATERNO; MATTOSO; OLIVEIRA Jr., 2001b). A automontagem por adsorção química, entretanto, possui limitações já que a continuidade do processo de deposição depende de reações químicas com alto rendimento, o qual pode ser diminuído pela presença de impurezas que podem inativar os grupos funcionais. Pode ocorrer também uma queda no rendimento por fatores de geometria molecular, como impedimentos estéricos. Tais limitações resultam em uma constante diminuição de material adsorvido a cada camada depositada, o que possivelmente pode produzir defeitos no filme formado ou até a interrupção do processo de fabricação do filme (DURÁN; MATTOSO; MORAIS, 2006; PATERNO; MATTOSO; OLIVEIRA Jr., 2001b).

A automontagem por adsorção física, proposta originalmente por Decher, Hong e Schmitt (1992), consiste na formação de camadas por meio do estabelecimento de interações físicas como atração eletrostática, ligações de hidrogênio ou interações hidrofóbicas. As energias envolvidas neste tipo de adsorção são menores do que as energias das ligações químicas. Porém, em 
sistemas poliméricos, como o número de ligações estabelecidas entre as cadeias do polímero e o substrato é grande, as camadas formadas se tornam fortemente aderidas e estáveis (DURÁN; MATTOSO; MORAIS, 2006; PATERNO; MATTOSO; OLIVEIRA Jr., 2001b).

O método proposto por Decher, Hong e Schmitt (1992) consistiu na imersão do substrato funcionalizado com cargas positivas em uma solução contendo um polieletrólito com cargas negativas (poliânion), por um tempo previamente determinado. A camada de poliânion se adsorveu devido à sua atração eletrostática pelas cargas positivas do substrato. Com a adsorção, a carga da superfície do substrato foi invertida, tornando-se negativa e com isso o processo de adsorção foi espontaneamente interrompido. A camada de poliânion adsorvida impedia que mais poliânion se aproximasse e se adsorvesse, por conta da repulsão eletrostática. Após esta etapa, o substrato com a camada adsorvida foi lavado para a remoção de material fracamente adsorvido. Posteriormente, o substrato foi imerso na solução de um policátion e resultou na formação de uma bicamada. A repetição sucessiva dessas etapas produziu um filme fino com multicamadas, como ilustrado esquematicamente na Figura 4.

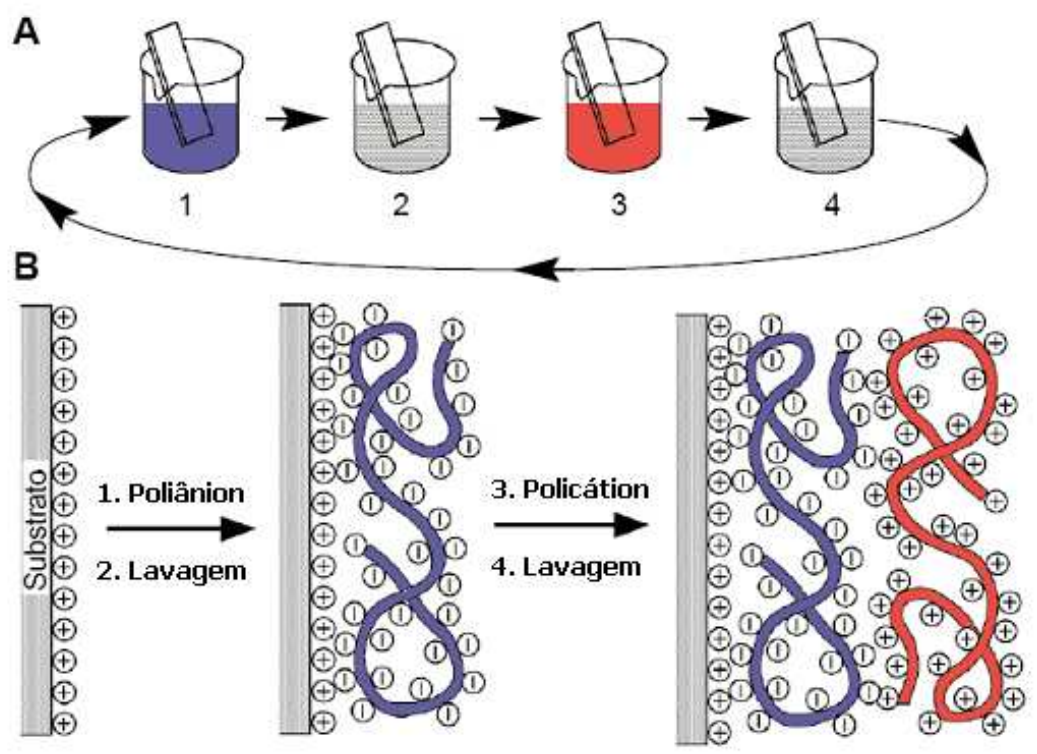

Figura 4 - llustração esquemática do processo de fabricação de um filme automontado por meio da atração eletrostática entre polieletrólitos. A - Esquema de soluções poliméricas e de limpeza. B Evolução da estrutura interna do filme com uma bicamada (DECHER, 1997). 
Filmes automontados podem também ser produzidos por meio de interações muito específicas regidas por enzimas e biomoléculas, como as interações do tipo biotina-avidina. Devido à especificidade destas interações, foi possível produzir camadas com materiais carregados com mesmo sinal elétrico (ANZAl et al., 1999).

Diversos tipos de materiais podem servir de substrato para os filmes automontados como vidro, plástico, metal e cerâmica, podendo estes apresentar os mais variados formatos. A superfície do substrato pode ser previamente carregada por diferentes métodos, como tratamento químico ou por plasma (DURÁN; MATTOSO; MORAIS, 2006).

Filmes nanoestruturados de polímeros neutros, como o poli(4-vinil-piridina) (PVP) e o poli(ácido acrílico) (PAA) adsorvem exclusivamente através de ligações de hidrogênio. Polieletrólitos fracos, como a polianilina (PAni), podem adsorver por atração eletrostática e/ou ligações de hidrogênio, onde a predominância de cada interação dependerá do $\mathrm{pH}$ e da força iônica das soluções poliméricas (DURÁN; MATTOSO; MORAIS, 2006; STOCKTON; RUBNER, 1997).

A espessura dos filmes nanoestruturados por automontagem pode ser controlada pelo número de camadas depositadas (número de imersões), e a espessura de cada camada pode ser ajustada pelo controle das condições das soluções de deposição. Tais características estão relacionadas com $0 \mathrm{pH}$, concentração de material e força iônica das soluções (BRAGA et al., 2008; PATERNO; MATTOSO, 2001a)

A grande vantagem do método de automontagem é que ele independe da forma e do tipo de substrato, além de necessitar apenas de equipamentos experimentais muito simples, sendo, portanto, um método de baixo custo e de grande potencial tecnológico. Outra vantagem é a possibilidade de utilizar a água como solvente para a maioria dos materiais utilizados. As limitações da técnica de automontagem são o baixo grau de organização das cadeias poliméricas e a dificuldade de obtenção de multicamadas mais espessas (PATERNO; MATTOSO; OLIVEIRA Jr., 2001b). 


\subsection{Língua Eletrônica}

As papilas gustativas estão presentes principalmente na língua, mas também em menor número no céu da boca, na superfície interna da bochecha e na garganta. No corpo humano existem cerca de 10.000 papilas gustativas, e estas são responsáveis pelo reconhecimento do gosto dos diferentes alimentos (DEISINGH; STONE; THOMPSON, 2004).

Uma papila gustativa contém de 50 a 100 células gustativas. Cada célula gustativa possui receptores que se ligam às moléculas e íons dos alimentos (DEISINGH; STONE; THOMPSON, 2004). Existem controvérsias na literatura se os receptores celulares respondem seletivamente ou genericamente a um determinado gosto, sugerindo a existência de vários mecanismos de percepção no corpo humano.

Entretanto, a língua humana não consegue discriminar cada substância química contida em um alimento. Ao invés disso, as sensações de gostos são classificadas apenas em cinco categorias básicas: doce, salgado, azedo, amargo e umami (DEISINGH; STONE; THOMPSON, 2004). A Tabela 1 fornece exemplos para cada sensação de gosto.

Tabela 1 - Exemplos de compostos padrões para as cinco sensações de gosto.

\begin{tabular}{ll}
\hline Sensação de gosto & Produzida pelos compostos \\
\hline Doce & Sacarose e glicose \\
Azedo & Íons $\mathrm{H}^{+}$presentes nos ácidos \\
Salgado & Cloreto de sódio \\
Amargo & Quinino e cafeína \\
Umami & Glutamato monossódico \\
\hline
\end{tabular}

Portanto, as principais características para a construção de um sensor de paladar artificial, visando à reprodução dos sentidos humanos, são alta sensibilidade, estabilidade e não-especificidade (RIUL Jr. et al., 2003c).

A utilização de sensores artificiais para avaliação do paladar é de grande interesse para o controle de qualidade nas indústrias de alimentos e de bebidas, pois quando esta avaliação é feita por humanos (técnica chamada de análise 
sensorial), é necessário uma longa seleção, avaliação e treinamento destas pessoas, além de ser também um método de custo elevado (DYMINSKI et al., 2006a).

Por estes motivos, a língua eletrônica (LE) tem recebido grande atenção nos últimos anos. A língua eletrônica é um dispositivo composto por um conjunto de sensores não-específicos que respondem diferentemente a cada analito, sendo capazes de reconhecê-lo e diferenciá-lo (TOKO, 1996).

O funcionamento da LE simula o mesmo conceito de seletividade global existente na língua humana, onde não há a identificação de uma substância específica, e sim uma resposta global de seus sensores (também chamada de impressão digital) que caracteriza e reconhece o gosto de um determinado alimento (TOKO, 1996). Por exemplo, o ser humano reconhece o sabor do café, mas não identifica separadamente as mais de mil moléculas diferentes que compõem esta bebida (RIUL Jr., 2002).

Diferentes tipos de LE vêm sendo desenvolvidos em todo o mundo. Em particular, o Grupo de Eletrônica Molecular da Escola Politécnica da USP (GEMEPUSP) tem trabalhado em uma LE com detecção por impedância elétrica via sensores poliméricos. Cada sensor desse tipo de LE é formado por um microeletrodo interdigitado de ouro recoberto por um filme polimérico ultrafino. A Figura 5 apresenta uma LE.

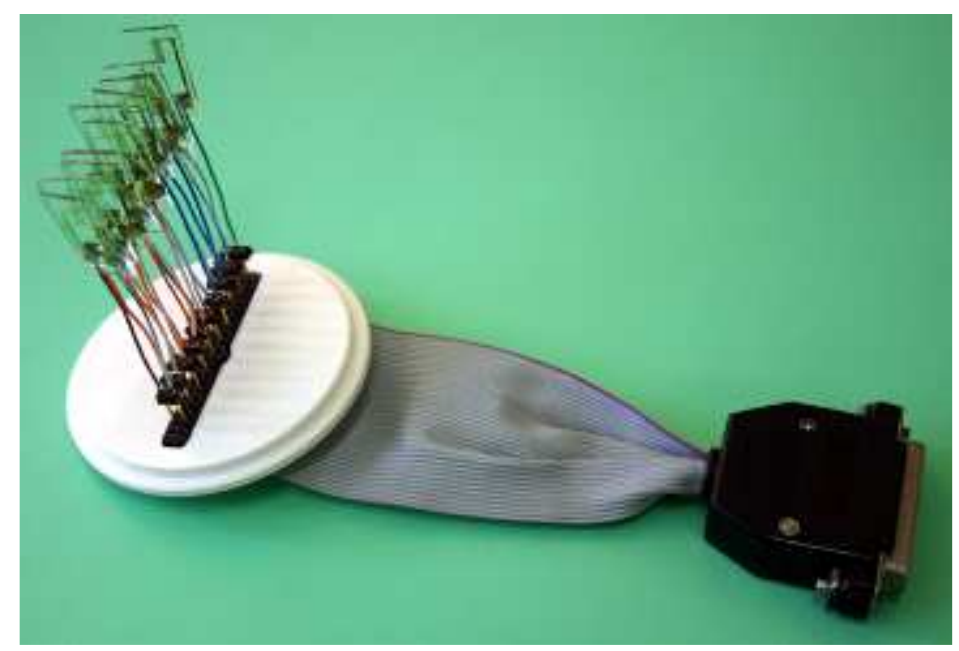

Figura 5 - Língua eletrônica 
Quando a LE é mergulhada na solução a ser analisada, seus diferentes sensores interagem de modo distinto, fornecendo sinais elétricos característicos de sua interação com o analito. Essa diferença de resposta elétrica entre um sensor e outro permite obter a impressão digital que identifica o analito (TOKO, 1996).

Diferentes materiais são geralmente empregados nos sensores de uma LE, resultando, portanto, em sensores com composições e características distintas. A variedade dos materiais utilizados é responsável por assegurar a sensibilidade da LE por diferentes classes de analitos. Além do material depositado, os sensores ainda podem se diferenciar quanto a espessura dos filmes ou em relação à geometria dos microeletrodos (WIZIACK, 2005; WIZIACK et al., 2007).

Quando se utiliza filmes ultrafinos de polímeros condutores, estes podem ser depositados por vários métodos, destacando-se os métodos de Automontagem (DECHER; HONG; SCHMITT, 1992; DECHER, 1997), Langmuir-Blodgett (ANDO et al., 1989) e Spin-Coating (LIMA; ANDRADE, 2006). A deposição dos filmes pode ser feita manualmente ou com o auxílio de máquinas dedicadas (BRAGA, 2006).

As medições elétricas com a LE são realizadas por técnicas eletroquímicas como potenciometria (CORTINA et al., 2005; GALLARDO et al., 2003), voltametria (GUTÉS et al., 2005; MARTINA et al., 2007; WINQUIST; WIDE; LUNDSTROM, 1997) ou espectroscopia de impedância (PIOGGIA et al., 2007a; 2007b). Neste trabalho foi utilizada a técnica de espectroscopia de impedância porque, por ser uma técnica onde se aplica um potencial alternado, é possível minimizar a degradação dos filmes de polímeros conjugados. As medidas AC impedem, por exemplo, 0 deslocamento de espécies químicas ionizadas para o interior dos filmes poliméricos (BORATO, 2002) e também evitam a polarização permanente destes. Além disso, esta técnica também possibilita a variação da freqüência elétrica da medida, fornecendo, assim, mais informações sobre as interações entre os filmes da LE e o analito (TAYLOR; MACDONALD, 1987).

A LE é utilizada para as mais variadas aplicações. Na análise de bebidas (LEGIN et al., 1997), destaca-se a diferenciação de tipos de vinhos (LEGIN et al., 1999, 2003; RIUL Jr. et al., 2003b, 2004), chás (LVOVA et al., 2003; SCAMPICCHIO et al., 2006), cafés (LVOVA et al., 2003) e águas (MORENO et al., 2006).

É possível também fazer a identificação da adulteração do leite de cabra com leite bovino (DIAS et al., 2009), além da detecção de diferentes tipos de leite (Di 
NATALE et al., 2000) e do envelhecimento do leite quando este é estocado a temperatura ambiente (WINQUIST et al., 1998).

O envelhecimento de damascos (KANTOR et al., 2008) e sucos de laranja (WINQUIST; WIDE; LUNDSTROM, 1997), e até mesmo a oxidação de óleos de oliva extra virgem (COSIO et al., 2007) também podem ser identificados através da LE. Há ainda a possibilidade de diferenciar variedades de maçãs (RUDNITSKAYA et al., 2006), méis (DIAS et al., 2008) e sucos de frutas (MARTINA et al., 2007).

Outra área muito importante de aplicação da LE é na análise clínica e farmacêutica, como na análise de urina humana (Di NATALE et al., 2000; LVOVA et al., 2009) e na quantificação de gostos de remédios, visando uma melhor aceitação do paciente (LEGIN et al., 2004).

\subsection{Soja}

A soja é um alimento muito utilizado pelos orientais e seu consumo vem crescendo no Ocidente. Ela é uma leguminosa que se destaca por conter alto teor de proteínas, além de também ser uma importante oleaginosa, pois de seus grãos extrai-se o óleo de soja, intensamente comercializado por todo o mundo.

No Brasil, a produção de soja na safra 2007/2008 foi da ordem de 60 milhões de toneladas, posicionando o país como o $2^{\circ}$ produtor mundial de soja, sendo superado apenas pelos Estados Unidos (UNITED STATES DEPARTMENT OF AGRICULTURE, 2009).

A soja tem diversas aplicações na indústria de alimentos, sendo comercializados além da soja em grãos, a farinha de soja, a proteína de soja texturizada, o extrato de soja e o tofu, entre outros produtos.

A proteína de soja texturizada é um produto especialmente muito importante, sendo a base de ingredientes usados em padarias, massas, produtos de carne, cereais, misturas preparadas, bebidas, alimentação para bebês e alimentos dietéticos (EMBRAPA SOJA, 2009). 
A soja também é utilizada na indústria de adesivos, alimentação animal, adubos, formulador de espumas, fabricação de fibras, revestimento e papel e ainda na emulsão de água para tintas (EMBRAPA SOJA, 2009).

Entretanto, seu uso mais conhecido é como óleo refinado, obtido a partir de seu óleo bruto. Nesse processo, também é produzida a lecitina, um agente emulsificante (substância que faz a ligação entre a fase aquosa e oleosa dos produtos), muito usada na fabricação de salsichas, maioneses, achocolatados, entre outros produtos (EMBRAPA SOJA, 2009).

Recentemente, a soja vem crescendo também como fonte alternativa de combustível. O biodiesel de soja já vem sendo testado por instituições de pesquisa e em diferentes cidades brasileiras.

Do ponto de vista nutricional, a soja contém componentes essenciais para a alimentação humana, apresentando cerca de $40 \%$ de proteínas nos grãos. Além disso, ela também possui um alto conteúdo de lipídeos, vitaminas e minerais. A Tabela 2 apresenta a composição de um grão padrão de soja (EMBRAPA SOJA, 2009).

Tabela 2 - Composição da soja (EMBRAPA SOJA, 2009).

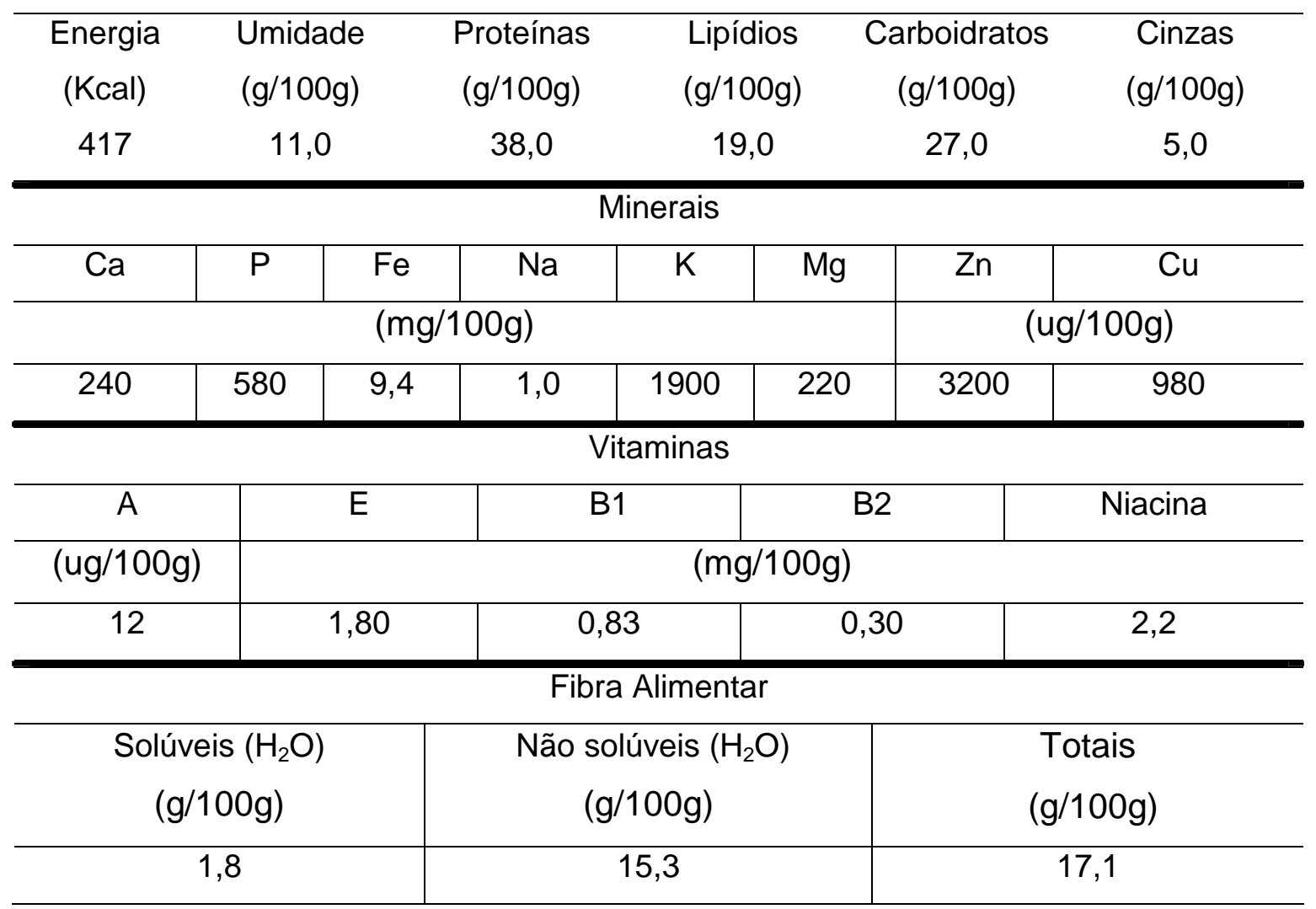


O consumo de soja pode trazer também benefícios adicionais. Os alimentos a base de soja podem, por exemplo, auxiliar na prevenção do câncer de mama, próstata, intestino, fígado, bexiga e estômago (BARNES, 1995).

As isoflavonas, compostos fenólicos encontrados na soja, auxiliam na reposição hormonal para mulheres no período pré-menopausa (CASSIDY; BINGHAM; SETCHELL, 1994), além de ajudar na redução da perda de massa óssea e do colesterol (GÓES-FAVONI et al., 2004).

Entretanto, assim como a maioria das leguminosas, se a soja for consumida crua ou inadequadamente processada, ela apresenta características antinutricionais. Neste caso, a soja pode provocar efeitos fisiológicos adversos ao homem, como hipertrofia (aumento do tamanho das células) e hiperplasia (aumento do número de células) do pâncreas, ou ainda reduzir a absorção de determinados nutrientes (LIENER, 1995). Para inativação destes fatores antinutricionais é necessário a aplicação de tratamentos térmicos (LAJOLO; GENOVESE, 2002).

\subsubsection{A aceitação dos produtos de soja}

Nos países ocidentais, os produtos a base de soja estão relacionados a sabores e odores desagradáveis para a maioria da população. Nas pesquisas sensoriais, as equipes de provadores relatam termos como gosto de feijão cru, mato e de tinta, além de adstringente, rançoso e amargo (TORRES-PENARANDA et al., 1998; TORRES-PENARANDA; REITMEIER, 2001).

Os sabores indesejados descritos anteriormente são provenientes da oxidação dos ácidos graxos poliinsaturados presentes nos grãos de soja. Este mecanismo ocorre principalmente através da ação das enzimas lipoxigenases presentes na soja, embora a auto-oxidação destes ácidos também seja verificada (TORRES-PENARANDA et al., 1998; TORRES-PENARANDA; REITMEIER, 2001). Pode-se ainda encontrar as lipoxigenases em sementes de pepino, melão, pêra, maçã, tomate, aspargos, banana, brócolis, repolho e outros vegetais (CIABOTTI, 2004). Mas na soja elas têm recebido grande atenção por serem constituintes 
expressivos - representam aproximadamente $2 \%$ do total de proteína de um grão de soja maduro (CIABOTTI, 2004).

As lipoxigenases estão envolvidas na formação de uma grande variedade de compostos voláteis, que incluem aldeídos, cetonas e álcoois, muitos dos quais são responsáveis pelos sabores e odores desagradáveis da soja (CIABOTTI, 2004; CIABOTTI et al., 2007; SILVA et al., 2007; TORRES-PENARANDA et al., 1998; TORRES-PENARANDA; REITMEIER, 2001). Podem ser citados os alcoóis hexanol, pentanol e heptanol e, principalmente o aldeído hexanal pela produção destas características indesejadas na soja (MATOBA et al., 1985).

Alguns compostos voláteis são produzidos durante o metabolismo normal da planta, entretanto, outros são produzidos exclusivamente quando a soja crua é sujeita à mastigação, corte ou processamento, o que permite misturar enzimas e substratos que estão normalmente separados (CIABOTTI, 2004).

A condição de estocagem também é um fator significante para a alteração do gosto dos produtos a base de soja, já que muitas reações podem ser aceleradas quando estes produtos são estocados sob elevadas temperaturas (LAMBRECHT et al., 1996).

$\mathrm{Na}$ tentativa de inativar as enzimas lipoxigenases, a indústria alimentícia normalmente submete os produtos a base de soja a tratamentos térmicos. Entretanto, como cada enzima possui um mecanismo particular, o tratamento térmico não é capaz de inativar todas as lipoxigenases presentes em um grão de soja (CIABOTTI, 2004). Adicionalmente, mesmo que fosse possível fazer esta total inativação com sucesso, continuaria existindo o processo de auto-oxidação dos ácidos graxos poliinsaturados, ainda que com uma velocidade menor (CIABOTTI, 2004). Além disso, os tratamentos térmicos são frequentemente dispendiosos e podem resultar na insolubilização das proteínas, e ainda gerarem outros sabores indesejáveis, como tostado e cozido (SILVA, 2009).

Portanto, a remoção genética das enzimas lipoxigenases apresenta-se como uma solução viável e tem sido amplamente pesquisada. Desta forma, é possível reduzir ou até mesmo eliminar o sabor indesejável da soja, aumentando a aceitação de seus produtos no mercado (DAVIES; NIELSEN; NIELSEN, 1987; FURUTA et al., 1996; SILVA, 2009). 


\subsubsection{Análise Sensorial de cultivares de soja}

A Análise Sensorial é uma técnica que utiliza os sentidos humanos (visão, olfato, tato, paladar e audição) para avaliar as características de um produto. É um método intensamente utilizado pelas indústrias, principalmente às de alimentos, bebidas, cosméticos, perfumes, produtos de limpeza, etc., para conhecer a preferência dos consumidores em relação a um produto. Esta técnica também é utilizada pela Embrapa Soja, durante o desenvolvimento de novos cultivares de soja, para classificá-los de acordo com suas características específicas.

Quando se deseja, por exemplo, analisar o gosto de cultivares de soja, é necessário que inicialmente seja realizada uma seleção dos provadores. Esta seleção avalia o desempenho dos candidatos em testes de reconhecimento de gostos básicos como sacarose, cafeína e cloreto de sódio, entre outros. Os provadores avaliam as amostras em cabines individuais com condições ambientais controladas (temperatura, iluminação, etc). Os candidatos com melhor desempenho são então selecionados para a próxima etapa (SILVA, 2009).

$\mathrm{Na}$ etapa seguinte, os candidatos selecionados provam, por exemplo, cinco cultivares de soja. Silva (2009) apresentou os cultivares para avaliação do gosto dentro de copos de plástico com tampa, contendo 10 grãos de soja cozidos, juntamente com um pouco do caldo de cozimento, a $45^{\circ} \mathrm{C}$. Nesta etapa, cada candidato deve provar os cultivares de soja e descrever os gostos sentidos (doce, ácido, salgado, amargo, umami e etc.) em um formulário. Antes da primeira amostra e entre cada amostra, os provadores devem enxaguar a boca com água mineral a $25^{\circ} \mathrm{C}$. Entre as avaliações, os candidatos devem fazer uma pausa de 5 minutos (SILVA, 2009).

Depois é promovida uma discussão em grupo, com o objetivo de selecionar os termos mais relevantes que foram citados e sugerir amostras de referência destes, para que sejam utilizadas em um treinamento (SILVA, 2009).

Silva (2009) realizou sete sessões de treinamento, com duração de 1 hora cada. Nesta etapa, os candidatos provam as amostras de referência e utilizam uma escala que contêm dois extremos de intensidade (nenhum e forte, por exemplo) para avaliar cada atributo de gosto estabelecido previamente na discussão em grupo. Este treinamento tem por finalidade familiarizar os provadores com esta escala. 
Novamente, os provadores são selecionados segundo seus desempenhos neste último treinamento (SILVA, 2009).

Finalmente, são apresentados aos provadores selecionados os cultivares de soja em que se deseja obter a avaliação do gosto. Cada provador avalia os cultivares segundo os atributos estabelecidos no treinamento e utilizando a escala de intensidades (SILVA, 2009).

Os dados de cada provador são então submetidos a uma análise estatística de interesse. A Figura 6 apresenta um fluxograma da análise sensorial de cultivares de soja realizada por Silva (2009).

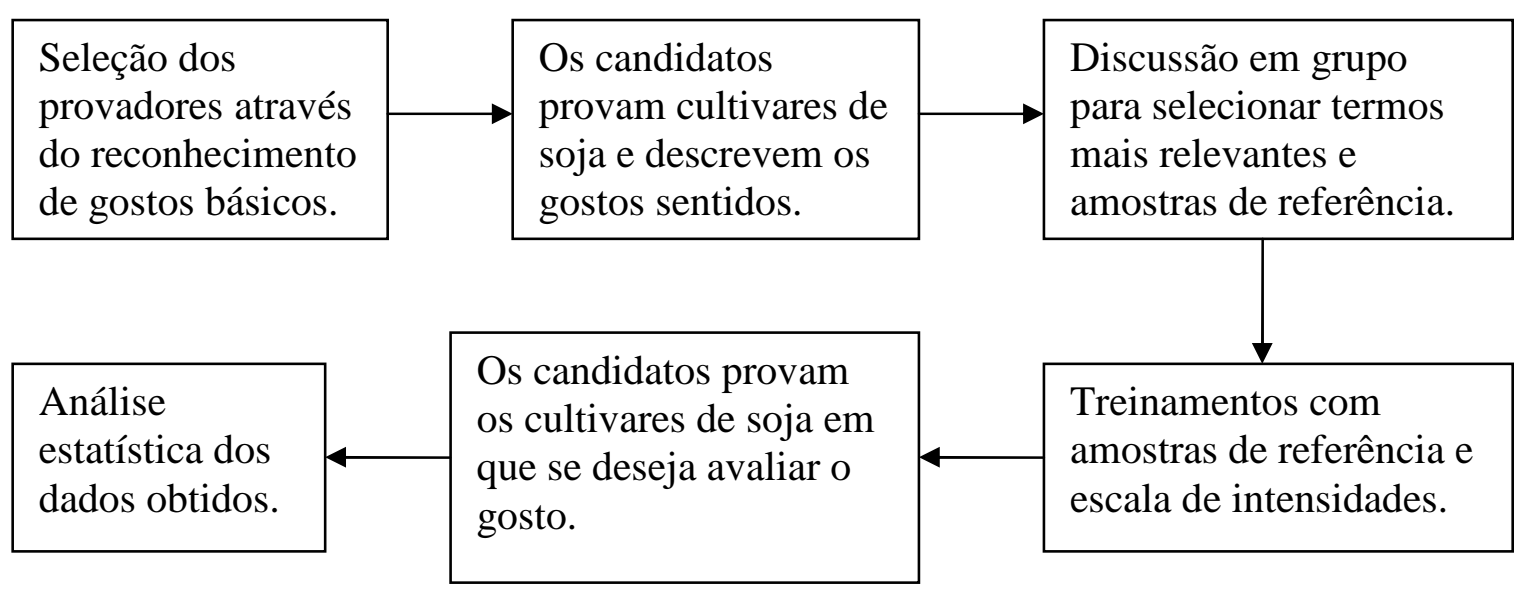

Figura 6 - Fluxograma da Análise Sensorial de cultivares de soja realizada por Silva (2009).

Como pode ser observado, a Análise Sensorial é uma técnica que requer um grande período de tempo para ser aplicada. Desta forma, o presente trabalho pretende apresentar um método para auxiliar na Análise Sensorial de cultivares de soja. Utilizando a LE, por exemplo, poder-se-ia realizar uma seleção inicial dos cultivares de soja onde apenas os cultivares que não foram discriminados pela LE seriam submetidos à Análise Sensorial. Isto reduziria os custos e acrescentaria um ganho de tempo e praticidade ao pesquisador ou à indústria. 


\subsubsection{Extrato de soja}

O extrato de soja pode ser definido como um produto obtido pela mistura entre soja e água, em uma proporção adequada. Ele pode ser consumido na forma de bebida ou como constituinte de diversos produtos lácteos como iogurtes e sorvetes. O extrato de soja é um importante substituto do leite de vaca para as pessoas com intolerância à lactose ou alérgicas a esse leite (CIABOTTI, 2004; SILVA et al., 2007). A adição de extrato de soja em suco de frutas está se tornando cada vez mais comum, e já possui uma boa aceitação no mercado.

O processamento da soja para a produção de seu extrato tem sido estudado, visando avaliar e aprimorar as qualidades deste produto. As principais etapas deste processo são: pesagem dos grãos, maceração, trituração, processamento térmico, filtração e correção do volume final (CIABOTTI, 2004). A Figura 7 apresenta um fluxograma deste processo.

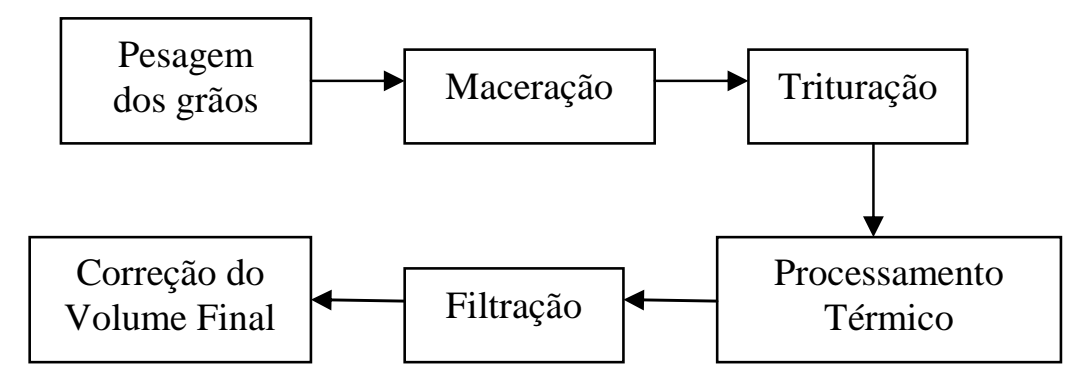

Figura 7 - Fluxograma do processamento do extrato de soja.

A maceração da soja é responsável pela hidratação dos grãos. Nesta etapa, os grãos de soja devem ficar imersos em água por 12 horas, quando atingem $134,42 \%$ de seu peso inicial (BAYRAM; ÖNER; KAYA, 2004). A hidratação é fundamental para amaciar a estrutura celular, reduzindo os custos de energia para moagem e aumentando, consequentemente, a extração de proteínas e emulsificação de gorduras (CIABOTTI, 2004). Após a maceração, deve-se fazer a trituração da soja com água, para que ocorra a extração das proteínas e demais nutrientes (CIABOTTI, 2004). A seguir, faz-se o tratamento térmico submetendo a 
soja à cerca de $98^{\circ} \mathrm{C}$ por 5 minutos, visando eliminar ou reduzir seus aspectos antinutricionais (LIENER, 1995). Esta etapa também auxilia na inativação das enzimas lipoxigenases para melhorar as características sensoriais da soja (CIABOTTI, 2004).

Finalmente, o extrato de soja é filtrado e faz-se a correção do volume final do produto, de acordo com a proporção soja:água proposta na metodologia utilizada (CIABOTTI, 2004).

\subsubsection{Sensores para soja}

$\mathrm{Na}$ literatura existem poucas publicações referindo-se a sensores para a soja. O enfoque principal destes trabalhos é o desenvolvimento de sensores visando o estudo da composição e o aprimoramento de odores e gostos dos molhos de soja (shoyu), muito populares no oriente. liyama, Yahiro e Toko (2000) reportaram o estudo de 25 molhos de soja diferentes utilizando uma LE com sensores poliméricos modificados com lipídios. Eles verificaram que os molhos produzidos por um mesmo fabricante, embora pertencentes a tipos diferentes, apresentaram características semelhantes, agrupando-se durante o tratamento de dados.

Aishima (2004) correlacionou a resposta obtida de um nariz eletrônico, com a análise sensorial e cromatografia gasosa de molhos de soja. Através da técnica de regressão por mínimos quadrados parciais (do inglês, Partial Least Squares Regression, PLS), o autor concluiu que a resposta do nariz eletrônico utilizado foi insatisfatória para a maioria dos aromas tratados no estudo.

Destaca-se ainda o desenvolvimento de biosensores para a determinação de L-glutamato em molhos de soja (JANARTHANAN; MOTTOLA, 1998; KWONG et al., 2000; NAKORN, et al., 2003). Este composto, também conhecido como ácido Lglutâmico ou ainda glutamato monossódico (GMS) é um aminoácido obtido por fermentação e amplamente consumido como aditivo alimentar ou realçador de sabor em alimentos. Entretanto, a adição excessiva do L-glutamato pode causar efeitos alérgicos como dores de cabeça e de estômago, entre outros. 
A composição dos molhos de soja também foi estudada por Komaba et al. (1998). Eles construíram um sensor capaz de quantificar a concentração de potássio em molhos de soja japoneses, já que o excesso deste composto em alimentos está associado a doenças renais.

Campanella et al. (1998) estudou a construção de um biosensor para a identificação de lecitina em diversos produtos comerciais, como óleos e farinha de soja, chocolate e suplementos alimentares. A lecitina é um fosfolipídio encontrado principalmente na soja e na gema do ovo. Ela é muito utilizada pela indústria alimentícia como emulsificante, estabilizante e surfactante, para a produção de chocolates, margarinas e biscoitos, entre outros produtos. Entretanto, seu consumo tem se destacado atualmente em produtos dietéticos e como suplemento alimentar. O estudo apresentou um método rápido e de baixo custo capaz de determinar a lecitina nestes alimentos.

Silva (2009) estudou as características físicas, químicas e sensoriais de cinco cultivares de soja, sendo quatro destes os mesmos utilizados neste trabalho (BRS 133, BRS 216, BRS 258 e BRS 267) e um outro cultivar (BRS 213) com características semelhantes ao cultivar BRS 257 (que possui ausência das enzimas lipoxigenases). Foi determinada a composição química e mineral dos grãos de soja, definindo também a atividade das enzimas lipoxigenases e o teor de n-hexanal nos grãos. Foram ainda quantificados o teor de ácidos graxos, isoflavonas, açúcares e aminoácidos presentes nos grãos de soja. Além disso, foram determinadas características físicas como textura, cor e tamanho dos grãos.

Silva (2009) realizou também uma Análise Sensorial destes cultivares de soja segundo o procedimento já descrito anteriormente. Em parceria com o Grupo GEMEPUSP, foram ainda realizadas medidas com a LE utilizada neste presente trabalho (LE 1). Entretanto, as amostras de Silva (2009) eram extratos de soja provenientes de grãos cozidos, diferentemente deste trabalho, que estudou extratos de soja produzidos sem cozimento. Silva (2009) concluiu que a LE foi capaz de discriminar os cultivares de soja estudados, sendo, portanto, um método eficaz e rápido para identificação de grãos de soja.

O presente trabalho teve por motivação o estudo de Silva (2009). Entretanto, foi eliminada a etapa de cozimento, já que a análise com a LE é realizada por sensores, e, por isso, não há restrições quanto as características anti-nutricionais presentes no grão de soja cru. Desta forma, foi estabelecido um novo método de 
preparo dos extratos de soja, simplificando o procedimento, mas alcançando o mesmo objetivo de discriminação dos cultivares de soja. 
4 MATERIAIS E MÉTODOS

\subsection{Materiais}

\subsubsection{Materiais para a preparação dos sensores}

Os polímeros poli(o-metoxianilina) (POMA) e poli(o-etoxianilina) (POEA) foram preparados por síntese química de acordo com método descrito na literatura (MATTOSO, 1996). As amostras na condição desdopada foram cedidas pela Embrapa Instrumentação Agropecuária de São Carlos. Polianilina desdopada (PAni, $\mathrm{Mw} 10.000 \mathrm{~g} \mathrm{~mol}^{-1}$ ), poliestireno sulfonato de sódio (PSS, Mw $70.000 \mathrm{~g} \mathrm{~mol}-1$ ), hidrocloreto de polialilamina (PAH), ftalocianina tetrasulfonada de níquel (FTC) e polipirrol (PPy) foram adquiridos da Aldrich e utilizados sem purificação adicional. Poli(3,4-etilenodioxitiofeno) (PEDOT) foi adquirido da Bayer (Baytron PVP Al4083 PEDOT:PSS 1:6 m/m) e a lignina sulfonada (LS) foi adquirida da Melbar Produtos de Lignina SA. As fórmulas estruturais dos diversos materiais empregados na preparação de filmes para os sensores são apresentadas na Figura 8. 


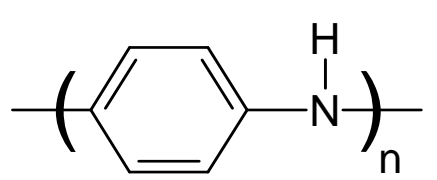

(a)

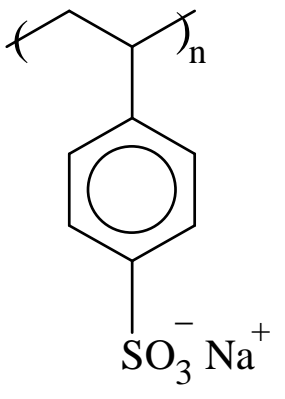

(d)

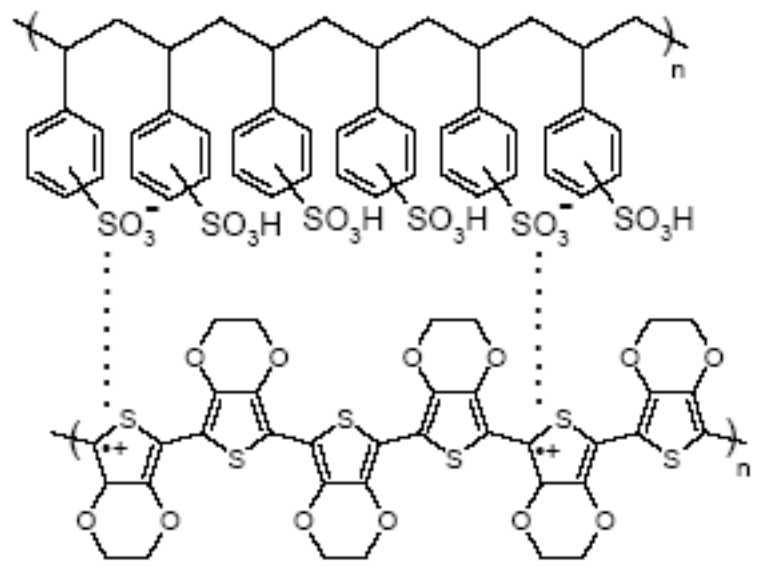

(f)

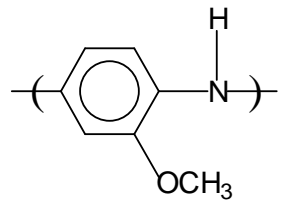

(b)

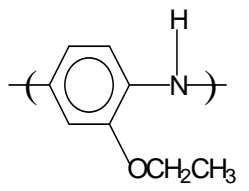

(c)

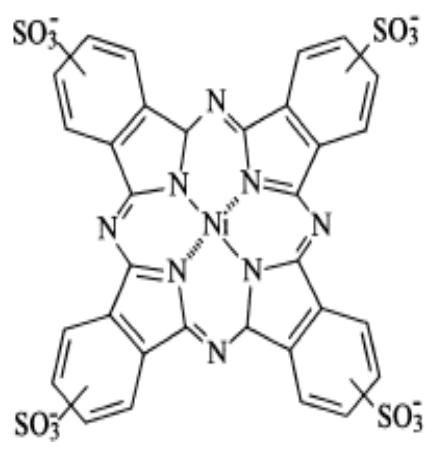

(e)<smiles>CC(C)C1C=CC=C1C(C)(C)C</smiles>

(g)

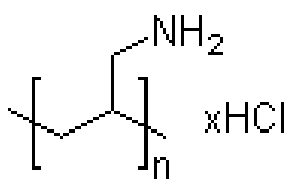

(h)

Figura 8 - Fórmulas estruturais (a) PAni, (b) POMA, (c) POEA, (d) PSS, (e) FTC, (f) PEDOT:PSS, (g) PPy e (h) PAH.

Os sensores da LE foram construídos utilizando-se microeletrodos interdigitados de ouro, conforme apresentado na Figura 9, confeccionados através das técnicas de sputtering e fotolitografia UV sobre placas de vidro. A produção dos microeletrodos foi realizada na Sala Limpa do Laboratório de Microeletrônica da Escola Politécnica da USP. 


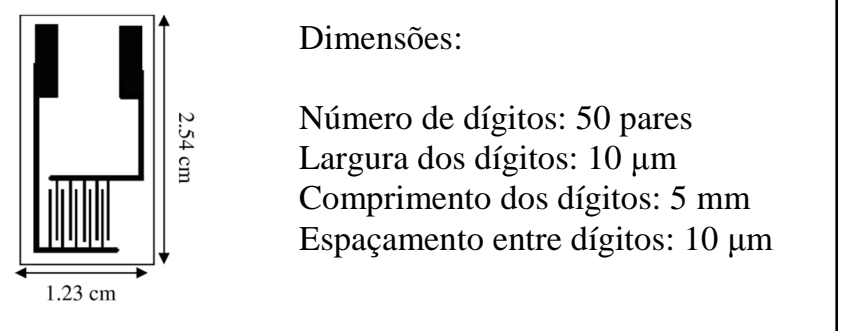

Figura 9 - llustração e dimensões do microeletrodo interdigitado.

\subsubsection{Amostras de soja}

Este trabalho envolveu a utilização de leite de soja comercial e soluções obtidas a partir de grãos de soja de cultivares desenvolvidos pela Embrapa Soja de Londrina, PR. O leite de soja comercial utilizado foi o Mais Vita Pura Soja, da marca Yoki (Figura 10). Ele foi selecionado por apresentar em sua composição apenas extrato de soja e água. Este produto foi empregado nos estudos de repetibilidade, a fim de se poupar a utilização dos grãos de soja.

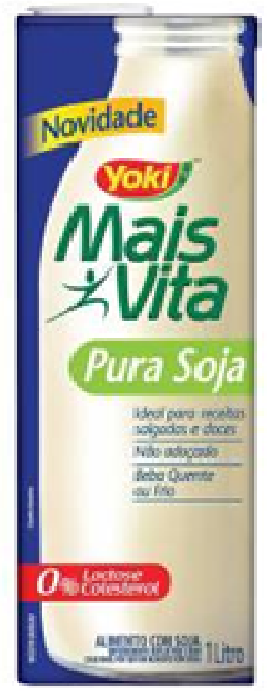

Figura 10 - Leite de soja Mais Vita Pura Soja da Yoki.

Os grãos de soja utilizados foram provenientes de cultivares desenvolvidos especialmente pela Embrapa Soja para possuírem composição e características sensoriais específicas. Neste trabalho, os cultivares de soja foram identificados com 
a mesma nomeação procedente da Embrapa Soja: BRS 133, BRS 216, BRS 257, BRS 258 e BRS 267. Eles podem ser visualizados na Figura 11.
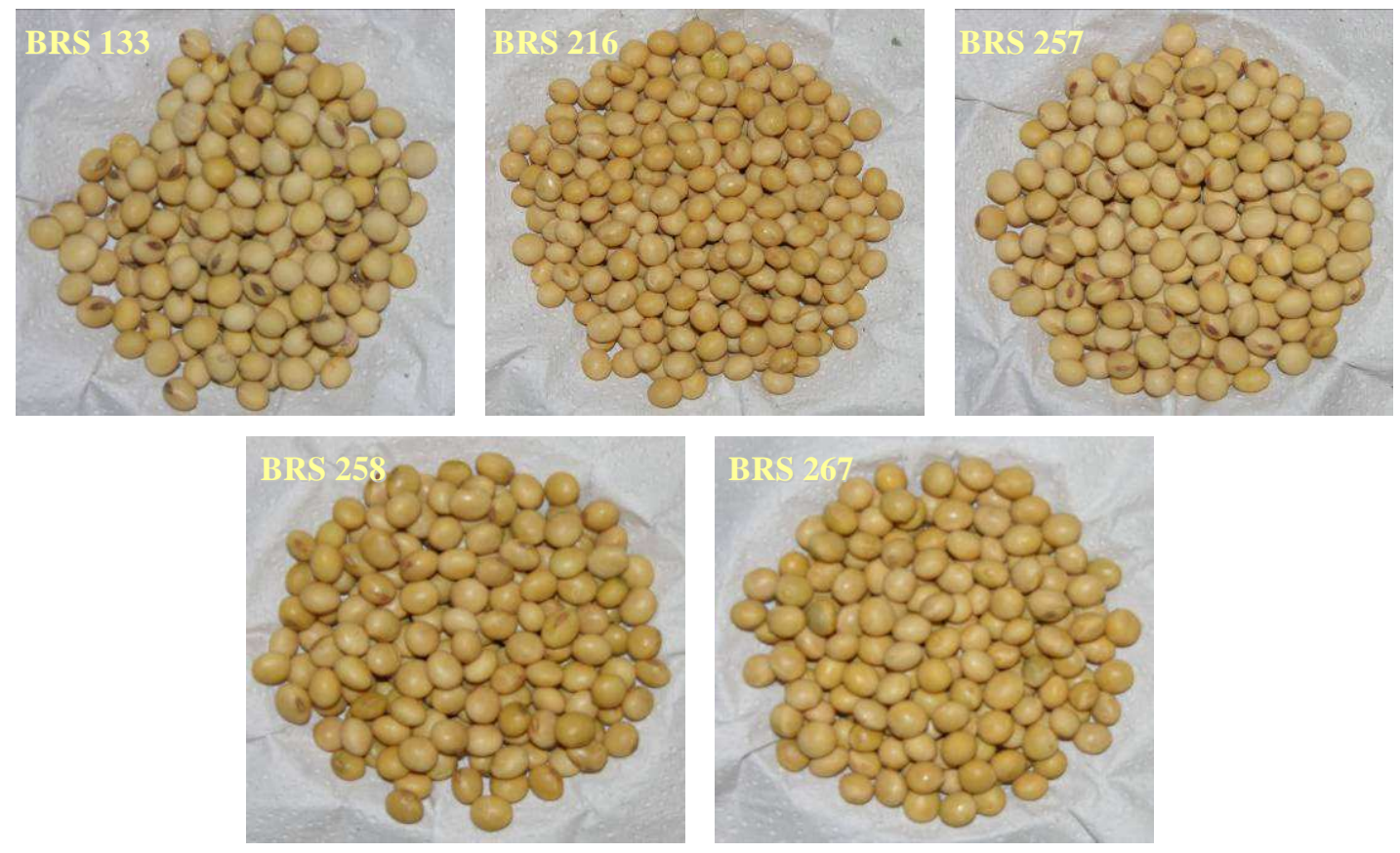

Figura 11 - Cultivares de soja utilizados neste trabalho.

Os cultivares de soja estudados foram selecionados por possuírem características notadamente distintas entre si. O cultivar BRS 133 é o grão de soja tradicional (EMBRAPA SOJA, 2010a). Já o cultivar BRS 216 apresenta grãos pequenos, o que permite maior exposição de sua superfície, facilitando a absorção de água e o cozimento. Esse cultivar também se destaca por possuir alto teor de proteínas, sendo ideal para a produção de natto e brotos de soja (AGRONLINE, 2010; PORTAL DO AGRONEGÓCIO, 2010; SILVA, 2009). O cultivar BRS 257 não apresenta três enzimas lipoxigenases, responsáveis pelo desenvolvimento do sabor desagradável associado aos produtos de soja (EMBRAPA SOJA, 2010b). O cultivar BRS 258 também é tido como convencional, mas possui características exigidas pelo mercado como sabor mais suave, sementes grandes e hilo marrom claro (EMBRAPA SOJA, 2010c; PORTAL DO AGRONEGÓCIO, 2010). E finalmente, o cultivar BRS 267 apresenta sabor adocicado, sendo ideal para a produção de tofu, farinhas e extrato de soja (EMBRAPA SOJA, 2010d; SILVA, 2009). Os cultivares BRS 216, BRS 257 e BRS 267 foram desenvolvidos pela Embrapa Soja 
especialmente para a alimentação humana. A Tabela 3 apresenta as principais características de cada cultivar.

Tabela 3 - Principais características dos cultivares de soja estudados.

\begin{tabular}{|c|c|c|c|}
\hline $\begin{array}{c}\text { Cultivar de } \\
\text { Soja }\end{array}$ & $\begin{array}{c}\text { Teor de Proteína } \\
(\%)\end{array}$ & $\begin{array}{c}\text { Teor de Óleo } \\
(\%)\end{array}$ & Informações adicionais \\
\hline BRS 133 & 38,60 & 18,00 & - \\
\hline BRS 216 & 43,00 & - & $\begin{array}{c}\text { Sementes pequenas } \\
\text { BRS 257 }\end{array}$ \\
\hline BRS 258 & 41,30 & 22,60 & $\begin{array}{c}\text { Não apresenta enzimas } \\
\text { lipoxigenases }\end{array}$ \\
\hline BRS 267 & 41,70 & 23,70 & $\begin{array}{c}\text { Sabor suave, sementes } \\
\text { grandes e hilo claro } \\
\text { Sabor adocicado }\end{array}$ \\
\hline
\end{tabular}

\subsection{Métodos}

\subsubsection{Preparação das amostras de soja}

O leite de soja comercial foi diluído na proporção de 1:100 v/v com água destilada. Para a preparação dos extratos, $0,5 \mathrm{~g}$ ou $5 \mathrm{~g}$ de cada cultivar foram mantidos imersos por 16 horas em $200 \mathrm{~mL}$ de água destilada. Após este período, adicionou-se $200 \mathrm{~mL}$ de água destilada e triturou-se em liquidificador (Philips Walita RI 2008) por cerca de 3 minutos. O extrato foi filtrado em papel de filtro comum. No caso do extrato preparado a partir de $5 \mathrm{~g}$ de grãos, após a filtração foi realizada uma diluição de 1:10 v/v com água destilada. A Figura 12 apresenta todas as etapas deste procedimento. 

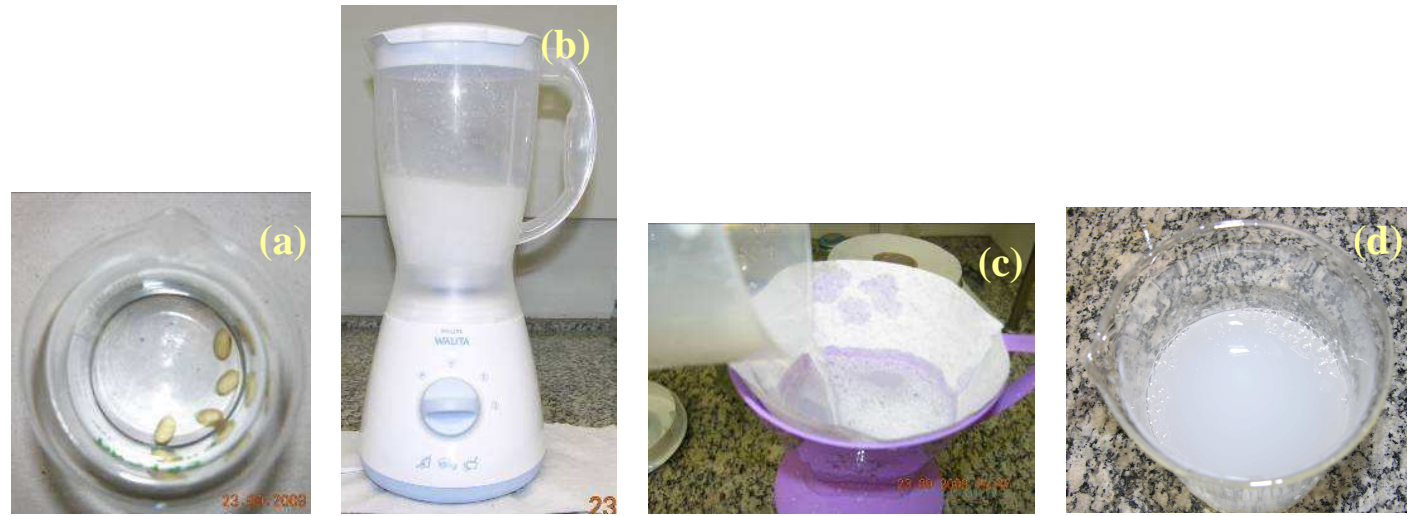

Figura 12 - Procedimento de preparação das amostras: (a) maceração de $0,5 \mathrm{~g}$ de grãos de soja em água destilada; (b) trituração dos grãos macerados no liquidificador; (c) filtração do extrato e (d) extrato final analisado.

Vale destacar que este método de preparação trata-se de uma alternativa, de modo a facilitar a preparação das amostras no local da produção dos grãos. O método tradicional de preparação das amostras, usado inclusive quando as amostras são analisadas por painelistas, realiza o cozimento da amostras em autoclave a $121^{\circ} \mathrm{C}$ por 5 minutos.

\subsubsection{Preparação dos sensores}

\subsubsection{Soluções}

As soluções de PAni, POMA e POEA foram preparadas nas concentrações de $0,15 \mathrm{~g} \cdot \mathrm{L}^{-1}, 0,4 \mathrm{~g} \cdot \mathrm{L}^{-1}$ e $0,4 \mathrm{~g} \cdot \mathrm{L}^{-1}$, respectivamente. Para estes três polímeros foi adotado o mesmo procedimento: o polímero desdopado foi dissolvido em dimetil acetamida (DMAc), sob agitação magnética por 18 horas. Após este período, a solução foi filtrada em papel de filtro semianalítico (porosidade 10 $\mu \mathrm{m}$ ), e adicionada uma solução de $\mathrm{HCl}$ 0,1 M gota a gota, até que o polímero atingisse a coloração verde característica de seu estado dopado. A solução com o polímero dopado foi posteriormente diluída com uma solução de $\mathrm{HCl}(\mathrm{pH}$ de 2,7) até a composição de solvente $1: 4 \mathrm{v} / \mathrm{v} \mathrm{DMAc/HCl}$. 
As soluções de PSS (0,2g. $\mathrm{L}^{-1}$, pH 2,7), PAH (1 g. $\mathrm{L}^{-1}$, pH 5,5), FTC (0,3 g.L ${ }^{-1}$, $\mathrm{pH} 2,7$ e 5,5) e LS $\left(0,34 \mathrm{~g} \cdot \mathrm{L}^{-1}, \mathrm{pH} 2,7\right.$ e 5,5) foram preparadas pela dissolução dos materiais em solução aquosa de $\mathrm{HCl}, \mathrm{pH} 2,7$ ou pH 5,5, sob agitação magnética por 2 horas. As dispersões de PEDOT:PSS e de PPy foram obtidas por diluição (1:10 v/v) em solução aquosa de $\mathrm{HCl}$ pH 2,7 das respectivas formulações comerciais, sob agitação magnética.

\subsubsection{Deposição dos Filmes por Automontagem}

Os sensores da LE foram produzidos pela deposição de filmes ultrafinos sobre microeletrodos interdigitados de ouro pela técnica de automontagem (DECHER; HONG; SCHMITT, 1992; DECHER, 1997; PATERNO; MATTOSO; OLIVEIRA Jr., 2001b). Inicialmente, os microeletrodos foram imersos em uma solução metanólica de ácido 3-mercapto propiônico (3-MPA, 100 mM) por 18 horas. Este pré-tratamento foi realizado com o objetivo de funcionalizar a superfície do ouro com grupos ácido carboxílico e assim facilitar a adsorção dos materiais positivamente carregados (policátions). O grupo tiol do 3-MPA se liga ao ouro e a outra extremidade da molécula exibe o grupo carboxila, livre (Figura 13).

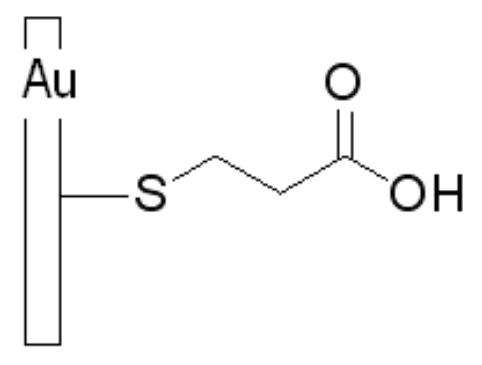

Figura 13 - Funcionalização do eletrodo de ouro com 3-MPA.

Após o pré-tratamento, os microeletrodos serviram de substrato para a deposição dos filmes, processo que foi realizado por um sistema automatizado, apresentado na Figura 14 (robô Haubenteuer MG 1100, V Company) (BRAGA et al., 2008). 


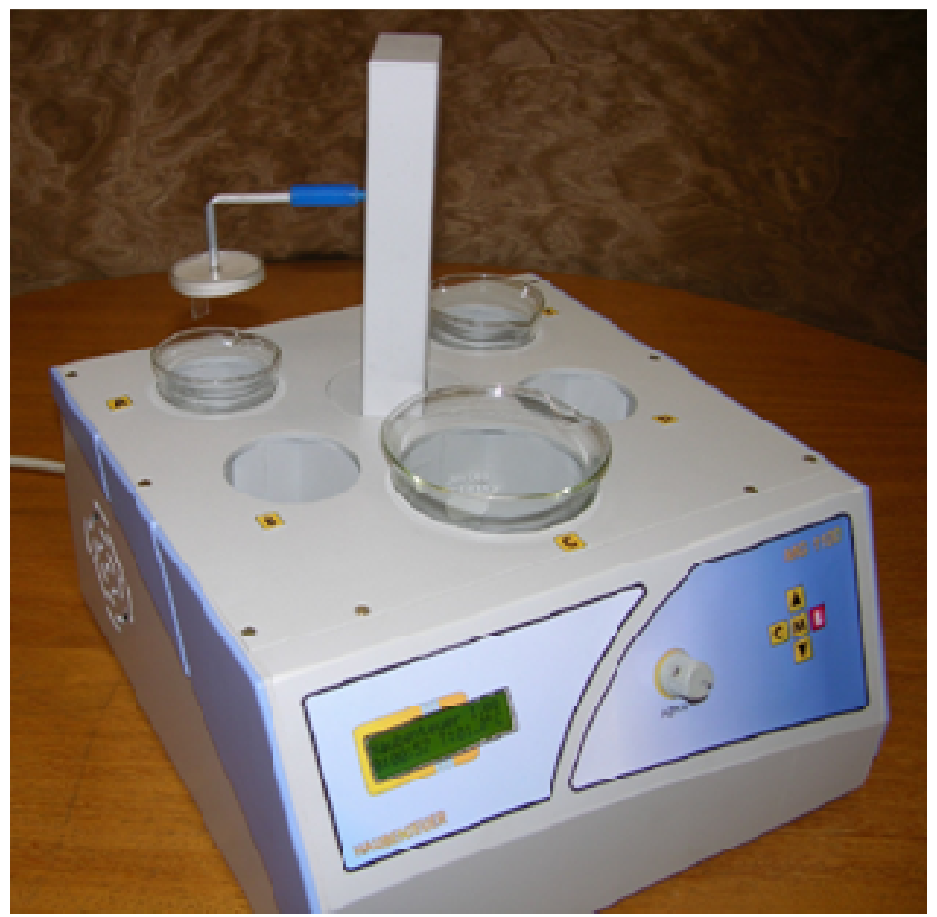

Figura 14 - Robô para a deposição de filmes por automontagem, Haubenteuer MG 1100.

Foram produzidos 7 sensores diferentes para a LE, todos compostos por filmes automontados de 10 bicamadas, utilizando diversos materiais segundo a composição apresentada na Tabela 4.

Tabela 4 - Composição dos sensores da LE

\begin{tabular}{ccc}
\hline Sensor & Policátion & Poliânion \\
\hline 1 & PAH & LS \\
2 & POEA & PSS \\
3 & POMA & PEDOT \\
4 & PAni & FTC \\
5 & POMA & PPy \\
6 & PAni & LS \\
7 & PAH & FTC \\
8 & & Sem filme \\
\hline
\end{tabular}


Os materiais que compõem os sensores, bem como os parâmetros de sua deposição, foram determinados com base em trabalhos anteriores realizados pelo Grupo GEM - EPUSP (BRAGA, 2006; BRAGA et al., 2008; PATERNO, 1999; PATERNO; MATTOSO, 2001a; PATERNO; MATTOSO; RIUL Jr., 2001b; WIZIACK, 2005; WIZIACK et al., 2007).

\subsubsection{Medidas Elétricas}

A impedância elétrica dos sensores quando imersos nas amostras é coletada como sinal de resposta às diferentes características de cada amostra de soja. $O$ sistema de medidas, conforme ilustrado na Figura 15, inclui um analisador de impedância elétrica HP LCR Meter modelo 4263A, conectado ao arranjo de sensores (LE) por meio de um sistema multiplexador. A temperatura da amostra analisada é mantida constante com o auxílio de um banho termostatizado (Quimis). O controle do analisador de impedância e o armazenamento de dados são realizados por um computador. O programa de controle e coleta de dados é baseado em plataforma LabView, desenvolvido pela Embrapa Instrumentação Agropecuária.

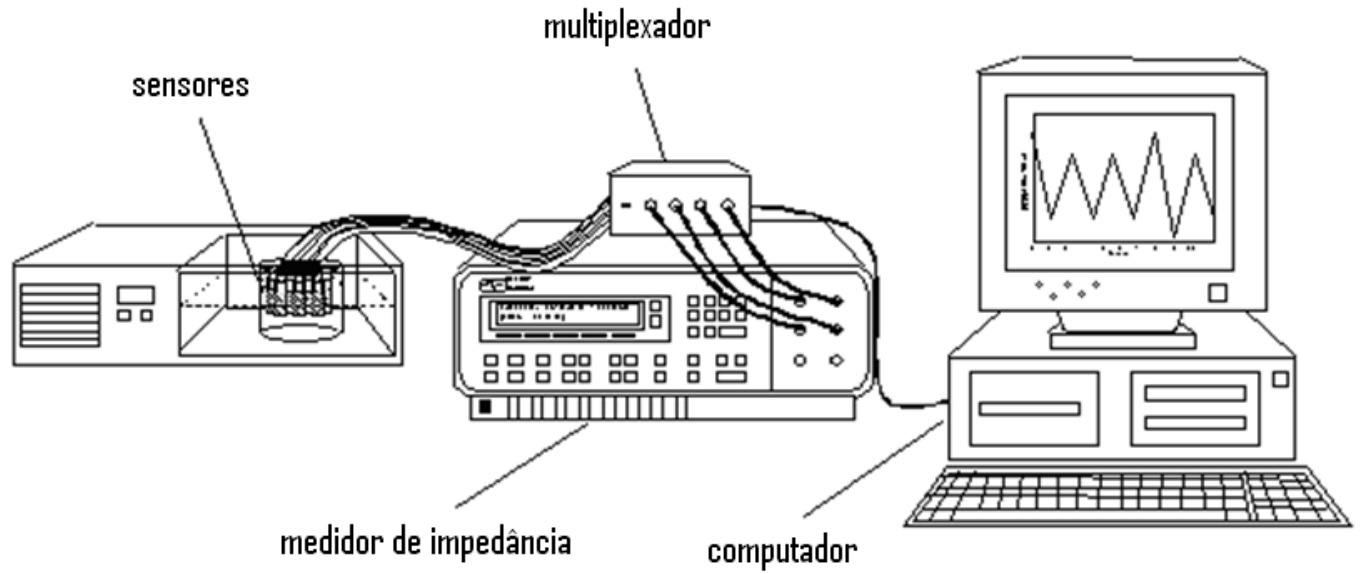

Figura 15 - Ilustração do sistema de medidas da LE. 
Foram realizadas medições nas freqüências de $100 \mathrm{~Hz}, 1 \mathrm{kHz}$ e $100 \mathrm{kHz}$. Deu-se preferência aos resultados obtidos na freqüência de $1 \mathrm{kHz}$, pois neste caso a resposta elétrica dos sensores da LE é proveniente apenas de mudanças na resposta elétrica dos filmes (TAYLOR; MACDONALD, 1987). Como forma de auxiliar na classificação, o pH e a condutividade elétrica (Figura 16) dos extratos de soja foram também determinados.

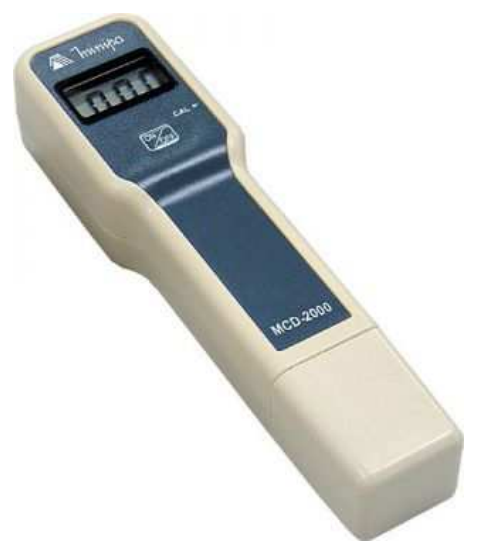

Figura 16 - Condutivímetro portátil Minipa modelo MCD-2000, utilizado nas medições de condutividade elétrica.

\subsubsection{Análise dos Dados}

A análise dos dados foi realizada aplicando-se o método da Análise das Componentes Principais (PCA, Principal Component Analysis) com o software MatLab (versão 7.0.1 / 2004). O PCA é uma técnica de análise estatística que usa um programa computacional para correlacionar estatisticamente os dados coletados pelos sensores da LE, indicando se determinada amostra analisada pelo sensor é semelhante ou não à outra (DYMINSKI, 2006b). É uma ferramenta estatística útil para compreensão, visualização e classificação dos dados.

Seu principal objetivo é reduzir a dimensionalidade de um conjunto de dados. Para tanto, um novo conjunto de variáveis menor do que o conjunto original e que mantém a maioria das informações relevantes das amostras é calculado. Este novo conjunto de variáveis é gerado através da combinação linear das variáveis iniciais 
que mais contribuem para tornar as amostras diferentes umas das outras. Essas combinações lineares dão origem a uma matriz de semelhança, que por sua vez estabelece um conjunto de eixos perpendiculares chamados de Componentes Principais (PC, Principal Component) (BORATO, 2002; DYMINSKI, 2006b).

As Componentes Principais são computadas de tal forma que a PC1 (Primeira Componente Principal) seja aquela que contenha a maior quantidade de informações importantes, e assim sucessivamente, sendo a PC2 (Segunda Componente Principal) a segunda componente com maior quantidade de informações relevantes. Cada componente principal é ortogonal entre si para evitar a redundância de informação (BORATO, 2002).

A importância de cada Componente Principal é expressa em termos de sua respectiva variância, que apresenta a quantidade de informação que pode ser retirada por cada componente, necessária para a diferenciação entre as amostras. Por exemplo, se uma determinada PC1 apresenta $63 \%$ de variância, isto significa que esta componente possui $63 \%$ das informações necessárias para a discriminação das amostras analisadas. Geralmente, $70 \%$ da variância está contida nas duas primeiras componentes principais (BORATO, 2002).

Borato (2002), Cosio et al. (2007), Dias et al. (2009), Di Natale et al. (2000), Dyminski et al. (2006a), Legin et al. (2003), Lvova et al. (2003), Moreno et al. (2006), Riul Jr. et al. (2003a), Scampicchio et al. (2006), Toko (1996), Winquist et al. (1998) e Wiziack et al. (2007) utilizaram PCA para análise dos dados nos seus experimentos com língua eletrônica e/ou nariz eletrônico.

\subsubsection{Imagens obtidas por Microscopia Óptica}

Com o objetivo de analisarmos mais a fundo os filmes dos sensores da LE, foram obtidas imagens a partir de um microscópio óptico acoplado a um computador, conforme ilustra a Figura 17. 


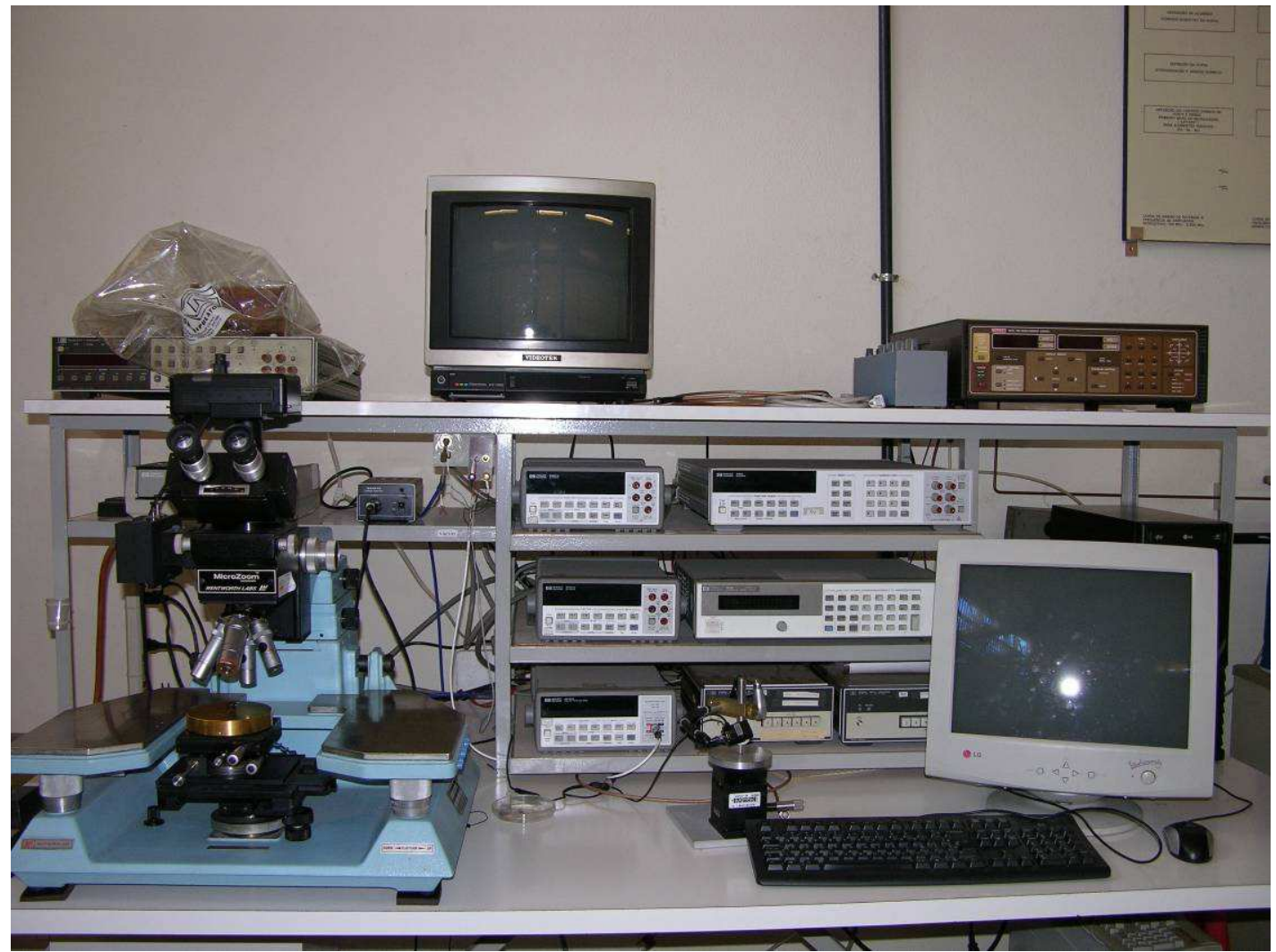

Figura 17 - Microscópio óptico utilizado.

As imagens apresentadas neste trabalho foram obtidas utilizando-se uma lente industrial com capacidade de ampliação de 8 vezes. 


\section{RESULTADOS E DISCUSSÃO}

\subsection{Estudo da repetibilidade das medições efetuadas pela Língua Eletrônica}

Com o objetivo de estudar-se a repetibilidade das medidas realizadas pelo dispositivo fabricado, foram realizadas 400 medições alternadas de capacitância elétrica da água destilada e do leite de soja comercial diluído. Os resultados obtidos com cada sensor são apresentados nas Figuras 18 e 19.

Os pontos inferiores em cada gráfico referem-se às medidas da capacitância elétrica da água destilada e, os pontos superiores são referentes às capacitâncias do leite de soja comercial diluído. Este procedimento foi realizado empregando-se a freqüência de $1 \mathrm{kHz}$ e a tensão elétrica de $50 \mathrm{mV}$. Entre cada medida os sensores foram imersos em água destilada, sob agitação por 5 minutos, para limpeza.

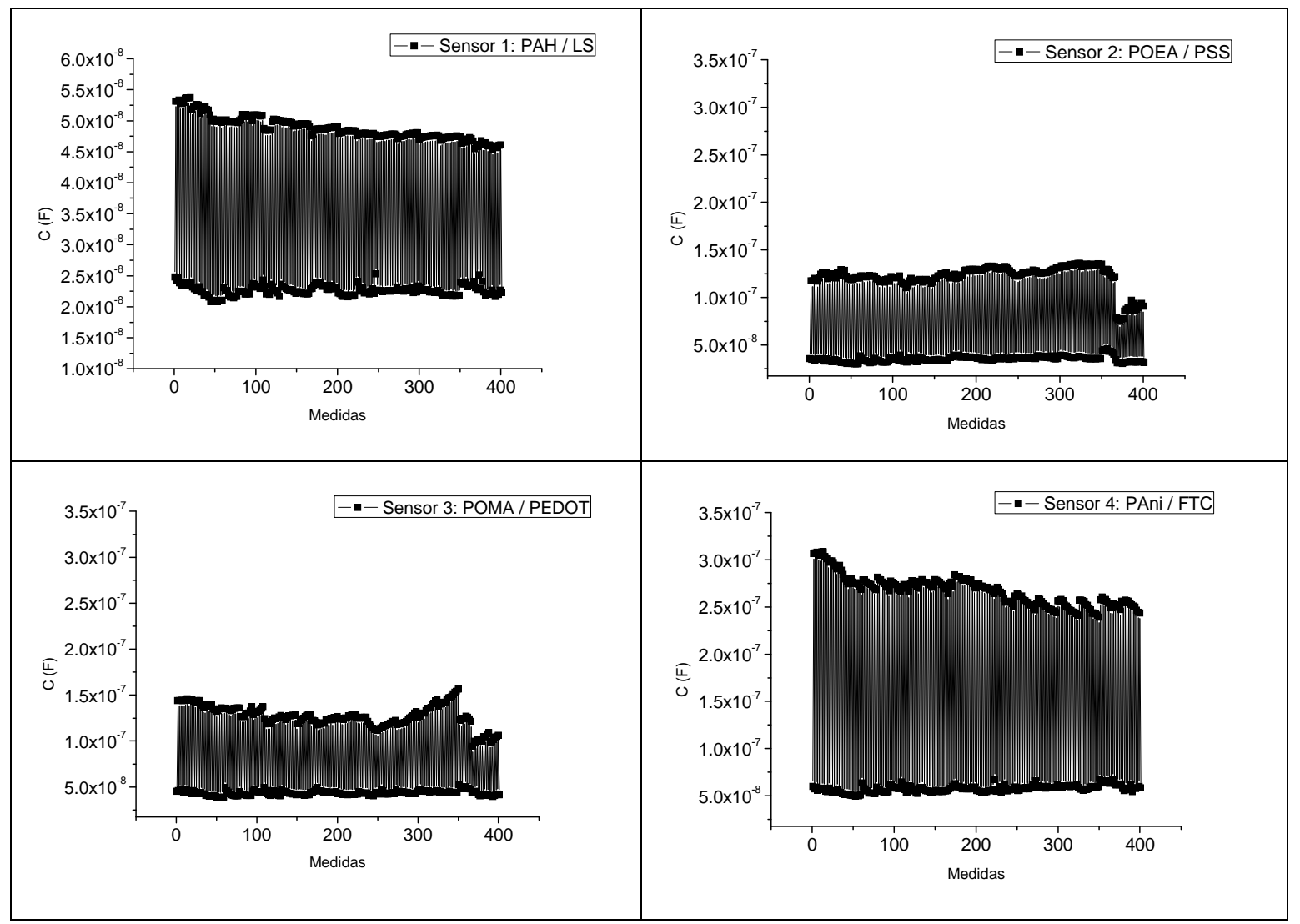

Figura 18 - Gráficos de medidas alternadas de capacitância elétrica da água destilada (menores valores) e leite de soja comercial (maiores valores), para os sensores 1 a 4 da LE. 


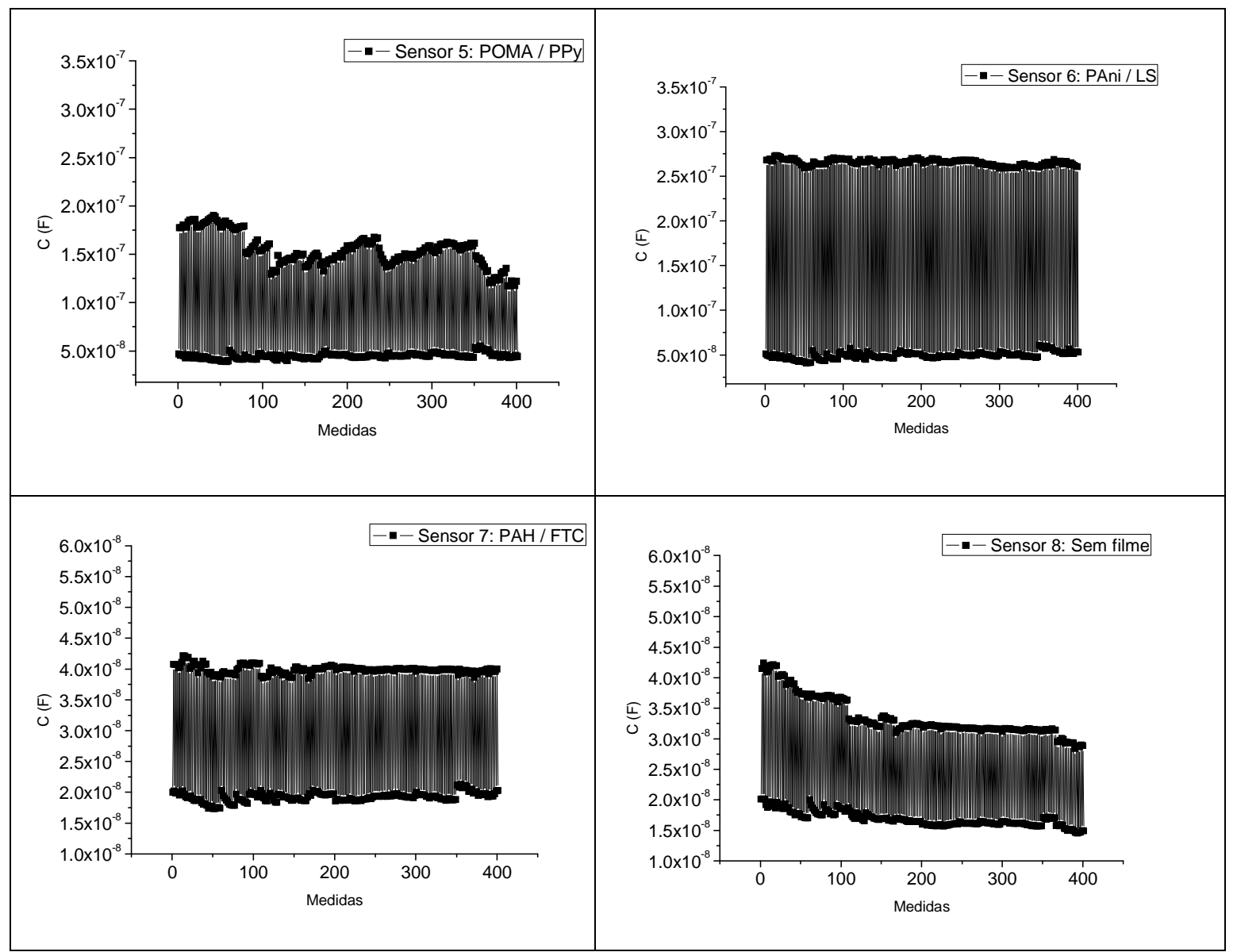

Figura 19 - Gráficos de medidas alternadas de capacitância elétrica da água destilada (menores valores) e leite de soja comercial (maiores valores), para os sensores 5 a 8 da LE.

Foi observado que as medições efetuadas pela LE construída apresentaram boa repetibilidade em geral. Por volta do $350^{\circ}$ ciclo ocorreu uma descontinuidade nas medidas. Ao se retomá-las os sensores 2, 3 e 5 apresentaram variações nas medidas de capacitância elétrica do leite de soja que podem ser justificadas por uma alteração dos sensores durante o período de interrupção. Entretanto, mesmo para estes sensores, as medidas de capacitância da água destilada foram estáveis até a $350^{\text {a }}$ medição, alcançando aproximadamente os mesmos valores em todas as medições.

Além disso, pode ser verificado também que os sensores compostos por PAni (sensores 4 e 6) foram os mais sensíveis, apresentando uma maior diferença entre os valores de capacitância elétrica da água destilada e do leite de soja. 


\subsection{Determinação do tempo de estabilização dos sensores da Língua Eletrônica}

Antes de iniciar uma medida, é preciso deixar os sensores imersos no analito por um tempo determinado, a fim de que ocorra a estabilização das interações entre os sensores da LE e a amostra. Finalmente, após a medida ter sido realizada, é preciso limpar os sensores, que estão impregnados com o analito. Esta limpeza normalmente é feita imergindo-se os sensores em água destilada sob agitação, por um determinado período de tempo.

Para verificar o tempo necessário de estabilização dos sensores, foi realizada a medição das capacitâncias elétricas do ar, analito (leite de soja comercial diluído) e água destilada (sob agitação), em sequência. Estas medidas foram obtidas em freqüência de $1 \mathrm{kHz}$ e tensão elétrica de $50 \mathrm{mV}$. Para cada amostra (ar, leite de soja e água destilada) foram realizadas 50 medições. Os resultados obtidos em cada sensor podem ser vistos nas Figuras 20 a 23.

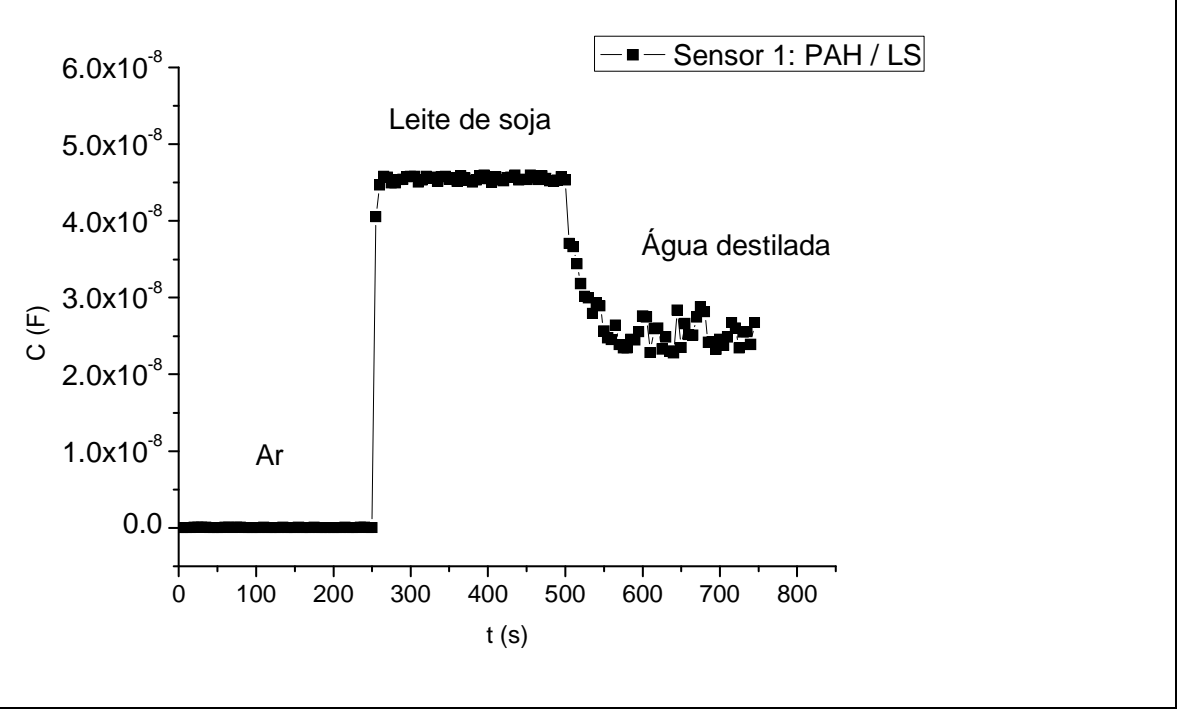

Figura 20 - Gráfico de medidas seqüenciais das capacitâncias elétricas do ar, leite de soja e água destilada sob agitação, para o sensor 1 da LE. 


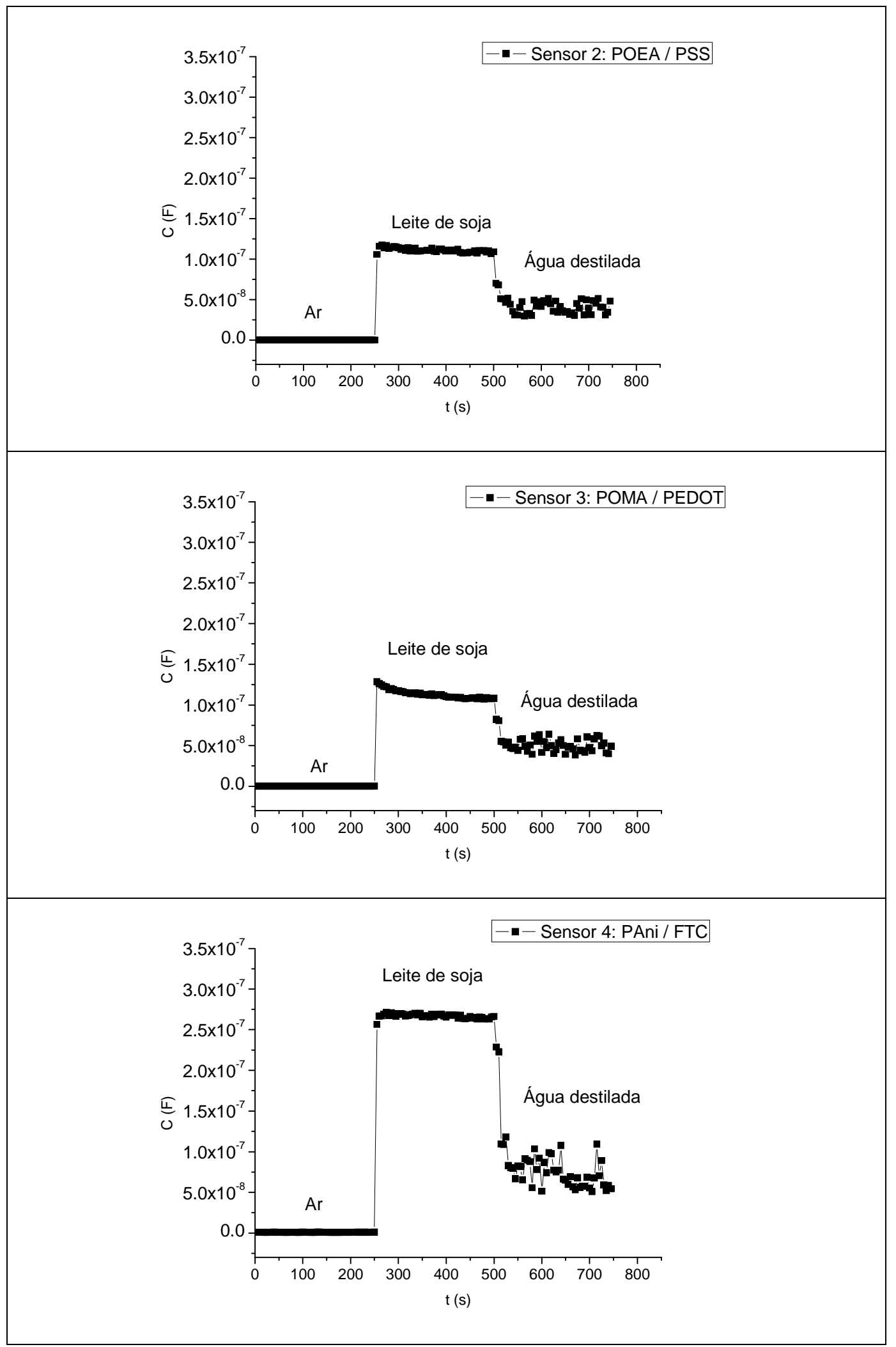

Figura 21 - Gráficos de medidas seqüenciais das capacitâncias elétricas do ar, leite de soja e água destilada sob agitação, para os sensores 2 a 4 da LE. 


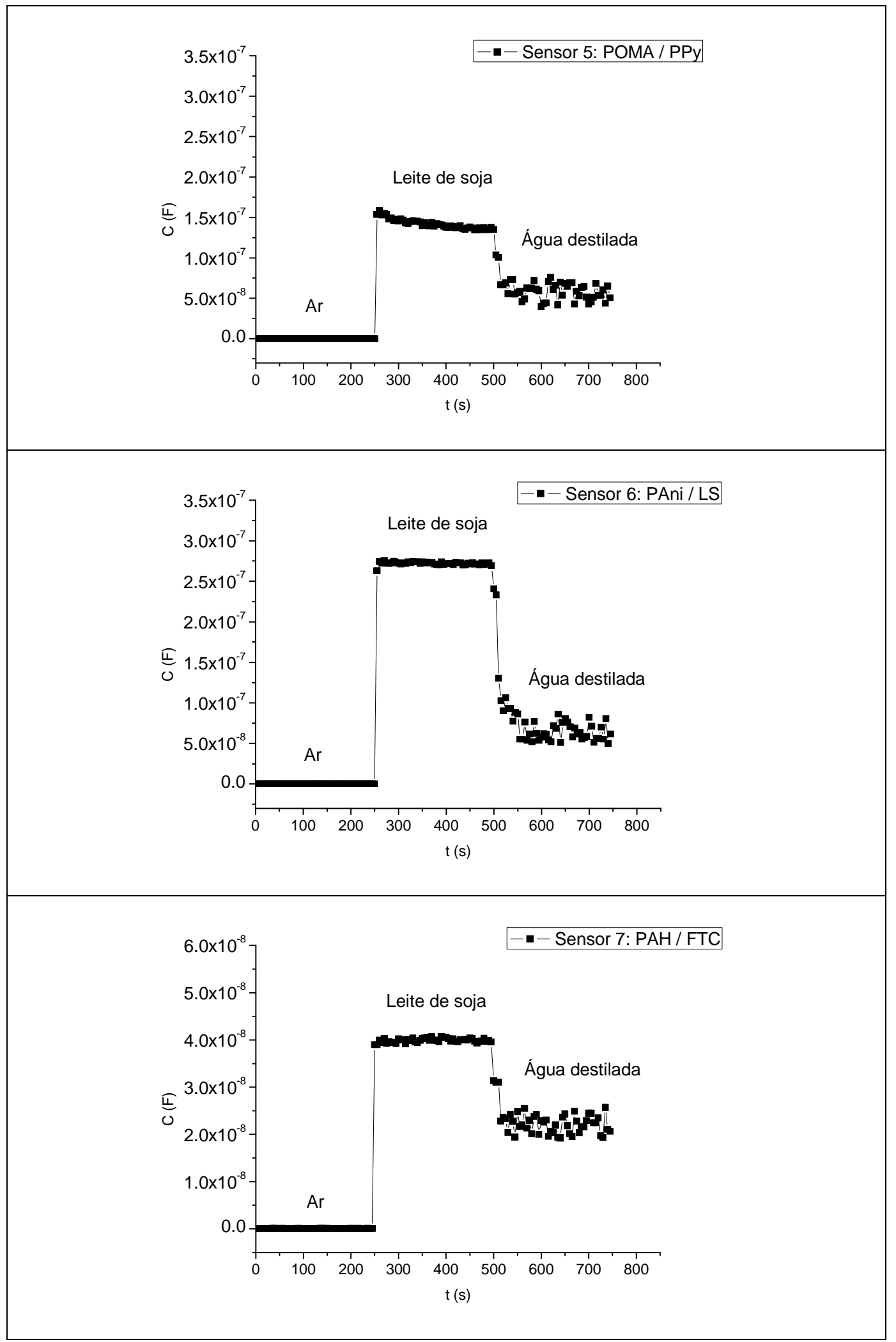

Figura 22 - Gráficos de medidas seqüenciais das capacitâncias elétricas do ar, leite de soja e água destilada sob agitação, para os sensores 5 a 7 da LE. 


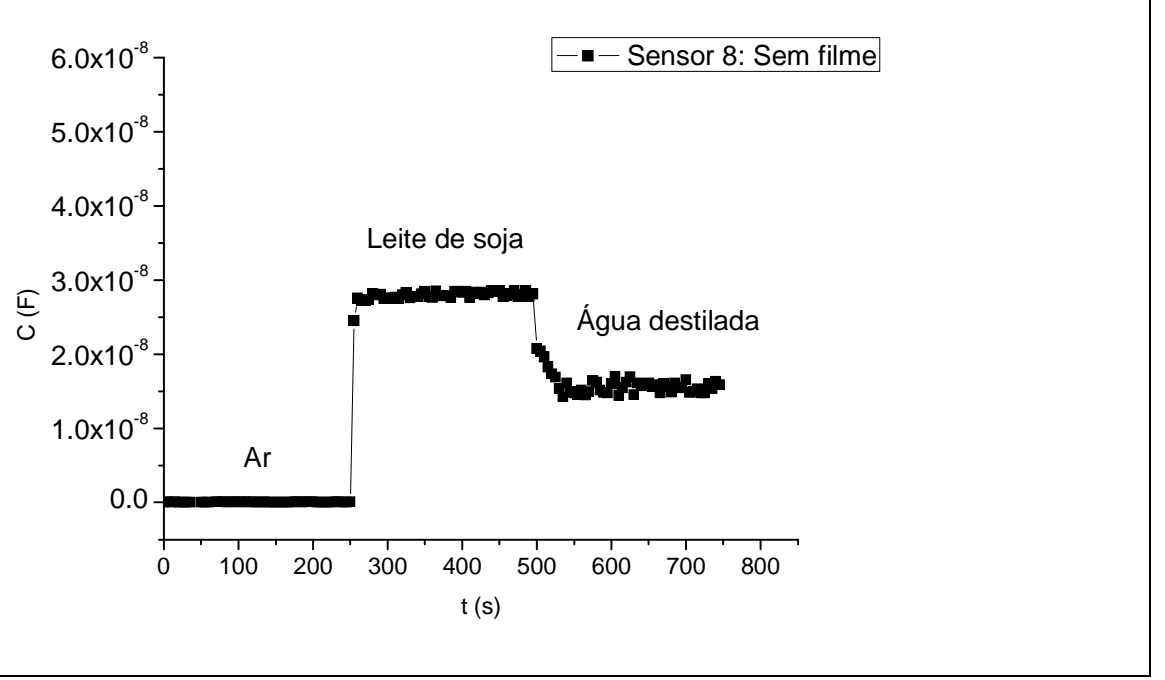

Figura 23 - Gráfico de medidas seqüenciais das capacitâncias elétricas do ar, leite de soja e água destilada sob agitação, para o sensor 8 da LE.

Observa-se que a resposta dos sensores aos analitos líquidos é quase que imediata, uma vez que a capacitância elétrica dos sensores muda instantaneamente quando são imersos nos líquidos. Portanto, para todos os sensores, o tempo de estabilização requerido é mínimo e foi fixado em 1 minuto.

\subsection{Comparação dos métodos de preparo do extrato de soja com e sem a utilização de tratamento térmico}

Os extratos de soja preparados neste trabalho foram produzidos a partir do seguinte procedimento: pesagem dos grãos, maceração, trituração e filtração. Quando se utilizou a massa de $5 \mathrm{~g}$ de grãos de soja, ao final do procedimento descrito anteriormente, foi efetuada também uma diluição com água destilada.

Habitualmente, na indústria e para a realização da análise sensorial, os extratos de soja produzidos passam por tratamentos térmicos, o que visa reduzir ou eliminar os aspectos antinutricionais presentes nesta leguminosa crua (LIENER, 1995) e ainda, auxiliar na inativação das enzimas lipoxigenases para melhorar a aceitação dos produtos de soja no mercado (CIABOTTI, 2004). Entretanto, para a análise com a LE, por se tratar de um sensor, não se faz necessário a realização destes tratamentos térmicos. 
Com o objetivo de compararmos o método tradicional e o método proposto neste trabalho, apresentamos um gráfico de PCA (Figura 24) obtido em um trabalho conjunto com Silva (2009), quando foi realizado o cozimento dos extratos de soja em autoclave a $121^{\circ} \mathrm{C}$ por 5 minutos. As medidas da cap acitância elétrica dos extratos de soja cozidos foram efetuadas pelo Grupo GEM - EPUSP, utilizando-se a mesma LE apresentada neste trabalho (LE 1).

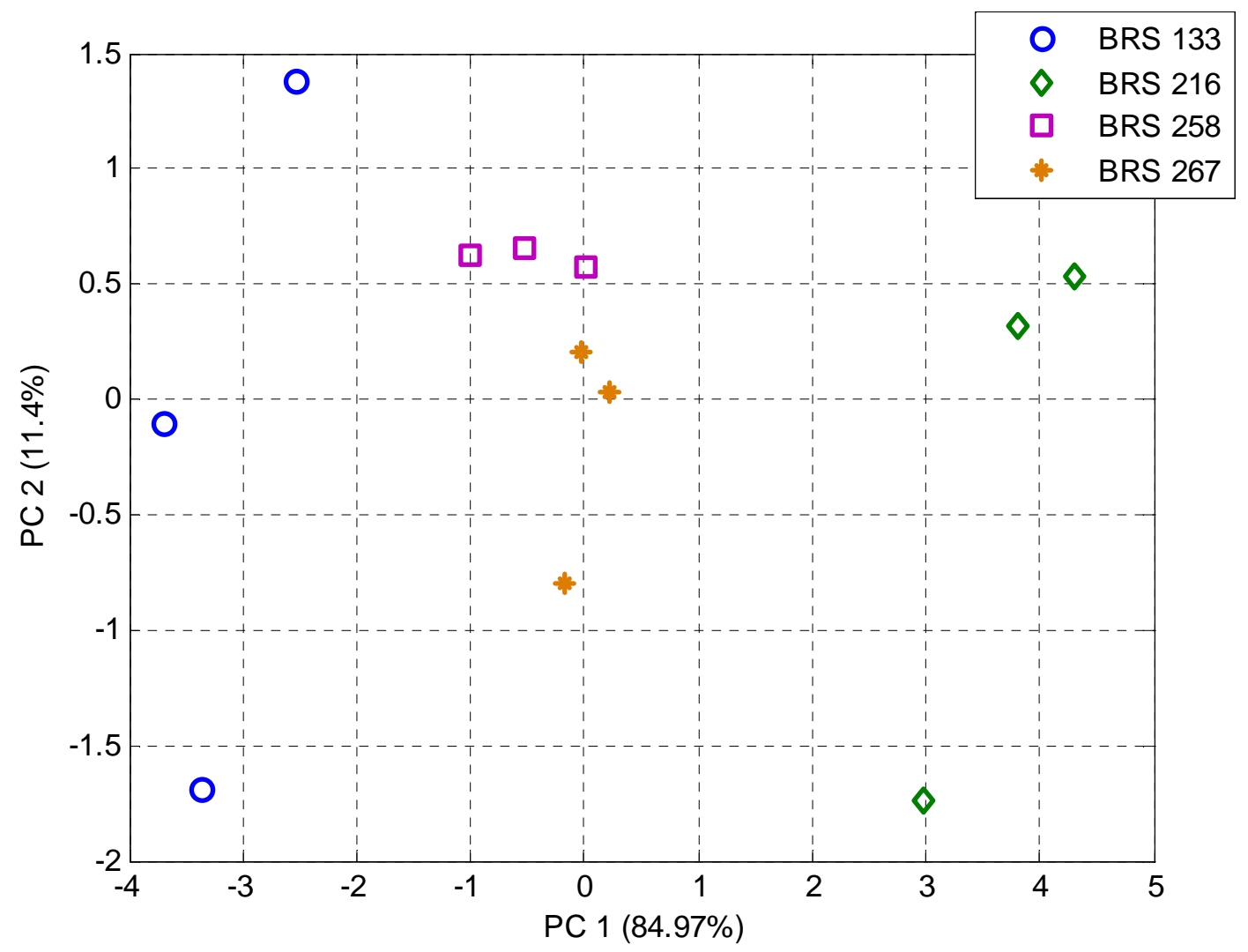

Figura 24 - Gráfico de PCA obtido com a LE a $1 \mathrm{kHz}$, a partir do extrato de soja fornecido por Silva (2009), submetido a um cozimento em autoclave $\left(121^{\circ} \mathrm{C}\right)$ por 5 minutos.

Os quatro cultivares pesquisados por Silva (2009) (BRS 133, BRS 216, BRS 258 e BRS 267) correspondem aos mesmos estudados neste trabalho, com a variação apenas do ano de colheita destes.

A próxima figura (Figura 25) apresenta um gráfico de PCA obtido a partir do procedimento proposto neste trabalho, sem a utilização de tratamentos térmicos. 


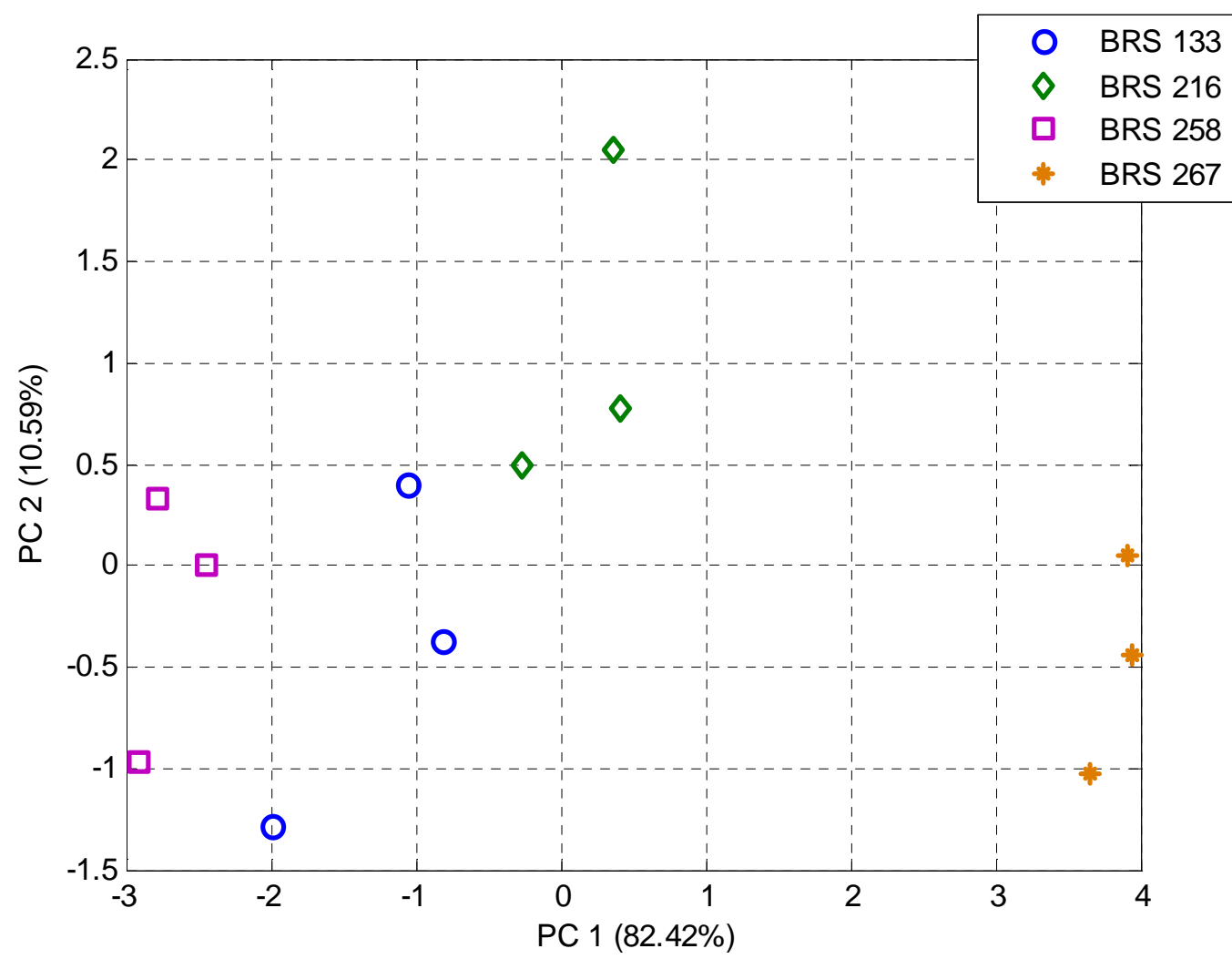

Figura 25 - Gráfico de PCA obtido com a LE a $1 \mathrm{kHz}$, sem a realização de tratamentos térmicos a partir de $5,0 \mathrm{~g}$ de grãos de soja.

Pode-se verificar que em ambos os gráficos de PCA (Figuras 24 e 25) a separação dos cultivares foi eficiente. Desta forma, a análise dos cultivares com 0 método proposto é satisfatória e ainda adiciona um ganho de tempo e praticidade ao procedimento, sem haver perda de informação na análise final.

\subsection{Caracterização dos cultivares de soja}

Inicialmente, o pH dos extratos de soja foi determinado e os resultados são apresentados na Figura 26. Os valores de $\mathrm{pH}$ referem-se a uma média de 30 medidas independentes para cada cultivar, realizadas ao longo de 30 dias. 


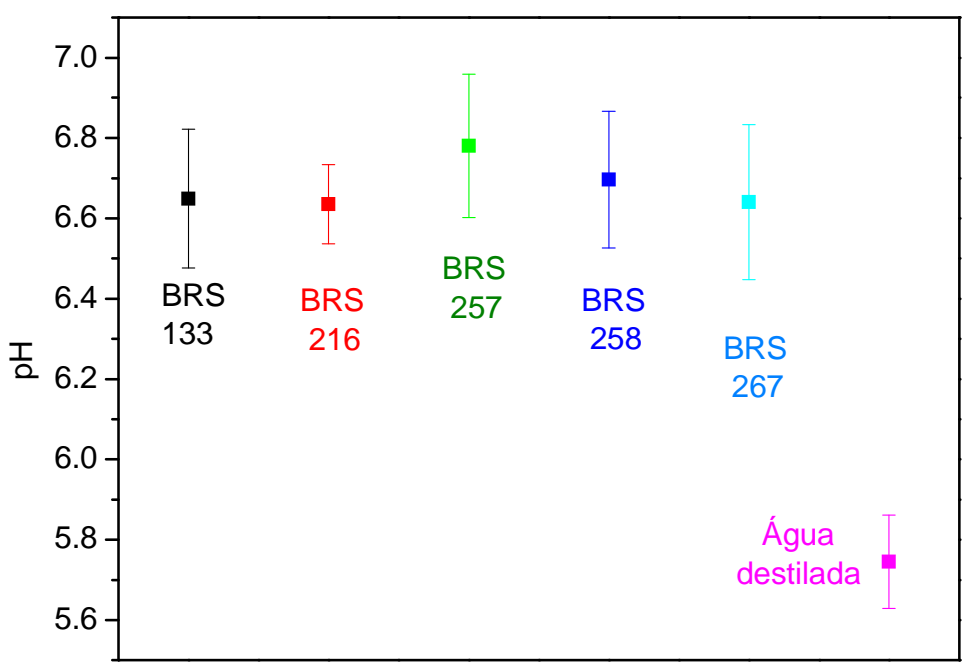

Figura 26 - Gráfico de pH dos cultivares de soja estudados.

É possível observar que as amostras possuem pHs semelhantes. No entanto, as medidas de condutividade elétrica (Figura 27) mostram pequenas diferenças entre os cultivares, segundo a sequência abaixo:

BRS $258<$ BRS $216<$ BRS $133<$ BRS $257<$ BRS 267

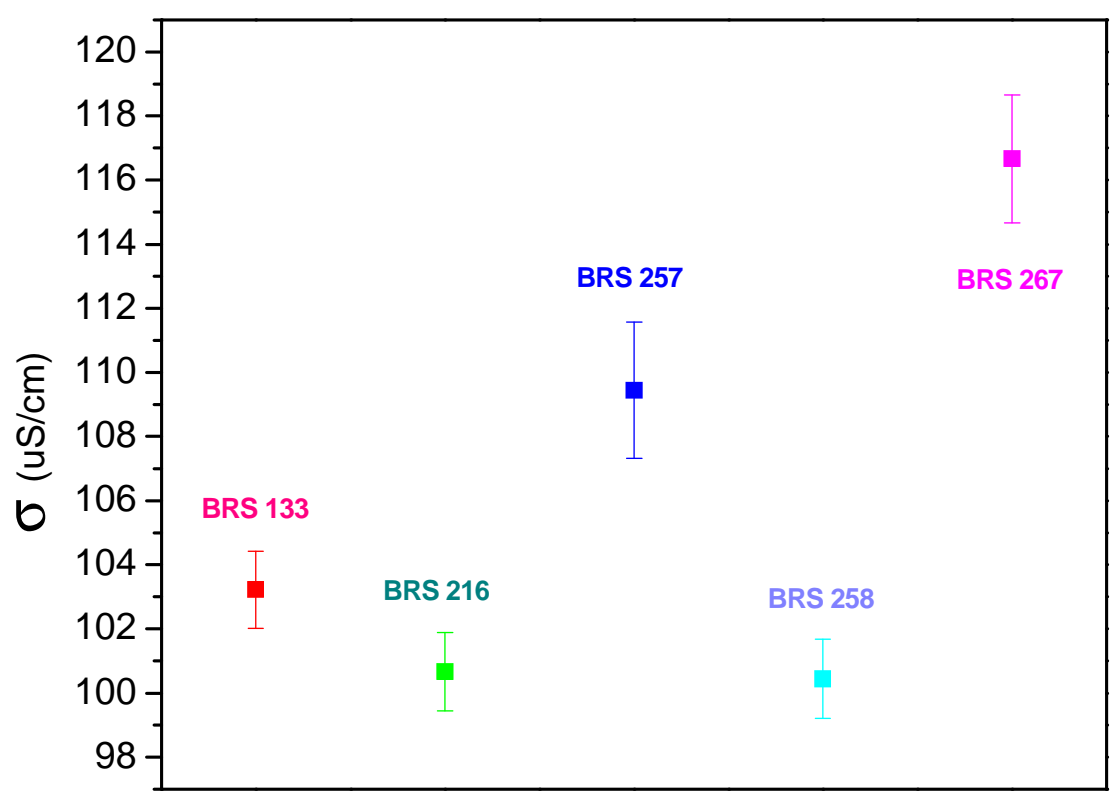

Figura 27 - Gráfico de condutividade elétrica dos cultivares de soja estudados.

Os valores de condutividade elétrica apresentados foram medidos a $25^{\circ} \mathrm{C}$ e referem-se a uma média de 9 medidas independentes para cada cultivar. 
Continuando este estudo inicial de caracterização das amostras, foi obtido o gráfico da impressão digital (Figura 28) das amostras através de medidas com a LE em $1 \mathrm{kHz}$.

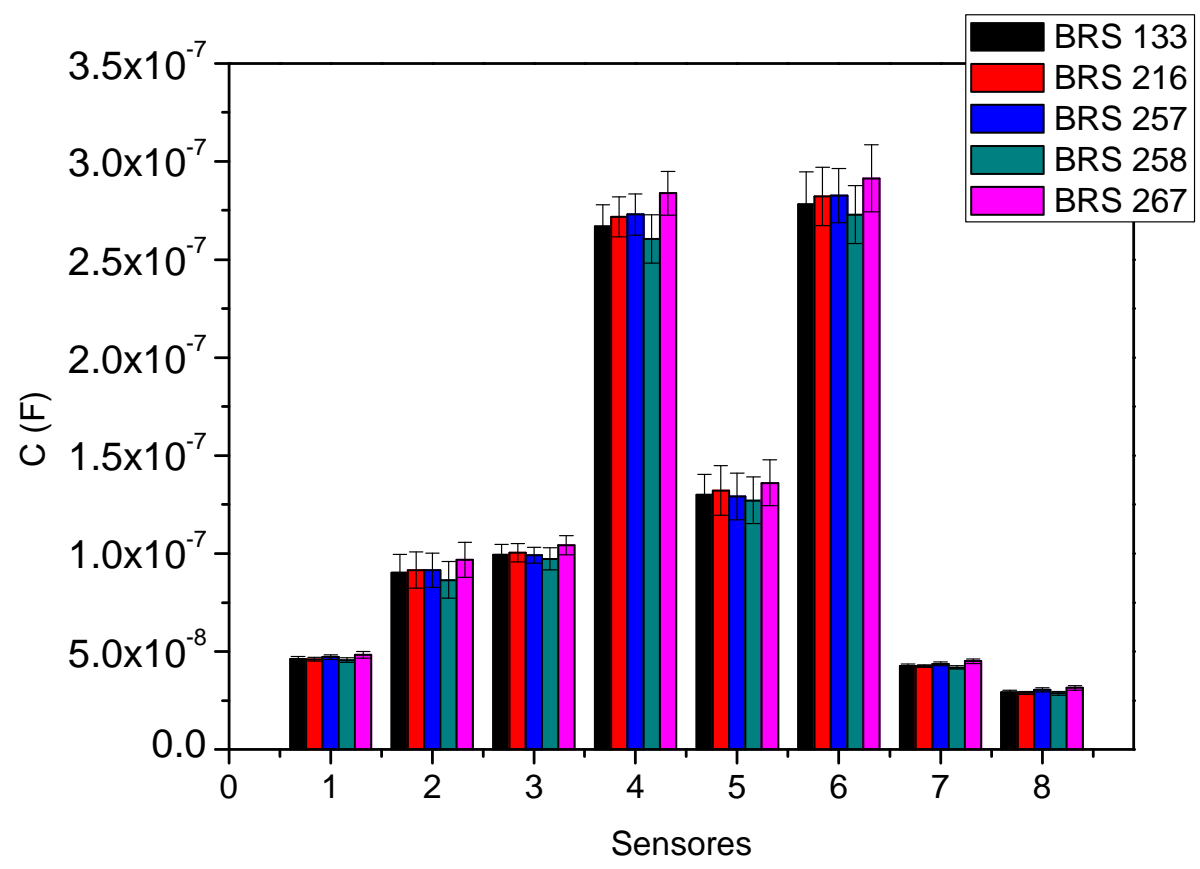

Figura 28 - Impressão digital elétrica dos cinco cultivares de soja estudados, obtida a $1 \mathrm{kHz}$ com a LE.

Os valores foram obtidos utilizando-se uma tensão de $50 \mathrm{mV}$. Cada coluna, representante de um cultivar, refere-se a uma média de 30 medidas independentes.

Observa-se que o sinal dos sensores é bastante próximo para cada cultivar avaliado, sendo porém ligeiramente maior para o cultivar BRS 267 e menor para o cultivar BRS 258. Contudo, as pequenas diferenças de sinal entre cada sensor para cada amostra foram suficientes para que a LE pudesse discriminar os diferentes tipos de cultivares, como veremos mais adiante. Os sensores baseados em filmes de PAni (sensores 4 e 6) apresentaram maior sinal em relação aos demais sensores, independentemente do cultivar analisado. 


\subsection{Discriminação dos cultivares de soja pela Língua Eletrônica}

Visando a discriminação dos cultivares de soja, extratos obtidos a partir de 0,5 $\mathrm{g}$ de grãos foram analisados com a LE, ao longo de 10 dias consecutivos de medições. Cada amostra de soja foi preparada e analisada em triplicatas. Novos extratos foram feitos a cada dia em que a medição foi realizada, de modo a minimizar uma possível degradação da amostra.

Foram efetuadas medidas de capacitância elétrica dos extratos com a LE, utilizando $50 \mathrm{mV}$ de tensão e $1 \mathrm{kHz}$ de frequência. Os resultados obtidos foram tratados com o método estatístico de Análise das Componentes Principais (PCA). A Figura 29 apresenta um gráfico de PCA preparado a partir dos dados do primeiro dia de medida. Como pode ser observado, a LE foi capaz de discriminar os cinco cultivares de soja estudados (GREGORUT et al., 2009).

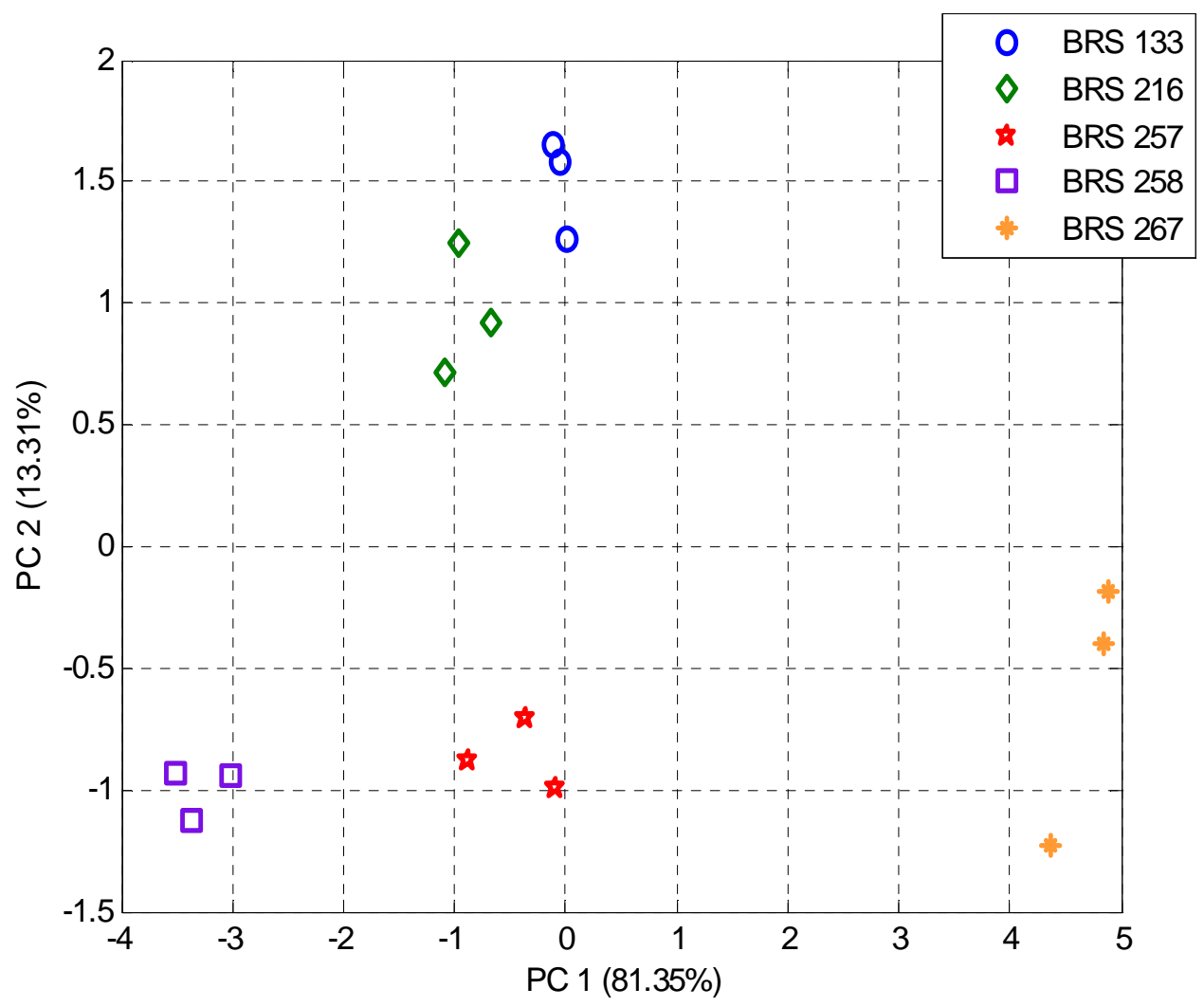

Figura 29 - Gráfico de PCA obtido com a LE a $1 \mathrm{kHz}$, a partir dos dados apenas do primeiro dia de medida. 
Entretanto, ao adicionarmos no PCA os dados provenientes de outros dias de avaliação, ocorreu a intersecção entre cultivares distintos. Isso é apresentado na Figura 30, obtida a partir dos dados dos três primeiros dias de avaliação.

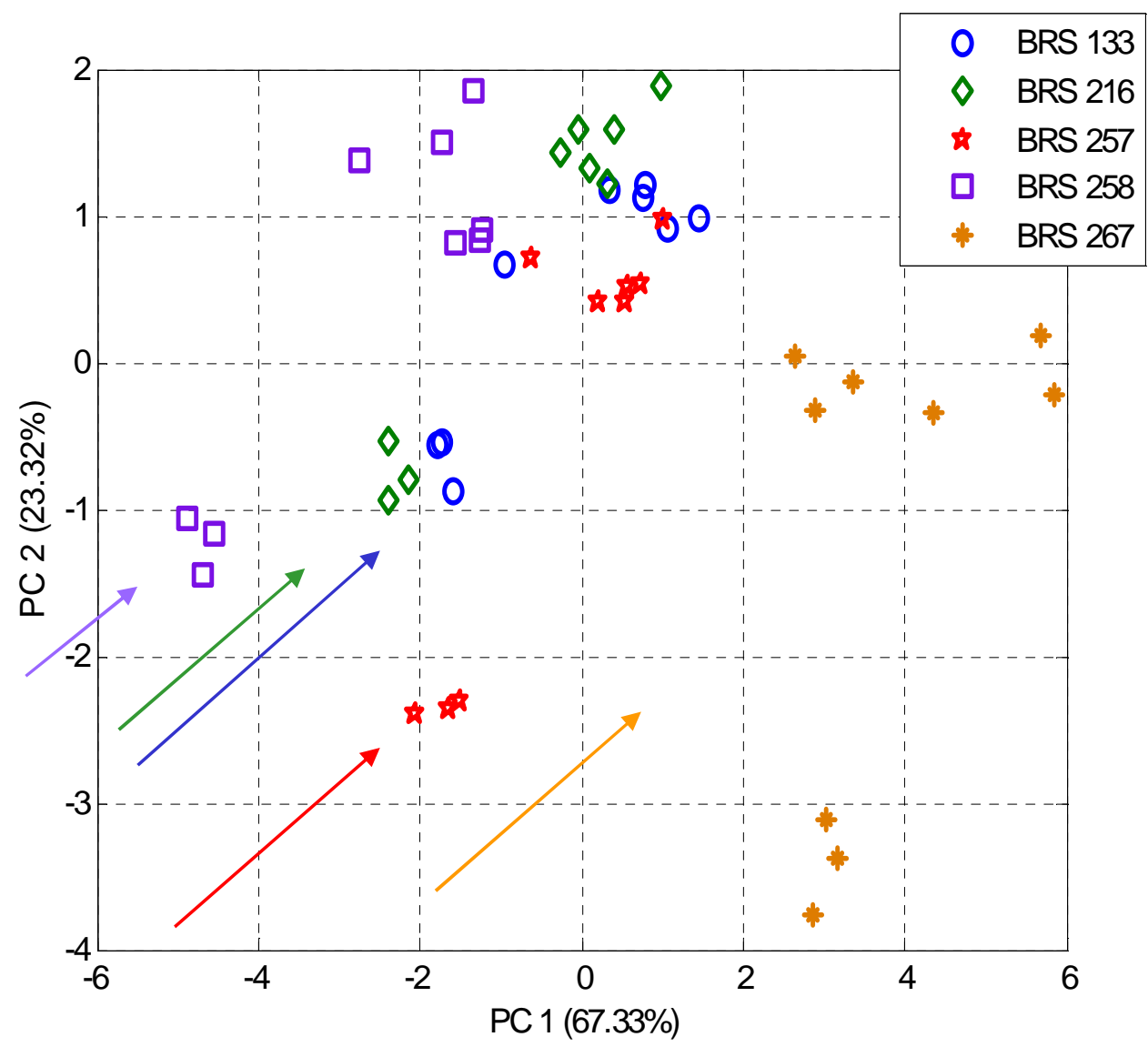

Figura 30 - Gráfico de PCA obtido com a LE a $1 \mathrm{kHz}$, a partir dos dados dos três primeiros dias de medida. As setas indicam a separação dos cultivares segundo a sequência: BRS 258, BRS 216, BRS 133, BRS 257 e BRS 267.

Contudo, o gráfico de PCA (Figura 30) ilustra que as amostras foram discriminadas seguindo a sequência crescente observada anteriormente nas medidas de condutividade: BRS 258, BRS 216, BRS 133, BRS 257 e BRS 267, como indicado pelas setas inseridas no gráfico. Podemos, portanto, concluir que a LE discrimina as amostras de soja de acordo com as diferenças de condutividade elétrica.

Porém, quando o gráfico de PCA é construído com os dados dos dez dias de avaliação, totalizando 30 amostras para cada cultivar, não foi possível verificar discriminação dos cultivares de soja estudados, como pode ser visto na Figura 31. 


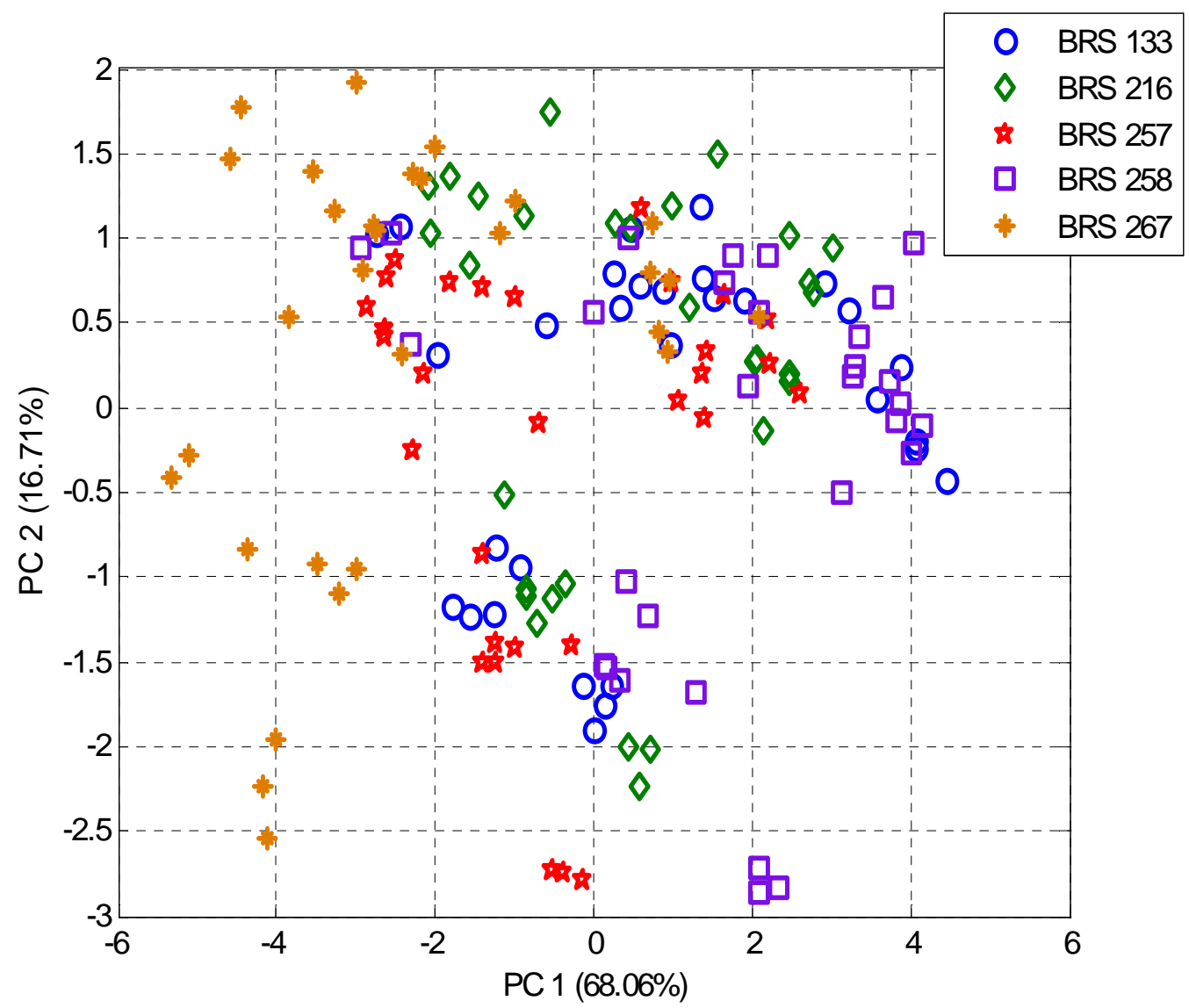

Figura 31 - Gráfico de PCA obtido com a LE a 1 kHz, a partir dos dados dos 10 dias de medida.

Nesse caso, pode ser atribuído a incapacidade da LE à qualidade das amostras preparadas, uma vez que sendo preparadas ao longo de vários dias pode haver variação na forma de preparo (erro humano) entre um dia e outro, bem como a degradação das propriedades do extrato.

A fim de minimizar a ocorrência de possíveis erros durante o preparo das amostras, aumentou-se em 10 vezes a massa de grãos pesados, preparando-se então extratos a partir $5 \mathrm{~g}$ de grãos. $O$ procedimento subseqüente adotado para a preparação dos extratos foi exatamente igual ao anterior, com exceção da adição, ao final, de uma diluição em 10 vezes com água destilada.

Este aumento da massa de grãos de soja teve por finalidade apenas minimizar a propagação de possíveis erros durante o procedimento de preparo dos extratos, já que os extratos finais analisados possuíam a mesma concentração dos extratos preparados a partir de $0,5 \mathrm{~g}$ de grãos de soja. 
Foram então realizados 3 dias de medidas de capacitância elétrica destes extratos com a LE, utilizando $50 \mathrm{mV}$ de tensão e $1 \mathrm{kHz}$ de frequência. Em cada dia, as amostras de soja foram analisadas em triplicata. Conforme pode ser visto na Figura 32, também foi possível a separação dos cinco cultivares de soja estudados quando se utilizou para a elaboração do gráfico de PCA apenas os dados do primeiro dia de medida.

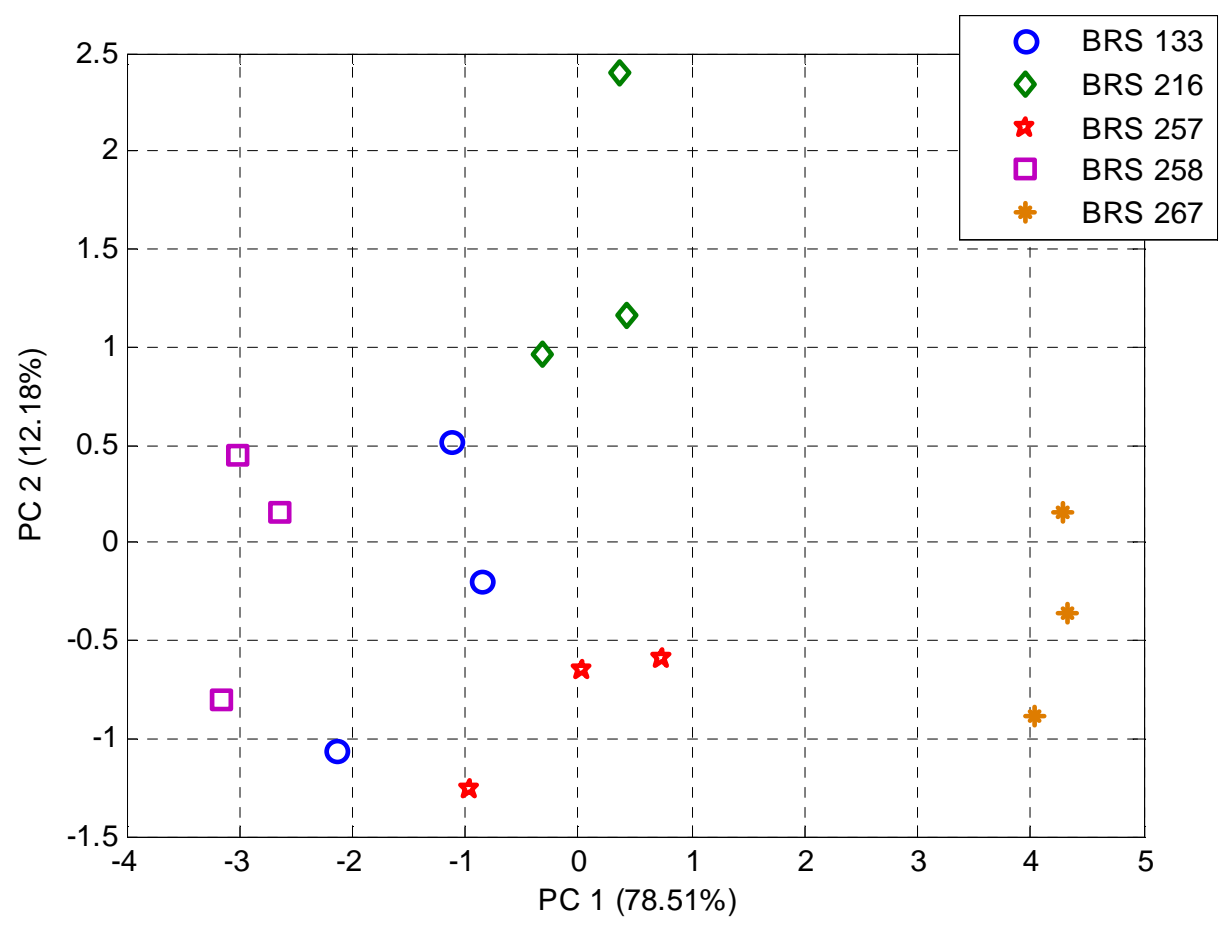

Figura 32 - Gráfico de PCA obtido com a LE a $1 \mathrm{kHz}$, a partir de 5,0 g de grãos de soja e utilizando-se os dados apenas do primeiro dia de medida.

Entretanto, de forma similar aos resultados apresentados anteriormente, quando se utilizou os dados dos 3 dias de medidas para a construção do gráfico de PCA (Figura 33), não foi possível discriminar os cultivares estudados. 


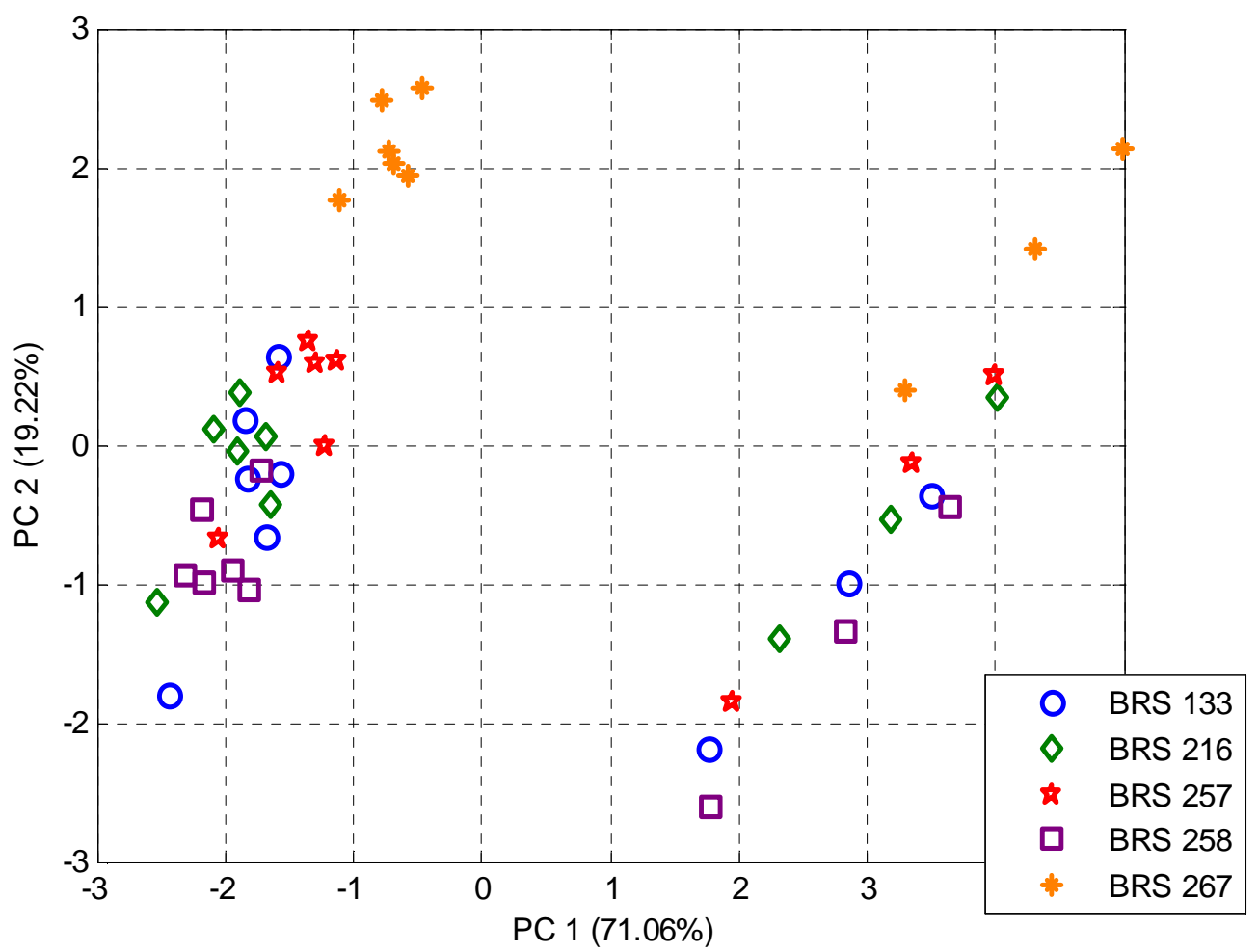

Figura 33 - Gráfico de PCA obtido com a LE a $1 \mathrm{kHz}$, a partir de 5,0 g de grãos de soja e utilizandose os dados dos 3 dias de medidas.

Desta forma, pode-se concluir que a massa dos grãos utilizada no preparo dos extratos de soja não exerce influência direta sobre a discriminação dos cultivares pela LE.

Continuando com a investigação sobre esta variação obtida ao longo de vários dias de medidas, foi realizado um estudo do comportamento dos sensores da LE durante e após as medições dos extratos de soja citadas anteriormente.

\subsection{Estudo dos sensores da Língua Eletrônica}

\subsubsection{Avaliação do envenenamento dos sensores da Língua Eletrônica}

Ao início e ao final de cada dia de medida, foram realizadas medições da capacitância elétrica da água destilada. Utilizando os dados previamente obtidos 
durante os 10 dias de medidas consecutivos dos extratos de soja (a partir de $0,5 \mathrm{~g}$ de grãos de soja), apresentados inicialmente nos gráficos de PCA das Figuras 29 a 31, foram construídos gráficos com a capacitância elétrica dos cultivares de soja incluindo a capacitância da água destilada. Através destes gráficos foi possível observar que não ocorreu o envenenamento dos sensores da LE, pois os valores de capacitância da água destilada (pontos inferiores) foram estáveis, retornando ao mesmo nível ao longo dos 10 dias de medidas. As Figuras 34 a 36 apresentam estes resultados.
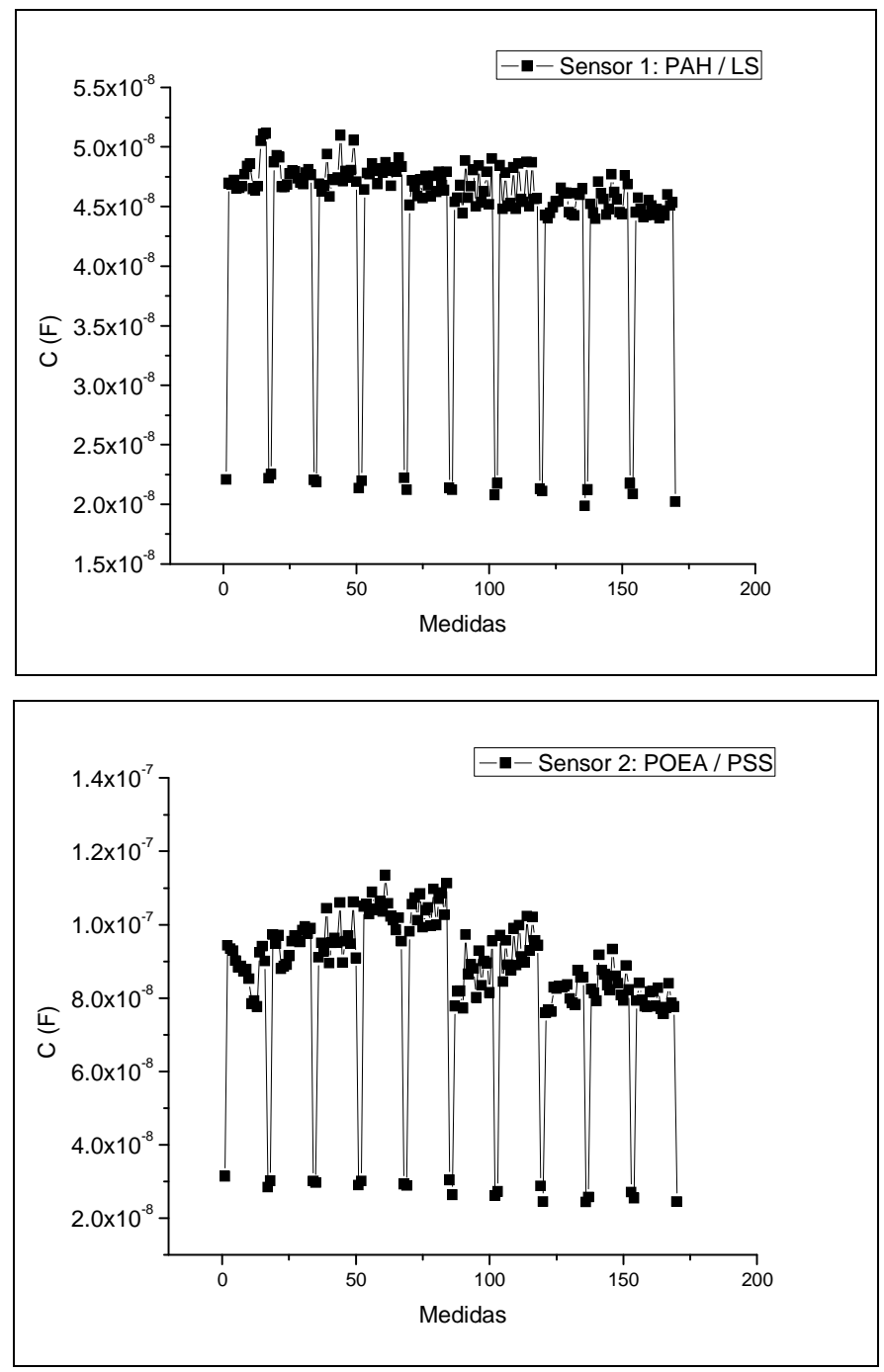

Figura 34 - Gráficos de 10 dias de medidas de capacitância elétrica da água destilada (menores valores) e dos extratos de soja (maiores valores), para os sensores 1 e 2 da LE. 

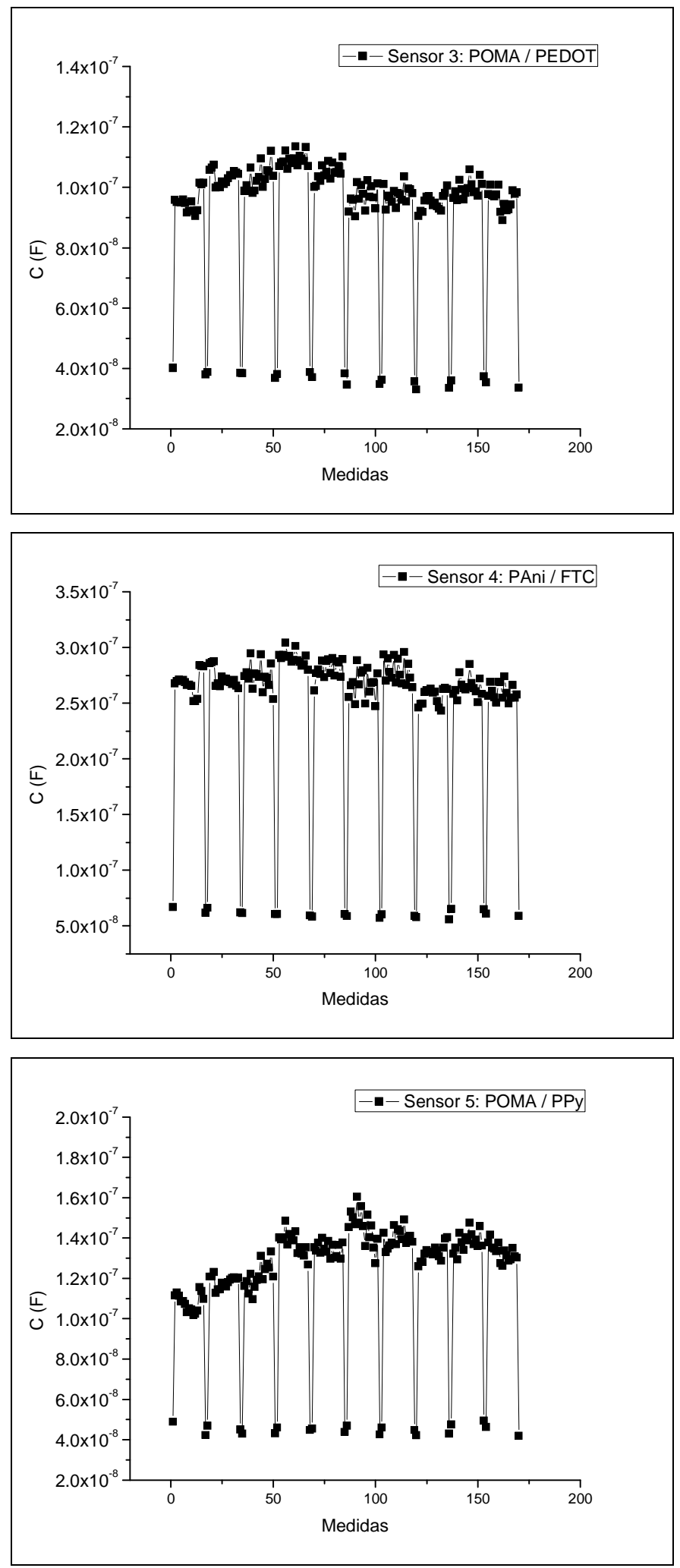

Figura 35 - Gráficos de 10 dias de medidas de capacitância elétrica da água destilada (menores valores) e dos extratos de soja (maiores valores), para os sensores 3 a 5 da LE. 

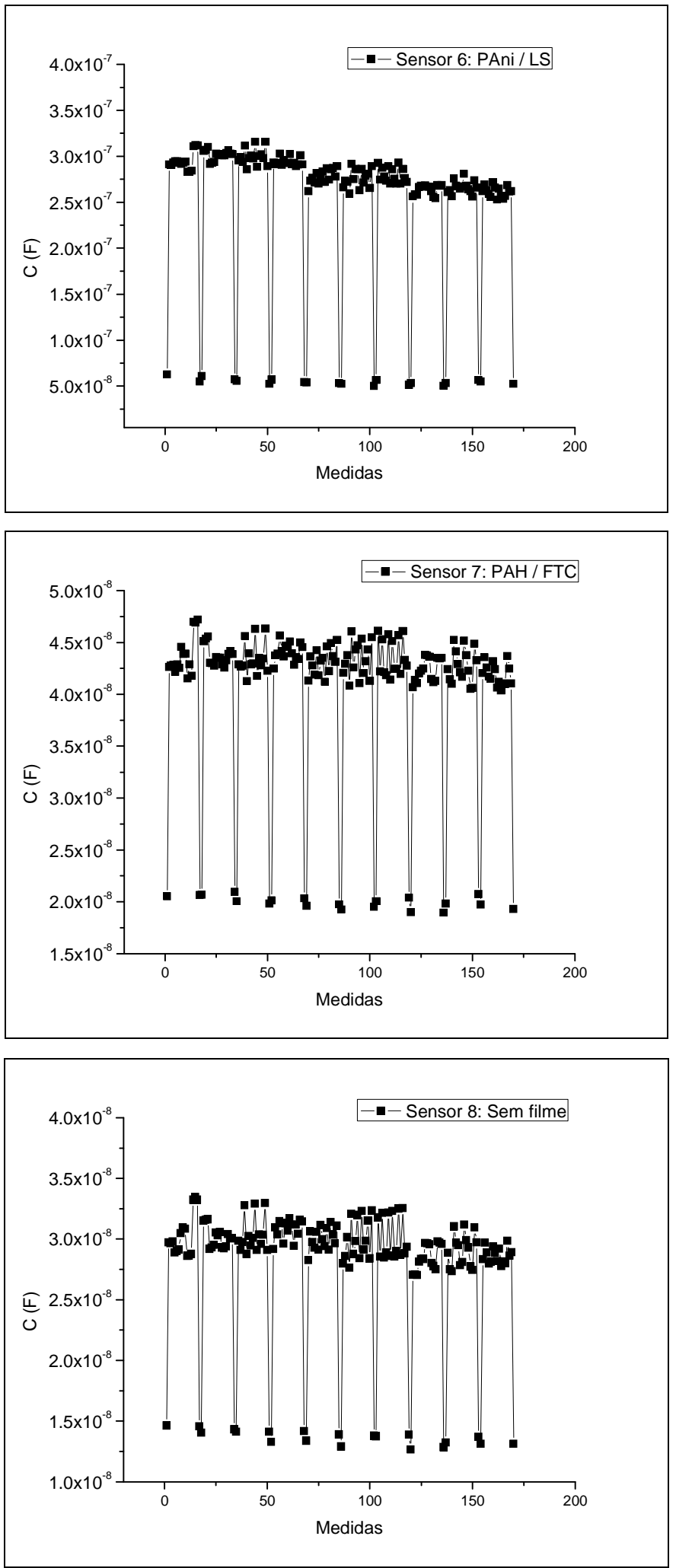

Figura 36 - Gráficos de 10 dias de medidas de capacitância elétrica da água destilada (menores valores) e dos extratos de soja (maiores valores), para os sensores 6 a 8 da LE. 
Foi possível então concluirmos que a dificuldade de discriminação dos cultivares de soja pela LE ao longo de vários dias independe da massa de grãos utilizada e também não está relacionada a um possível envenenamento de seus sensores.

\subsubsection{Avaliação microscópica dos sensores da LE}

Para verificar a eventual degradação do filme polimérico do sensor, imagens de microscopia óptica foram obtidas de todos os sensores, após sucessivo uso. Estas imagens focalizaram a região dos dígitos dos microeletrodos de ouro, após o término de todos os experimentos. Como foram obtidas imagens muito semelhantes para todos os sensores da LE, a Figura 37 apresenta apenas as imagens dos sensores 1 e 2.
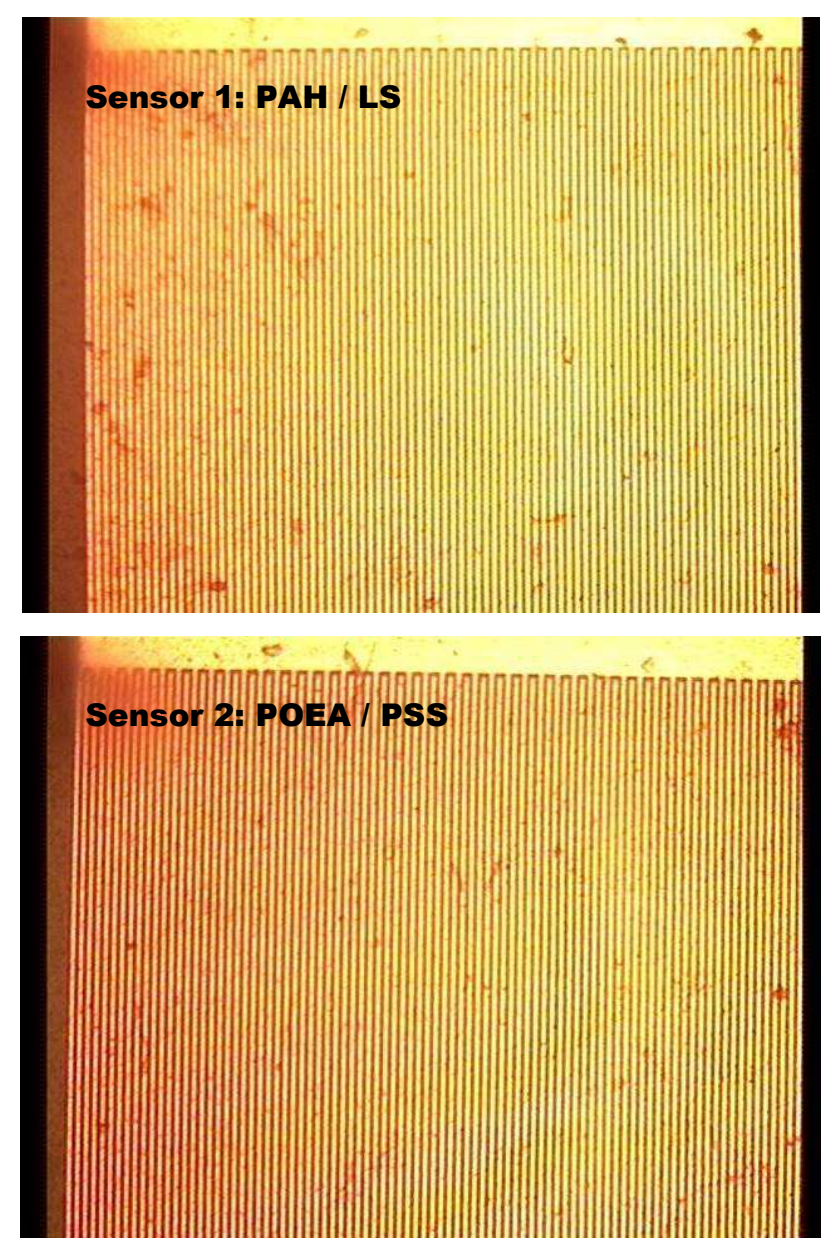

Figura 37 - Imagens obtidas através do microscópio óptico dos sensores 1 e 2 da LE, com ampliação de 8 vezes. 
Como pode ser observado na Figura 37, estão presentes alguns aglomerados, que são típicos do acúmulo irregular de material polimérico, assim como observado por Braga (2006). Entretanto, não se observa o acúmulo de resíduos de soja ou a presença de colônias de bactérias ou fungos, fato comum quando se trabalha com alimentos. Esse resultado confirma a eficácia da etapa de limpeza dos sensores entre cada medida, o que garante o uso prolongado da LE sem perder a confiabilidade dos resultados obtidos.

Após os estudos sobre os sensores da LE que excluíram as hipóteses de degradação e envenenamento destes, seguimos com o estudo de uma possível degradação das amostras analisadas.

\subsection{Estudo da degradação dos cultivares de soja com a Língua Eletrônica}

\subsubsection{Degradação dos extratos de soja produzidos}

Analisando-se cuidadosamente o gráfico de PCA da Figura 32 e levando-se em consideração a ordem de análise das amostras durante aquele dia, é possível notar que a LE foi capaz de captar a degradação das amostras ao longo de um mesmo dia de medidas.

A Figura 38 apresenta o mesmo gráfico PCA ilustrado anteriormente na Figura 32, porém exibindo a ordem de medição realizada. 


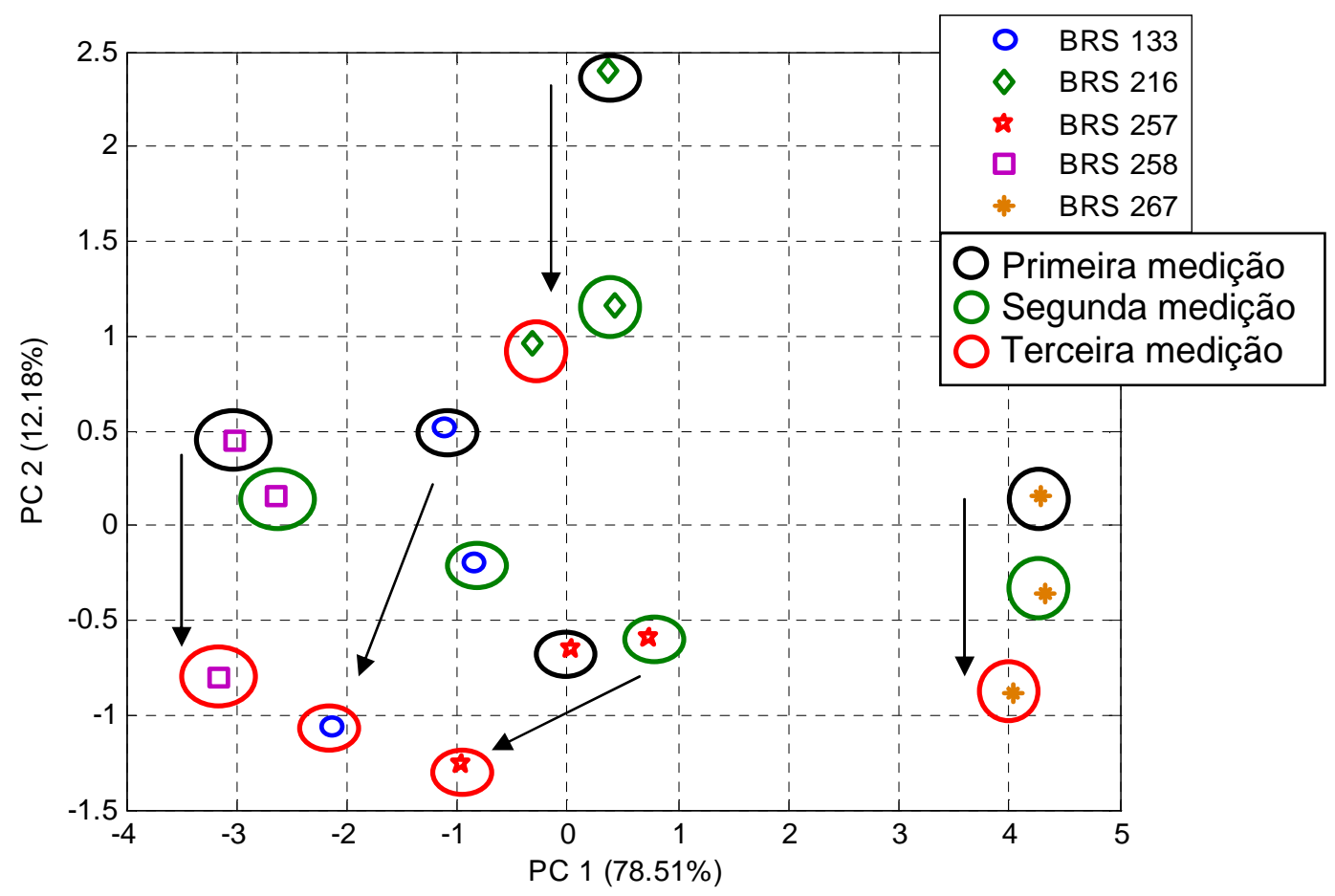

Figura 38 - Gráfico de PCA obtido com a LE a $1 \mathrm{kHz}$, a partir de $5,0 \mathrm{~g}$ de grãos de soja e utilizando-se os dados apenas do primeiro dia de medida. As setas indicam a ordem das medições.

É possível observar que, para todos os cultivares, houve uma variação semelhante regida pela ordem das medições realizadas durante o dia. Isto possivelmente expressa a degradação das amostras ao longo de um dia, captada pela LE.

Analisando-se os outros dias de medidas efetuadas e levando-se em consideração a sua ordem, foram obtidos resultados similares ao exibido na Figura 38. A Figura 39 exemplifica a detecção da degradação das amostras analisadas no terceiro dia de medidas. 


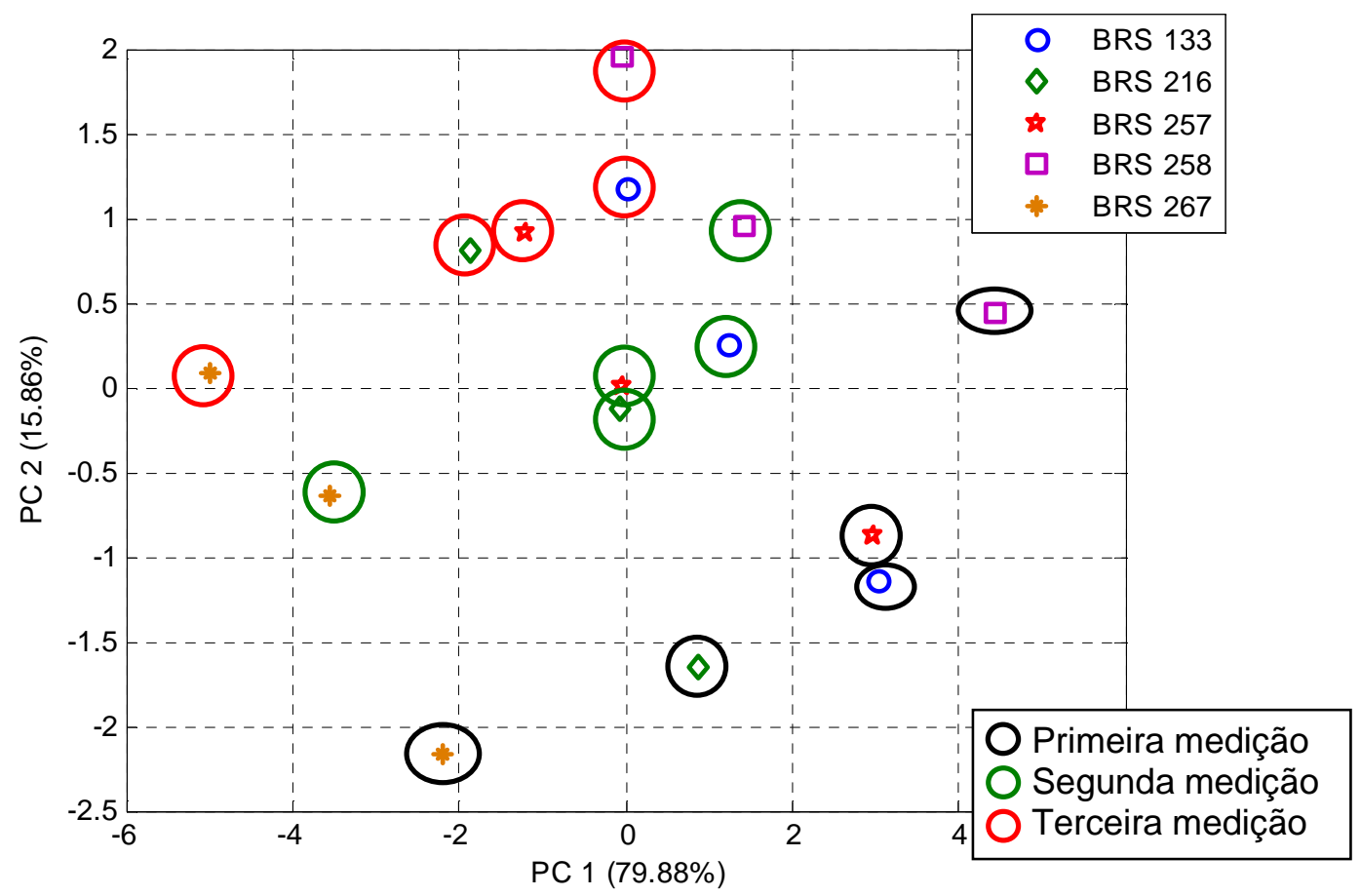

Figura 39 - Gráfico de PCA obtido com a LE a $1 \mathrm{kHz}$, a partir de 5,0 g de grãos de soja e utilizando-se os dados apenas do terceiro dia de medida.

Portanto, especialmente por se tratar de uma amostra orgânica, atribui-se a variação dos resultados obtidos durante um mesmo dia de medida, como uma possível degradação dos extratos de soja produzidos.

\subsubsection{Degradação dos grãos de soja}

Os grãos de soja analisados durante toda a extensão deste trabalho foram mantidos em embalagens plásticas com fecho hermético e armazenados dentro de uma geladeira comum.

Para verificar a ocorrência de uma possível degradação dos grãos de soja ao longo dos dias, foram construídos gráficos de PCA com os dados de medidas efetuadas pela LE dos extratos de soja e de água destilada, obtidas no período de agosto de 2009 a maio de 2010. A fim de se facilitar a visualização, foram construídos gráficos de PCA separadamente para cada cultivar (Figuras 40 a 42). 

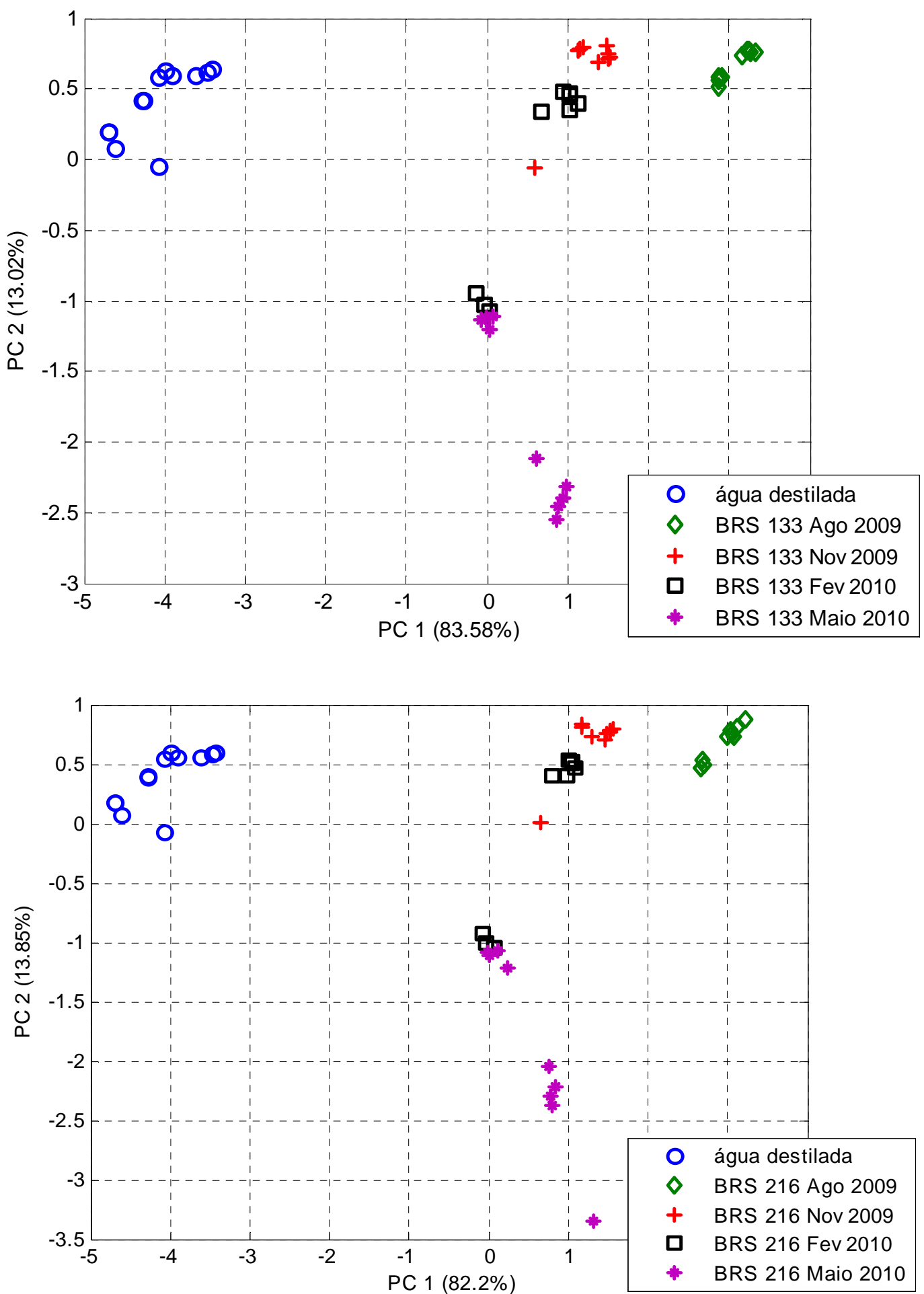

Figura 40 - Gráficos de PCA obtidos com a LE a $1 \mathrm{kHz}$, a partir de medidas da capacitância elétrica dos extratos de soja dos cultivares BRS 133 e BRS 216, obtidas entre agosto de 2009 e maio de 2010. 

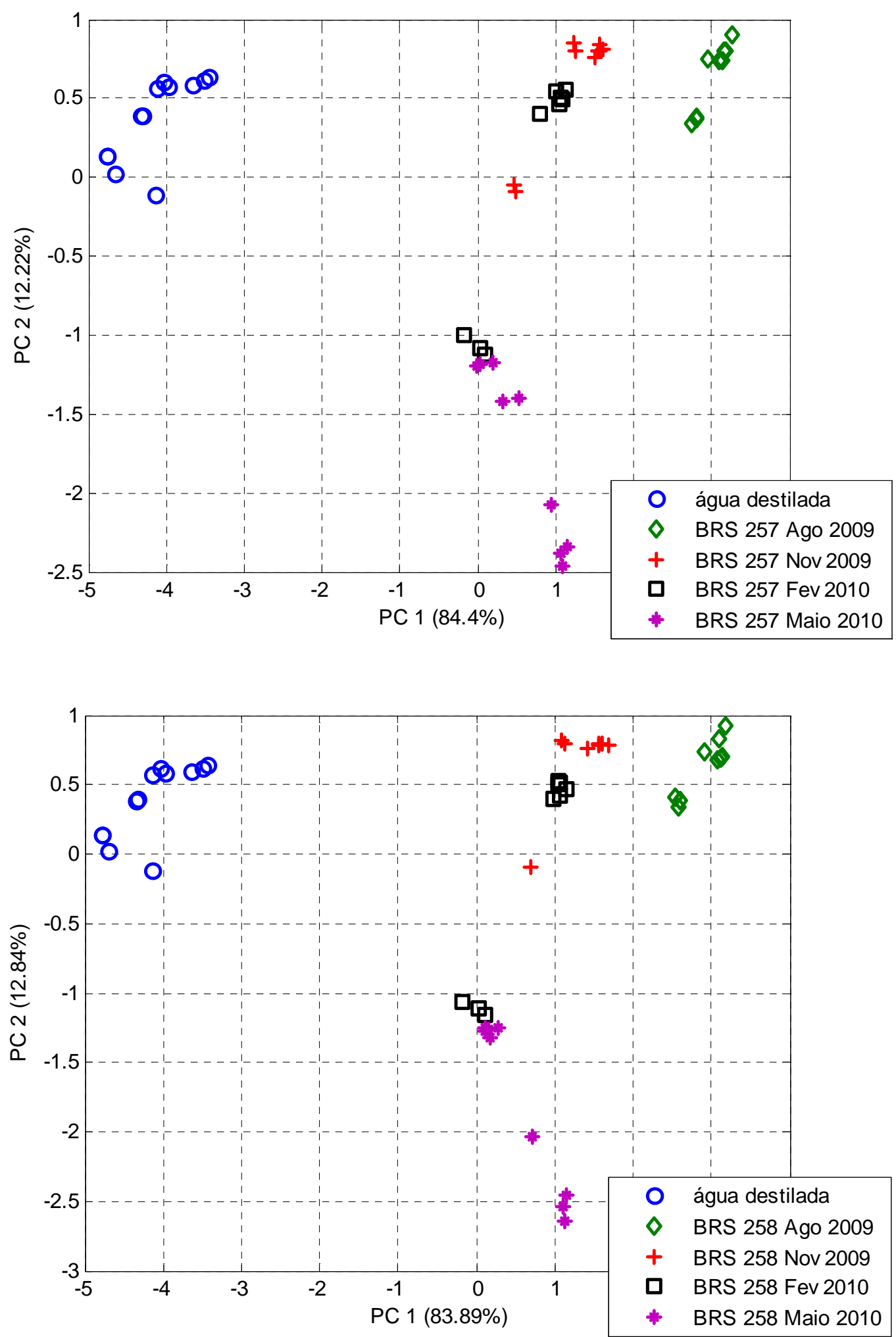

Figura 41 - Gráficos de PCA obtidos com a LE a $1 \mathrm{kHz}$, a partir de medidas da capacitância elétrica dos extratos de soja dos cultivares BRS 257 e BRS 258, obtidas entre agosto de 2009 e maio de 2010. 


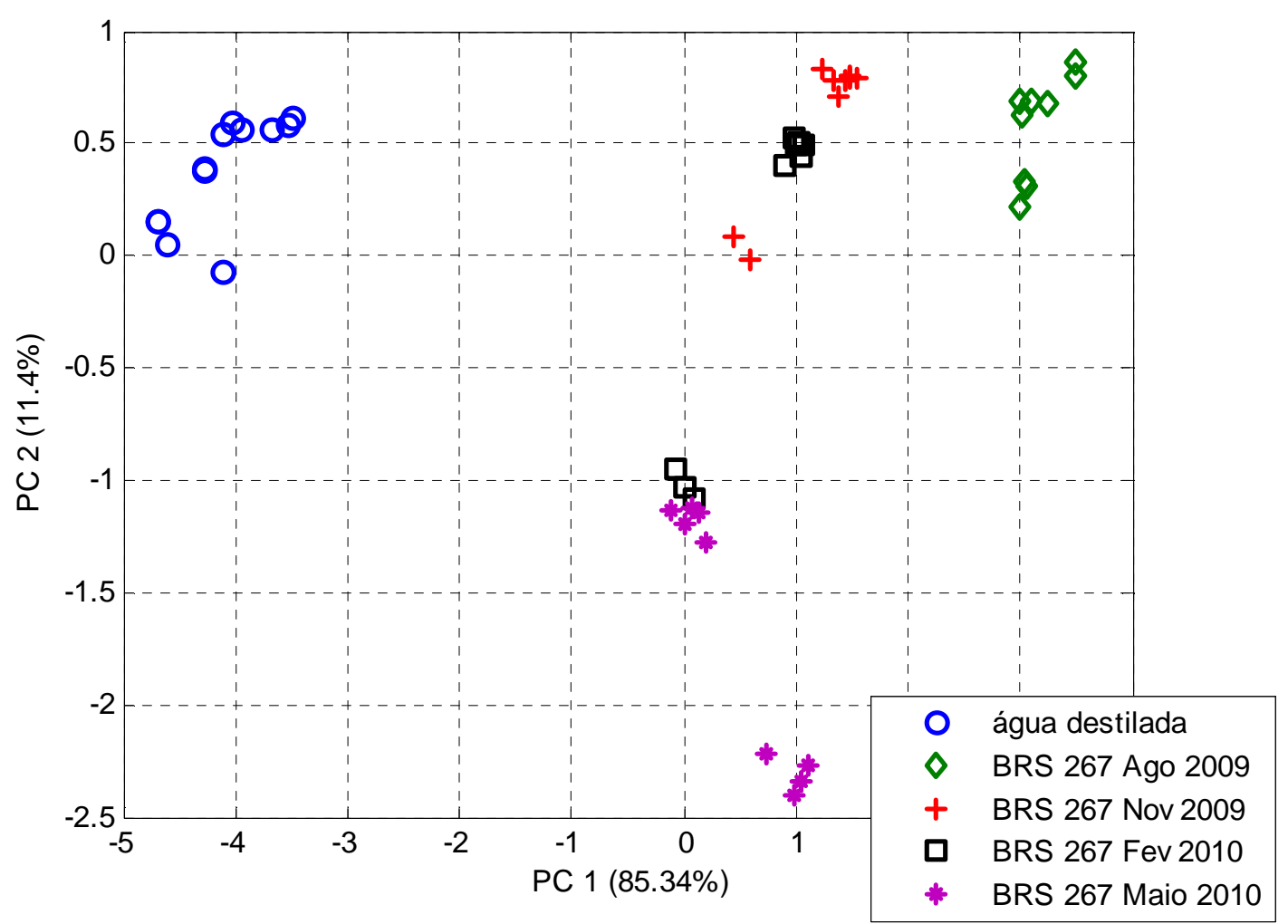

Figura 42 - Gráfico de PCA obtido com a LE a $1 \mathrm{kHz}$, a partir de medidas da capacitância elétrica dos extratos de soja do cultivar BRS 267, obtidas entre agosto de 2009 e maio de 2010.

Para cada mês citado nos gráficos, foram realizados três dias consecutivos de medidas da capacitância elétrica dos extratos de soja, sendo que, para cada dia, os extratos foram medidos em triplicatas, totalizando-se assim nove medidas a cada mês. Ao início de todos os dias, foi medida a capacitância elétrica da água destilada.

Foi observado que, ao longo de todos estes meses não ocorreu uma variação na medida de capacitância elétrica da água destilada. Entretanto, os extratos de soja apresentaram uma grande variação nas medidas de agosto a maio, o que sugere a ocorrência de um processo de degradação dos grãos de soja armazenados.

\subsection{Teste cego}

Com o objetivo de simularmos um procedimento de identificação de cultivares de soja, foram realizadas inicialmente medidas da capacitância elétrica dos extratos 
de soja produzidos a partir dos cinco cultivares estudados. Para cada cultivar foram produzidos e analisados dois extratos de procedência conhecida. Finalmente, neste mesmo dia, foram produzidos mais cinco extratos de soja desconhecidos (nãonomeados), para cada um dos cultivares estudados, e então, foram realizadas as medições de suas capacitâncias a fim de identificá-los.

Finalmente, foram elaborados gráficos de PCA, apresentados nas Figuras 43 a 47, a partir dos dados obtidos.

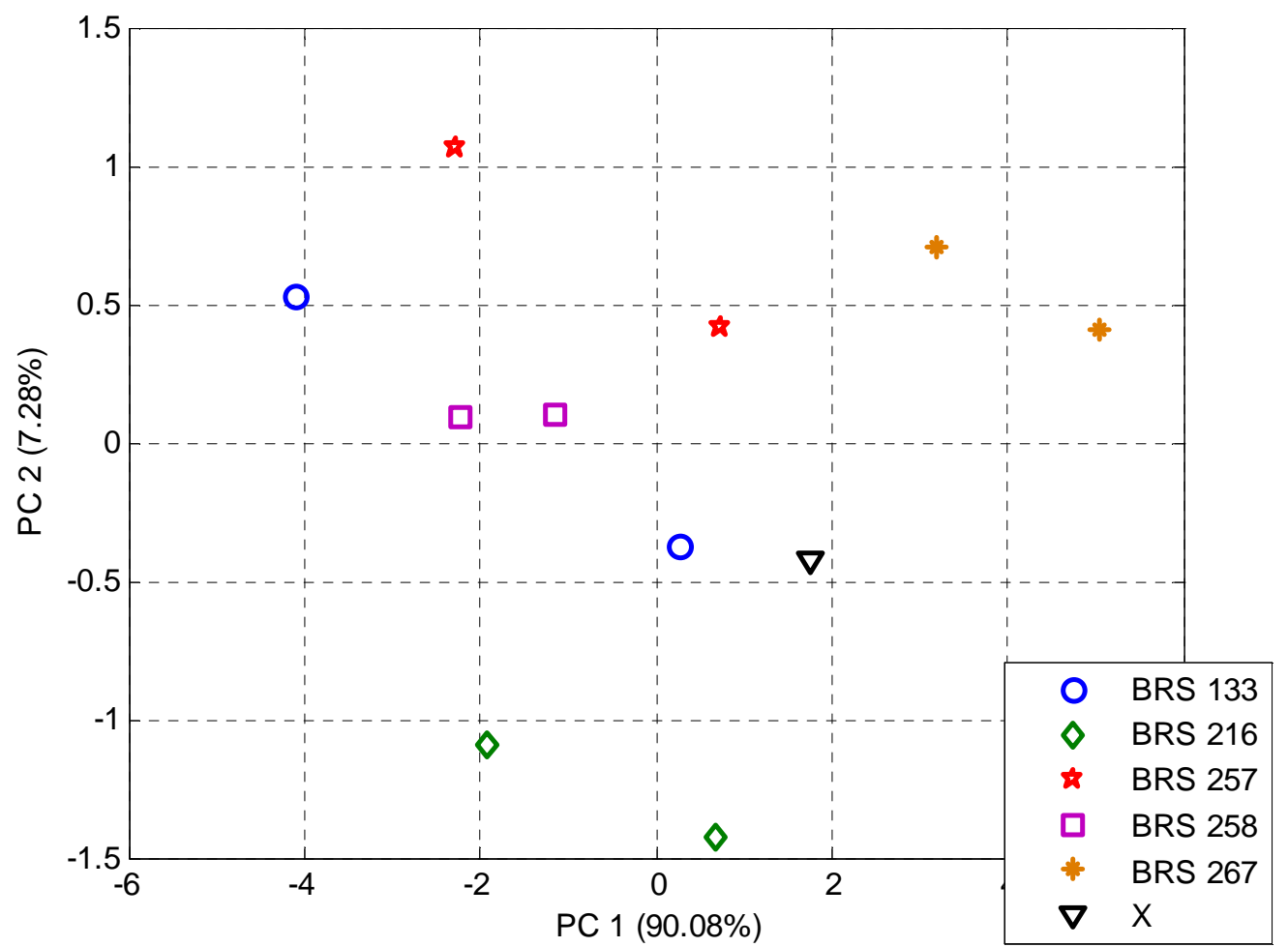

Figura 43 - Gráfico de PCA obtido com a LE a $1 \mathrm{kHz}$, onde o cultivar desconhecido X corresponde ao cultivar BRS 133. 


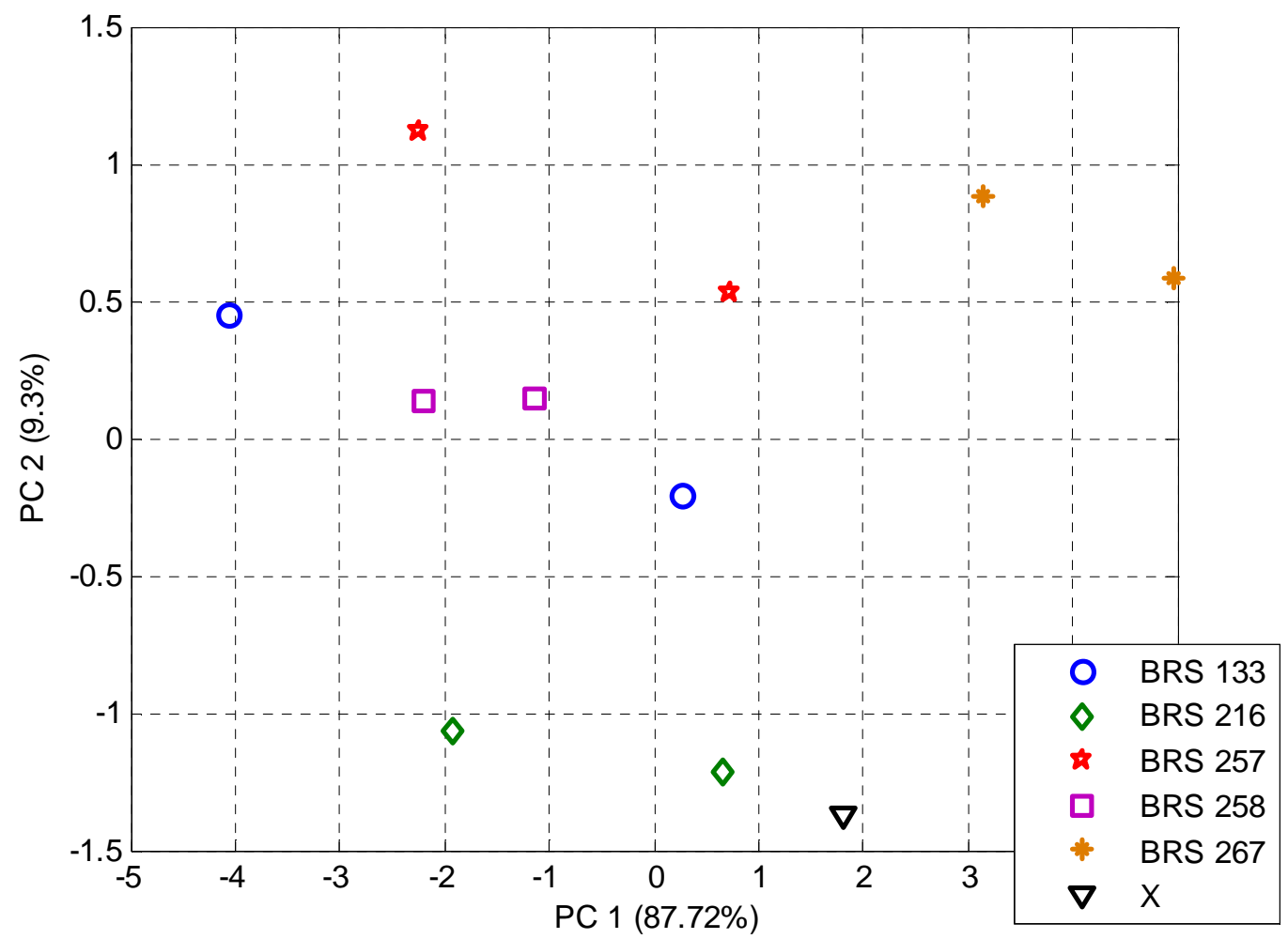

Figura 44 - Gráfico de PCA obtido com a LE a $1 \mathrm{kHz}$, onde o cultivar desconhecido X corresponde ao cultivar BRS 216.

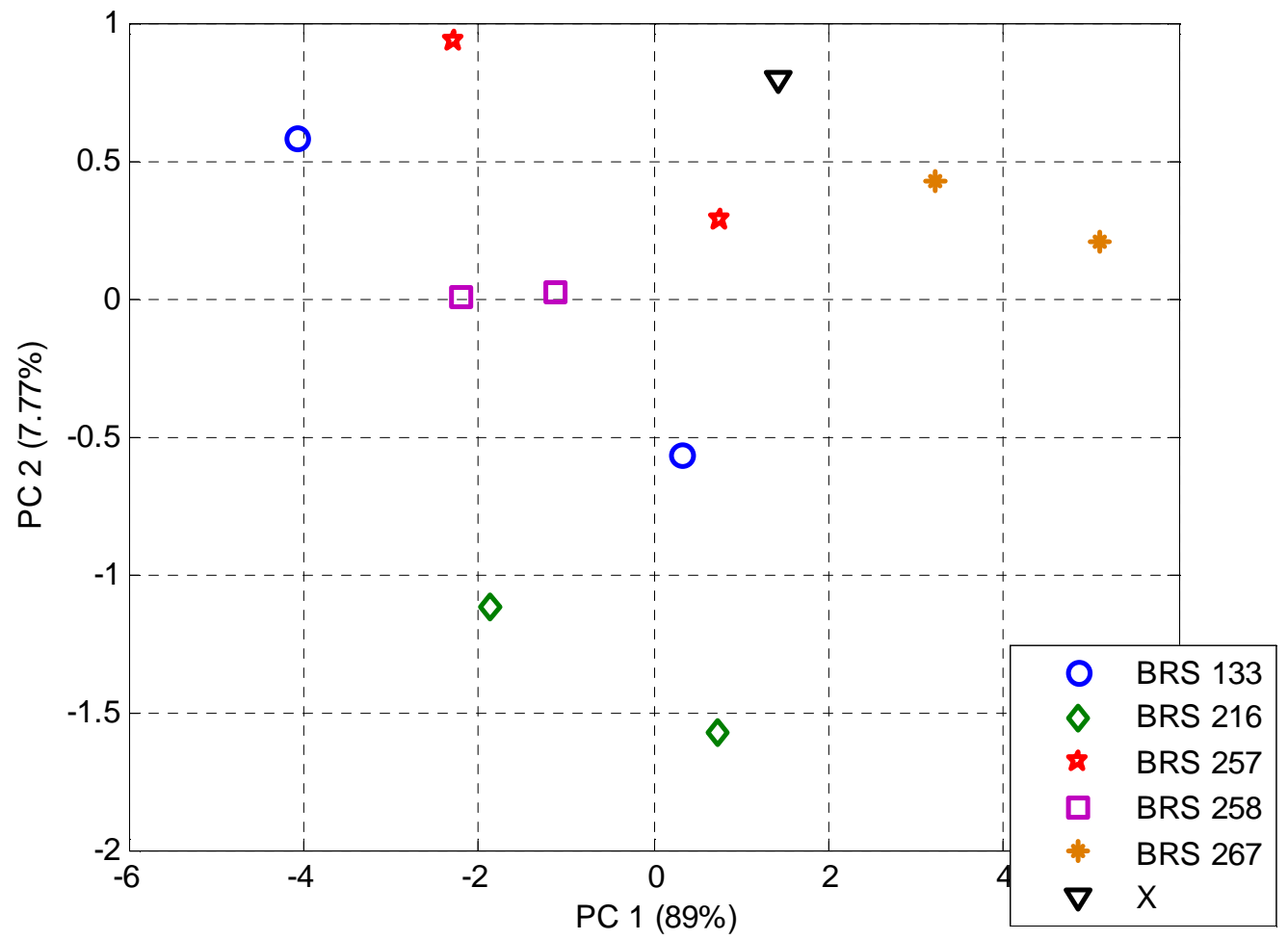

Figura 45 - Gráfico de PCA obtido com a LE a $1 \mathrm{kHz}$, onde o cultivar desconhecido X corresponde ao cultivar BRS 257. 


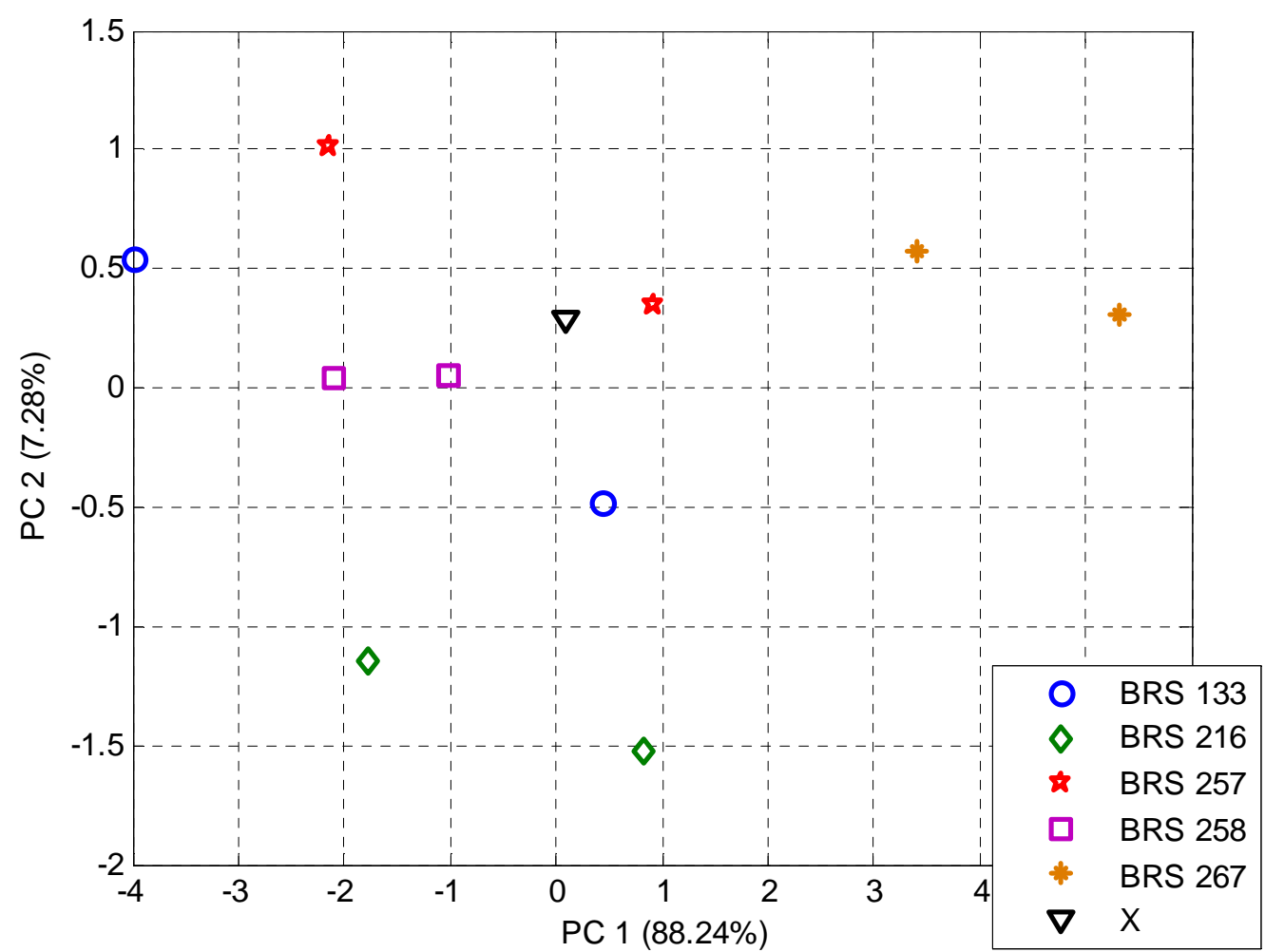

Figura 46 - Gráfico de PCA obtido com a LE a $1 \mathrm{kHz}$, onde o cultivar desconhecido X corresponde ao cultivar BRS 258.

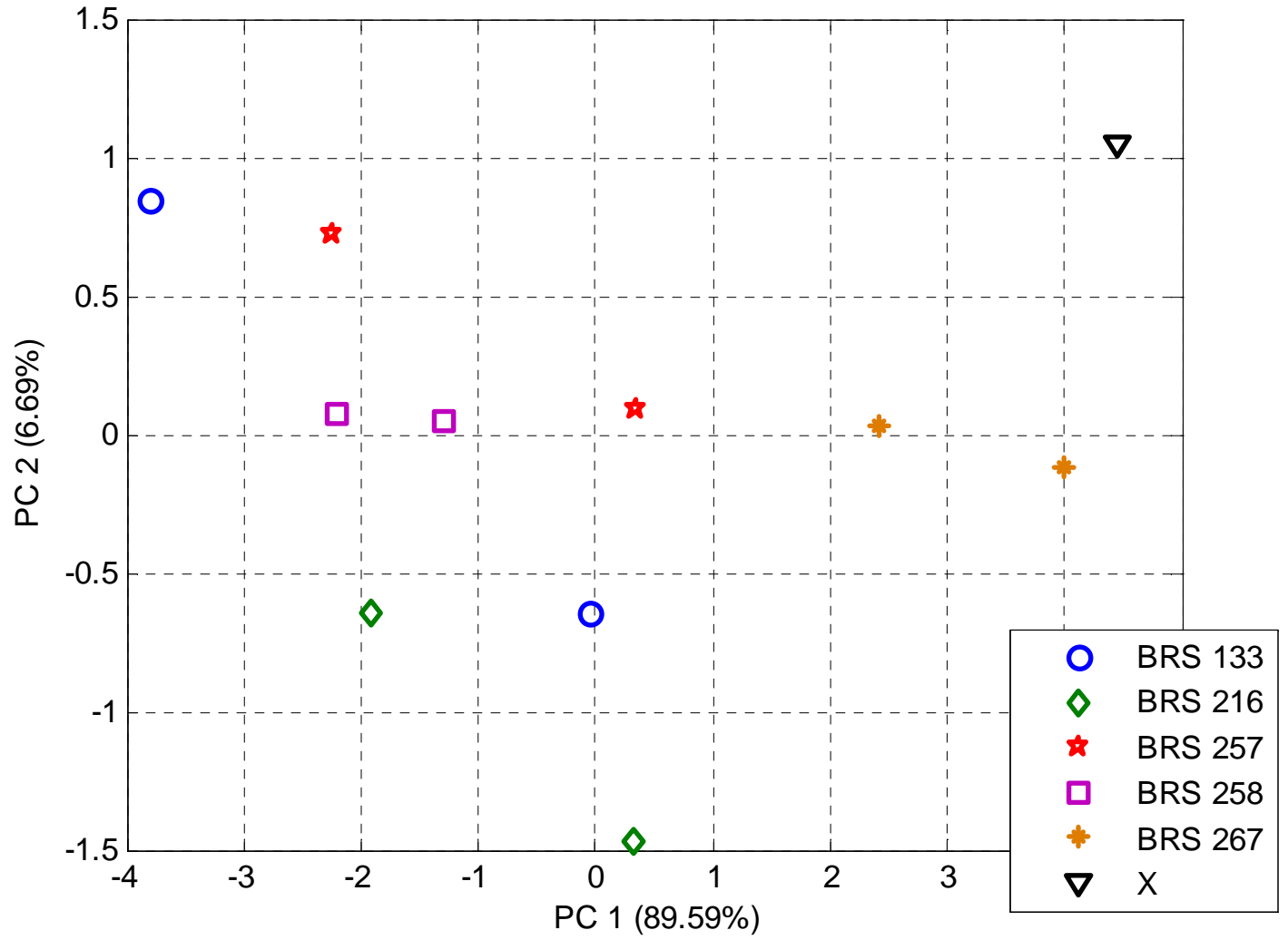

Figura 47 - Gráfico de PCA obtido com a LE a $1 \mathrm{kHz}$, onde o cultivar desconhecido X corresponde ao cultivar BRS 267. 
Foi possível verificar que os cultivares que possuem características especiais (BRS 216, BRS 257 e BRS 267) foram identificados mais facilmente em relação aos cultivares tradicionais (BRS 133 e BRS 258). Portanto, foram elaborados gráficos de PCA apenas com os cultivares especiais (Figuras 48 a 50) e, desta forma, a identificação do cultivar de soja desconhecido foi ainda mais efetiva.

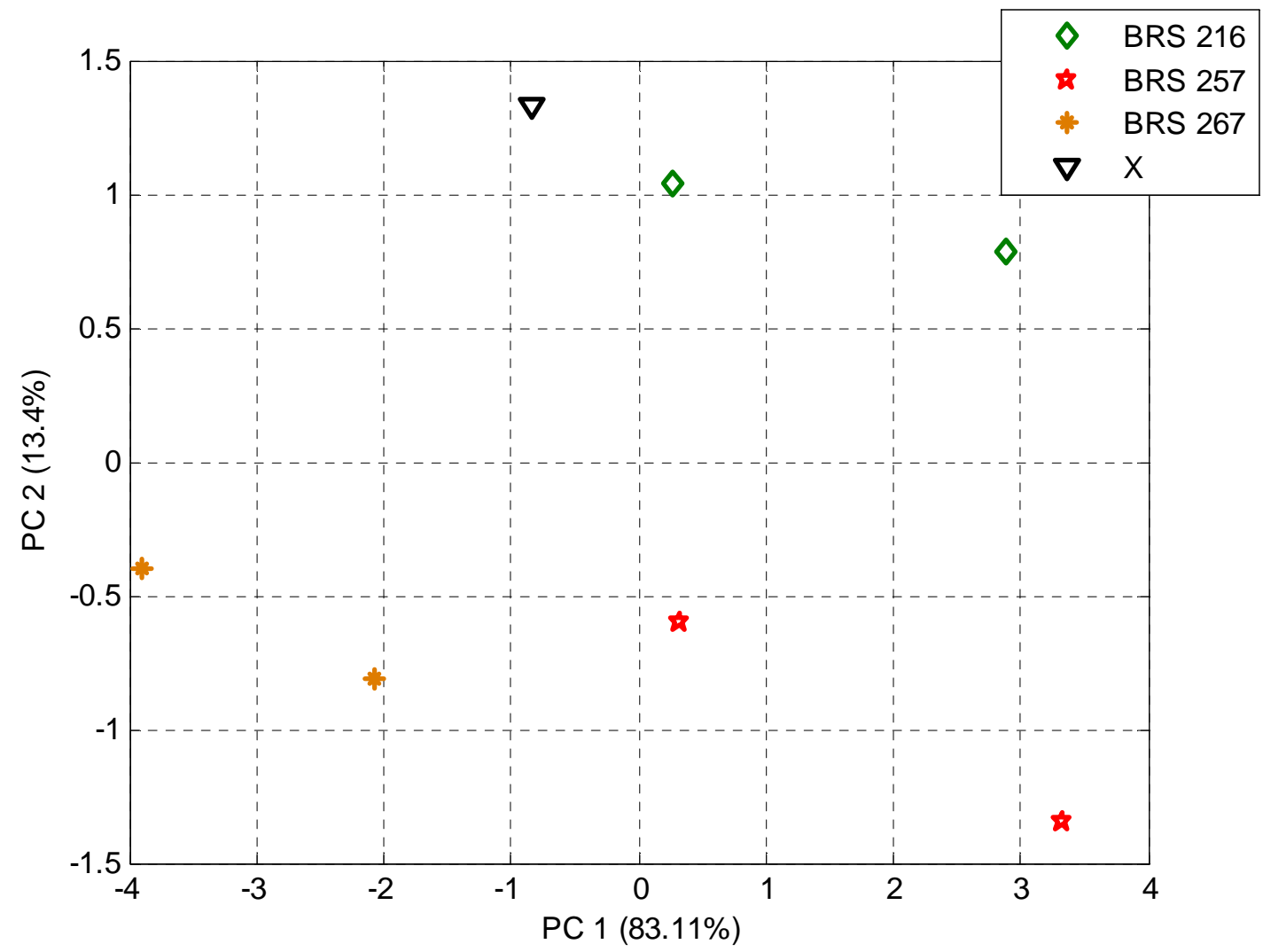

Figura 48 - Gráfico de PCA obtido com a LE a $1 \mathrm{kHz}$, onde o cultivar desconhecido X corresponde ao cultivar BRS 216. 


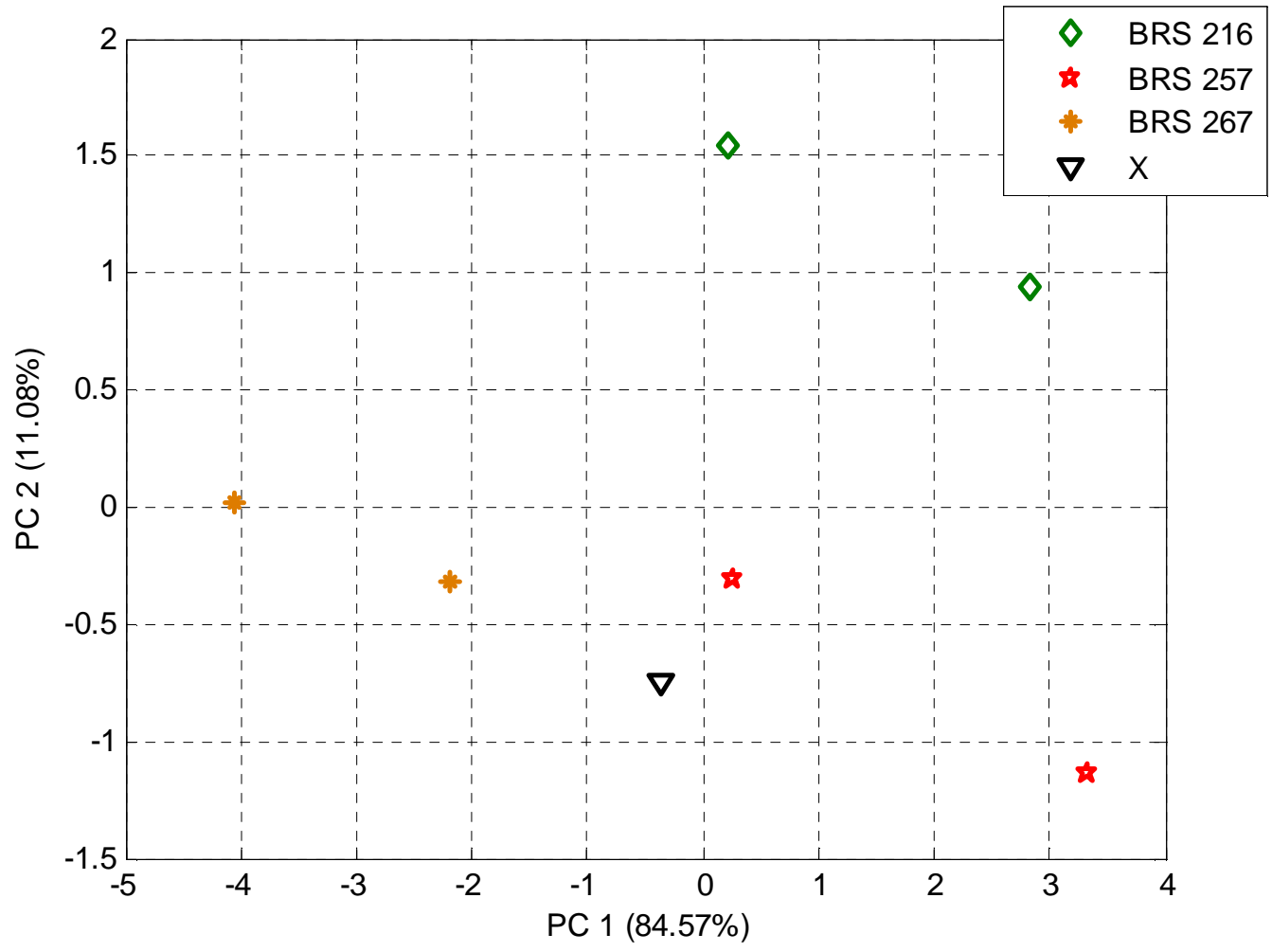

Figura 49 - Gráfico de PCA obtido com a LE a $1 \mathrm{kHz}$, onde o cultivar desconhecido X corresponde ao cultivar BRS 257.

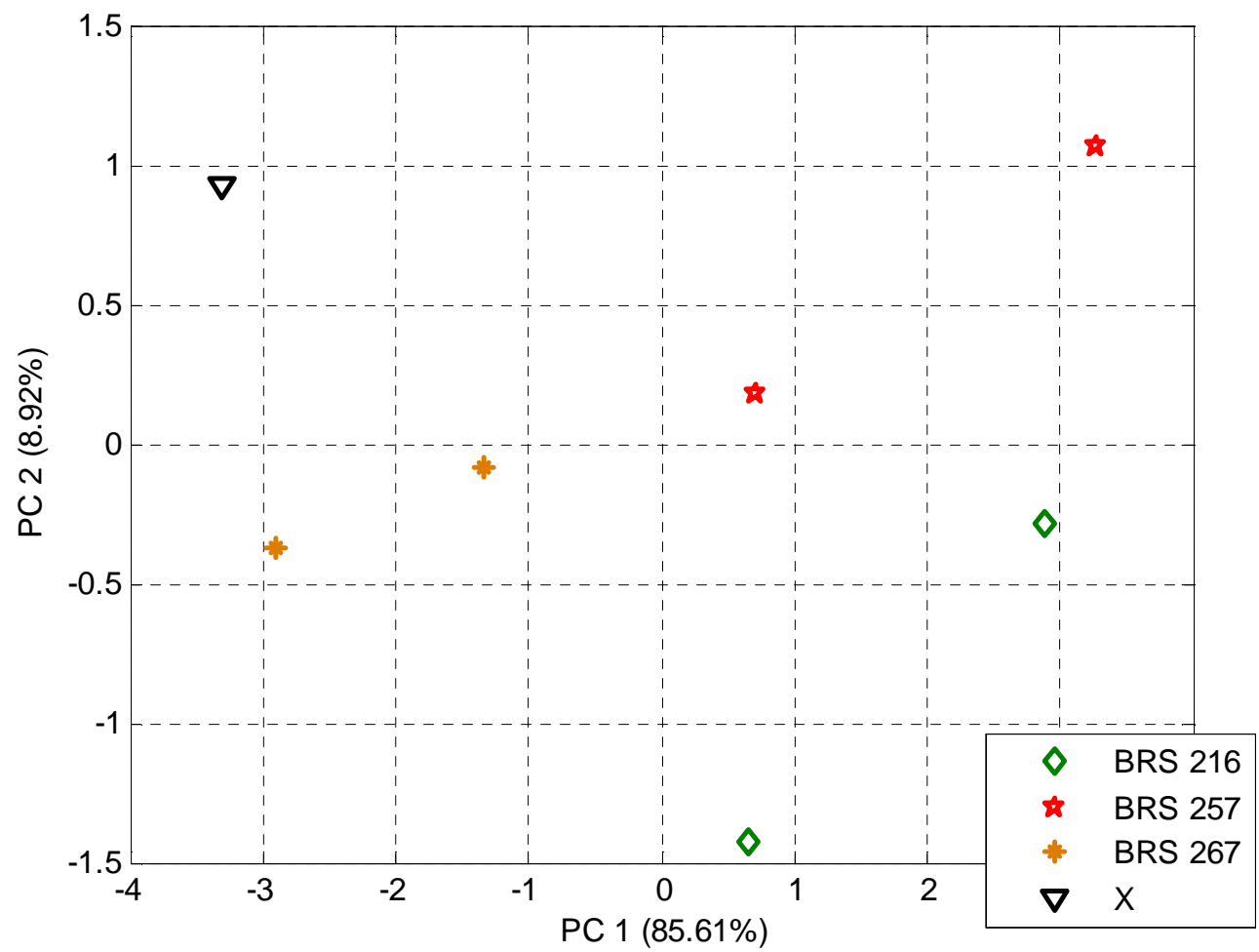

Figura 50 - Gráfico de PCA obtido com a LE a $1 \mathrm{kHz}$, onde o cultivar desconhecido X corresponde ao cultivar BRS 267. 
Portanto, foi possível verificar que a LE apresentou um desempenho razoável na identificação de amostras de soja desconhecidas e ainda, que o reconhecimento de um cultivar de soja pela LE é facilitado quando se utiliza grãos com características específicas.

\subsection{Avaliação da reprodutibilidade da Língua Eletrônica}

Visando avaliar a reprodutibilidade do dispositivo utilizado, foi construído uma segunda Língua Eletrônica (LE 2), apresentada na Figura 51 (b).
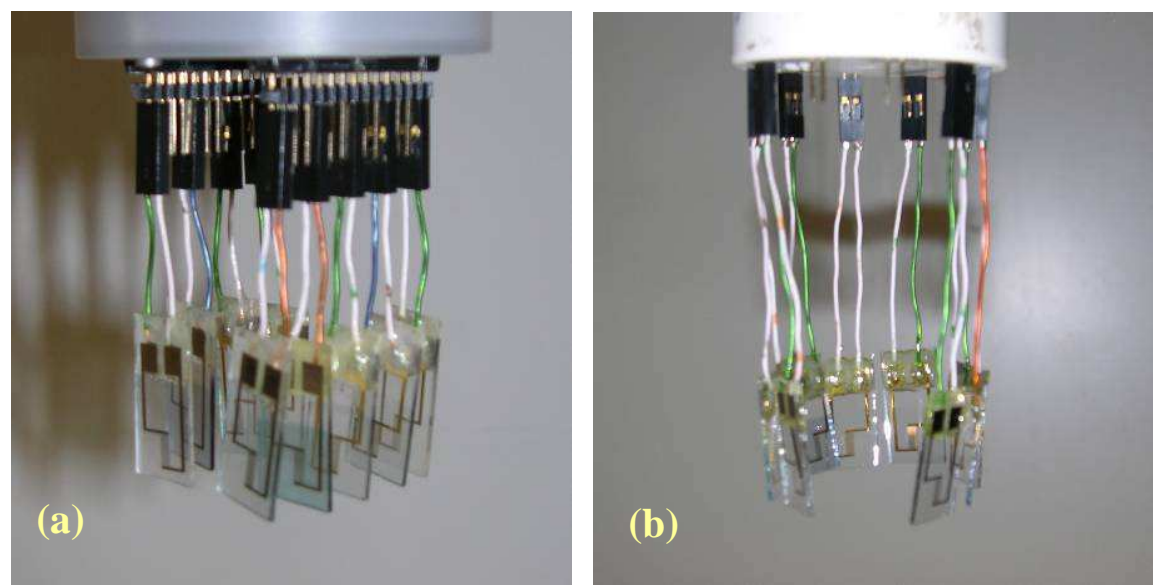

Figura 51 - Línguas Eletrônicas utilizadas (a) LE 1 e (b) LE 2.

A LE 2 foi construída de forma semelhante à LE 1, contendo inclusive a mesma composição de materiais em seus sensores. Estes sensores foram posicionados obedecendo a ordem idêntica àquela da LE 1.

Iniciando o estudo da reprodutibilidade da LE, foi obtido o gráfico da impressão digital (Figura 52) dos cultivares de soja através de medidas com a LE 2 em $1 \mathrm{kHz}$. 


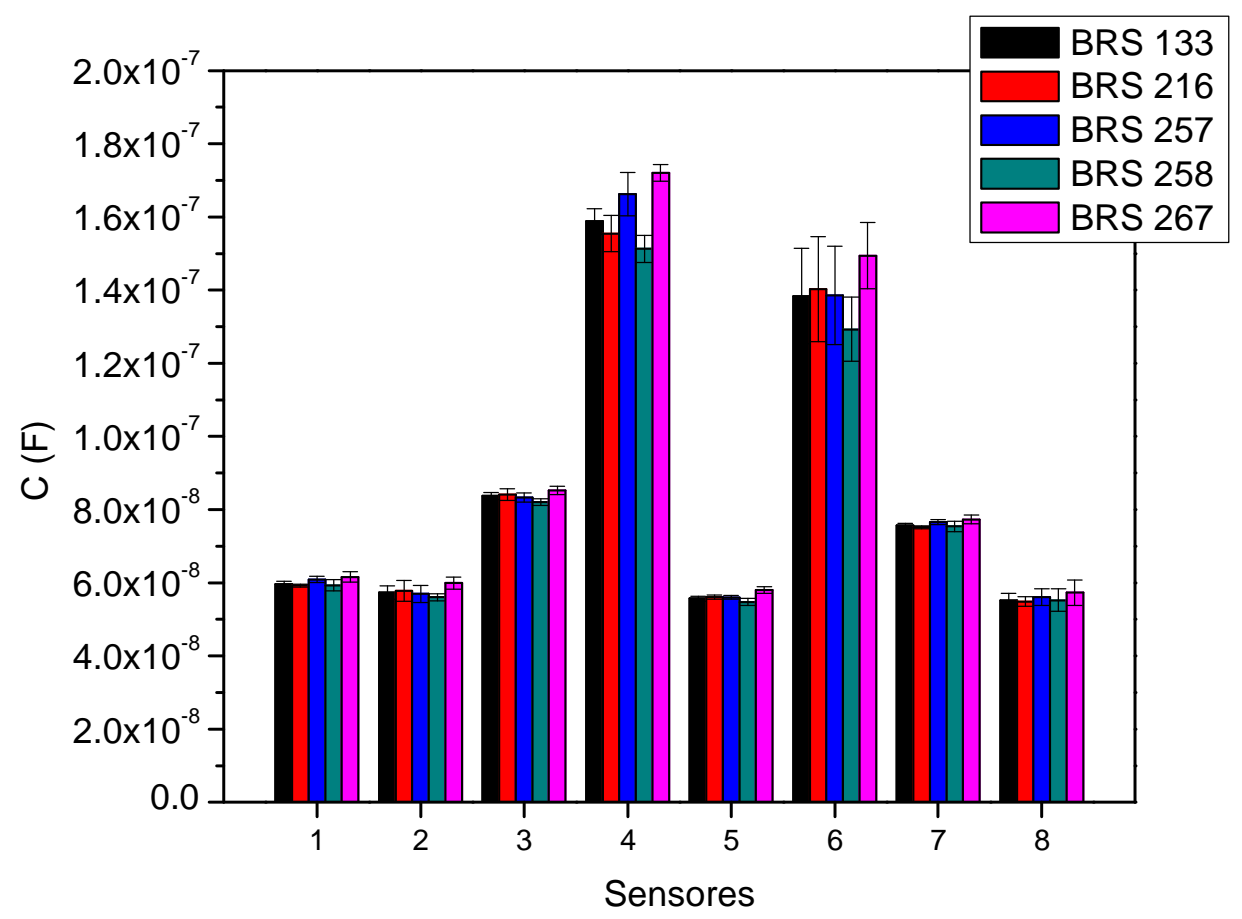

Figura 52 - Impressão digital elétrica dos cinco cultivares de soja estudados, obtida a $1 \mathrm{kHz}$ com a LE 2.

As medidas de capacitância elétrica dos extratos de soja com a LE 2 foram obtidas utilizando-se uma tensão de $50 \mathrm{mV}$. Cada coluna, representante de um cultivar, refere-se a uma média de 6 medidas independentes. Como pode ser observado na Figura 52, os sensores 4 e 6 da LE 2, constituídos também por filmes de PAni / FTC e PAni / LS assim como na LE 1, foram os mais sensíveis, apresentando os maiores valores. De forma similar também à LE 1 , o sinal do cultivar BRS 267 foi maior e o cultivar BRS 258 apresentou o menor sinal em relação aos demais cultivares.

Visando a discriminação dos cultivares de soja estudados pela LE 2, foram realizados 3 dias consecutivos de medições de capacitância elétrica, a $50 \mathrm{mV}$ e 1 $\mathrm{kHz}$, dos extratos de soja.

Os extratos analisados foram obtidos a partir de $0,5 \mathrm{~g}$ de grãos de soja. Para cada amostra foram preparadas duplicatas, na tentativa de se minimizar a degradação dos extratos. A Figura 53 apresenta o gráfico de PCA obtido com os dados do primeiro dia de medidas. 


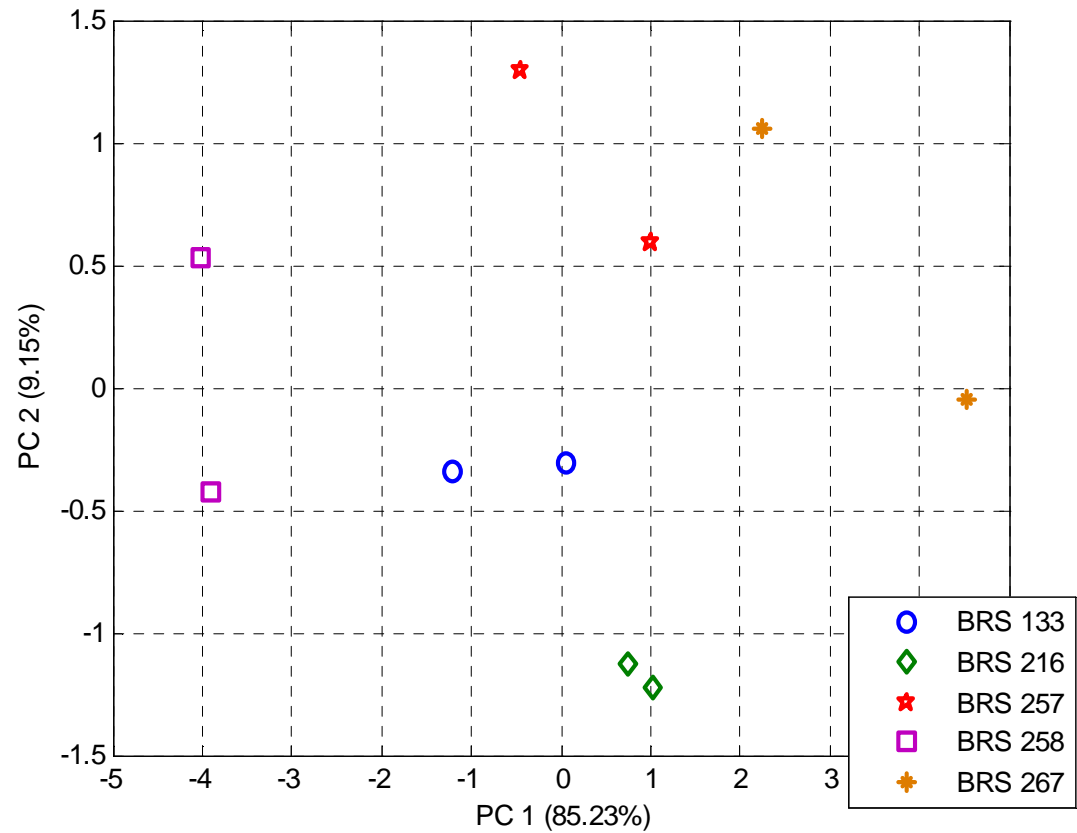

Figura 53 - Gráfico de PCA obtido com a LE 2 a $1 \mathrm{kHz}$, a partir de $0,5 \mathrm{~g}$ de grãos de soja e utilizandose os dados apenas do primeiro dia de medida.

Como pode ser visto na Figura 53, a LE 2 foi igualmente capaz de diferenciar os cinco cultivares de soja estudados. Entretanto, quando foram utilizados os dados dos 3 dias de medidas (Figura 54), a LE 2 também não foi capaz de discriminar os cultivares estudados, possivelmente devido a degradação dos grãos durante estes 3 dias. 


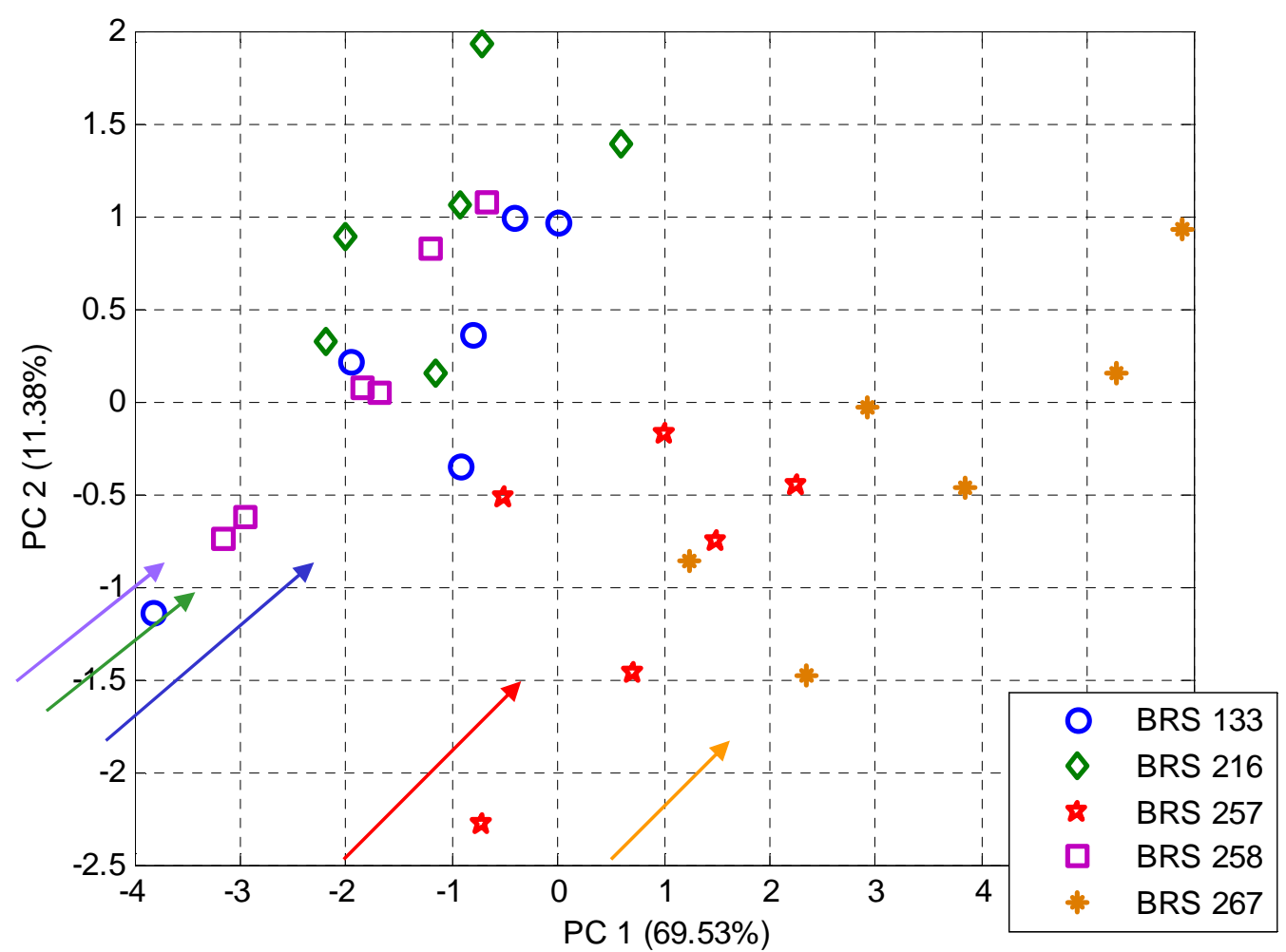

Figura 54 - Gráfico de PCA obtido com a LE 2 a $1 \mathrm{kHz}$, a partir de $0,5 \mathrm{~g}$ de grãos de soja e utilizandose os dados dos 3 dias de medidas. As setas indicam a separação dos cultivares segundo a sequência: BRS 258, BRS 216, BRS 133, BRS 257 e BRS 267.

É importante notar que a LE 2, de forma similar à LE 1, discriminou os cultivares de soja estudados seguindo a sequência de condutividade elétrica crescente apresentada anteriormente. Desta forma, foi possível concluir que a LE apresentou boa reprodutibilidade. 


\section{CONSIDERAÇÕES FINAIS}

Foi construída uma Língua Eletrônica para a caracterização e discriminação de grãos de soja provenientes de cinco cultivares com propriedades distintas. Foi possível concluir que os sensores do dispositivo fabricado apresentaram repetibilidade nas medidas elétricas, sendo os sensores compostos por PAni os mais sensíveis. Foi verificado ainda que a resposta da LE estabilizou rapidamente quando imersa na amostra.

O método proposto neste trabalho, com a produção dos extratos de soja sem a utilização de tratamentos térmicos, apresentou bom desempenho quando comparado ao método tradicional. Portanto, a análise de cultivares de soja utilizando a LE, por não requerer tratamento térmico, se mostrou vantajosa e eficaz.

Foi constatado, também, que a LE foi capaz de discriminar os cinco cultivares de soja. Esta discriminação foi regida pela diferença no valor de condutividade das amostras. Entretanto, quando foi utilizada uma grande quantidade de dados, a LE não foi capaz de separar os cultivares em grupos distintos. Esta dificuldade foi atribuída a uma possível degradação dos grãos de soja. A possível ocorrência deste processo de degradação foi investigada ao longo de nove meses (agosto a maio), apresentando notáveis variações nas medidas de capacitância elétrica dos extratos de soja e estabilidade nas medidas de capacitância elétrica da água destilada. A LE se mostrou também sensível a uma possível degradação dos extratos de soja ao longo de cada dia de medida.

Portanto, para a aplicação da LE na identificação de cultivares de soja, embora não seja usual, sugere-se que os grãos tidos como "padrões" (com características já conhecidas) sejam medidos pela LE ao início de cada dia de trabalho, dado à instabilidade do analito.

Foi concluído ainda que não ocorreu o envenenamento e/ou degradação dos filmes que compõem os sensores da LE quando foram analisados os extratos de soja.

$\mathrm{Na}$ realização do teste cego, a LE apresentou bom desempenho, especialmente para os cultivares que possuem características distintas. Desta forma, a LE se mostrou viável para ser utilizada em uma pré-seleção de cultivares de soja, aonde apenas os cultivares que não pudessem ser discriminados pela LE seriam 
submetidos à Análise Sensorial. Isto resultaria em um ganho significativo de praticidade e tempo para o pesquisador ou à indústria.

A LE também apresentou boa reprodutibilidade, obtendo-se resultados similares quando um segundo dispositivo foi construído. A LE 2 exibiu impressão digital e discriminação dos cultivares de soja estudados semelhantes àqueles obtidos com a LE 1. 


\section{CONCLUSÃO}

Foi concluído que a Língua Eletrônica apresentou um bom desempenho na análise de cultivares de soja. $O$ dispositivo construído exibiu boa repetibilidade e reprodutibilidade, possuindo, portanto, um grande potencial para ser aplicado em indústrias e instituições de pesquisa. Foi proposto também um método mais simples para o preparo de extratos de soja, eliminando-se a etapa de tratamento térmico. Através do procedimento proposto, o preparo de extratos de soja torna-se mais prático e de menor custo. A LE apresentou ainda um bom desempenho no teste cego, comprovando assim, ser um método eficiente e capaz de auxiliar as técnicas tradicionais (análise sensorial e química) na identificação de cultivares de soja. 


\section{SUGESTÕES PARA TRABALHOS FUTUROS}

De acordo com os resultados, vimos que a LE desenvolvida apresenta um grande potencial para avaliar os cultivares de soja. Contudo, seu desempenho pode ser melhorado através de investigações detalhadas sobre as propriedades dos cultivares de soja, bem como de métodos reprodutivos para a preparação e medição dos extratos analisados. Dessa forma, são propostas as seguintes sugestões para trabalhos futuros:

- Caracterização química dos cultivares de soja estudados;

- Estudo de cultivares de soja pertencentes a uma mesma família, com características semelhantes, utilizando a LE;

- Desenvolvimento de novos métodos de preparação dos extratos de soja, visando minimizar sua degradação;

- Congelamento dos grãos de soja;

- Estudo da correlação existente entre a resposta da LE e outros métodos de análise. 


\section{REFERÊNCIAS}

AGRONLINE. Embrapa lança cultivares de soja específicas para consumo humano. 2001. Disponível em:

<http://www.agronline.com.br/agronoticias/noticia.php?id=187>. Acesso em: 25 de junho de 2010.

AISHIMA, T. Correlating sensory attributes to gas chromatography - mass spectrometry profiles and e-nose responses using partial least squares regression analysis. Journal of Chromatography A, v.1054, p.39-46, 2004.

ANDO, M.; WATANABE, Y.; IYODA, T.; HONDA, K.; SHIMIDZU, T. Syntheses of conducting polymer Langmuir-Blodgett multilayers. Thin Solid Films, v.179, p.225$231,1989$.

ANZAI, J.; KOBAYASHI, Y.; NAKAMURA, N.; NISHIMURA, M.; HOSHI, T. Layer-byLayer Construction of Multilayer Thin Films Composed of Avidin and Biotin-Labeled Poly(amine)s. Langmuir, v.15, p.221-226, 1999.

BARNES, S. Effect of Genistein on In Vitro and In Vivo Models of Cancer. Journal of Nutrition, v.125, p.777-783, 1995. Supplement, 3.

BAYRAM, M.; ÖNER, M. D.; KAYA, A. Influence of soaking on the dimensions and colour of soybean for bulgur production. Journal of Food Engineering, v.61, p.331339, 2004.

BORATO, C. E. Estudo de filmes poliméricos ultrafinos de polianilinas para aplicação em sensores de gases. 2002. 91p. Dissertação (Mestrado) - Escola Politécnica, Universidade de São Paulo. São Paulo, 2002.

BRAGA, G.S. Influência dos parâmetros de fabricação em filmes automontados poliméricos. 2006. 81p. Dissertação (Mestrado) - Escola Politécnica, Universidade de São Paulo. São Paulo, 2006.

BRAGA, G. S.; PATERNO, L. G.; LIMA, J. P. H.; FONSECA, F. J.; ANDRADE, A. M. Influence of the deposition parameters on the morphology and electrical conductivity of PANI/PSS self-assembled films. Materials Science and Engineering C, v.28, p.555-562, 2008. 
CAMPANELLA, L.; PACIFICI, F.; SAMMARTINO, M. P.; TOMASSETTI, M. A new organic phase bienzymatic electrode for lecithin analysis in food products. Bioelectrochemistry and Bioenergetics, v.47, p.25-38, 1998.

CASSIDY, A.; BINGHAM, S.; SETCHELL, K. D. R. Biological effects of a diet of soy protein rich in isoflavones on the menstrual cycle of premenopausal women. American Journal of Clinical Nutrition, v.60, p.333-340, 1994.

CHIANG, C. K.; FINCHER Jr, C. R.; PARK, Y. W.; HEEGER, A. J.; SHIRAKAWA, H.; LOUIS, E. J.; GAU, S. C.; MACDIARMID, A. G. Electrical conductivity in doped polyacetilene. Physical Review Letters, v.39, n.17, p.1098-1101, outubro 1977.

CIABOTTI, S. Aspectos químico, físico-químico e sensorial de extratos de soja e tofus obtidos dos cultivares de soja convencional e livre de lipoxigenase. 2004. 122p. Dissertação (mestrado) - Universidade Federal de Lavras. Lavras, 2004.

CIABOTTI, S.; BARCELOS, M. F. P.; PINHEIRO, A. C. M.; CLEMENTE, P. R.; LIMA, M. A. C. Características sensoriais e físicas de extratos e tofus de soja comum processada termicamente e livre de lipoxigenase. Ciência e Tecnologia de Alimentos, v.27, n.3, p.643-648, 2007.

CORTINA, M.; GUTÉS, A.; ALEGRET, S.; Del VALLE, M. Sequential injection system with higher dimensional electrochemical sensor signals Part 2. Potentiometric e-tongue for the determination of alkaline ions. Talanta, v.66, p.1197-1206, 2005.

COSIO, M. S.; BALLABIO, D.; BENEDETTI, S.; GIGLIOTTI, C. Evaluation of different storage conditions of extra virgin olive oils with an innovative recognition tool built by means of electronic nose and electronic tongue. Food Chemistry, v.101, p.485-491, 2007.

DAVIES, C. S.; NIELSEN, S. S.; NIELSEN, N. C. Flavor Improvement of Soybean Preparations by Genetic Removal of Lipoxygenase-2. Journal of the American Oil Chemists' Society, v.64, n.10, p.1428-1433, 1987.

DECHER, G.; HONG, J. D.; SCHMITT, J. Buildup of ultrathin multilayer films by a self-assembly process: III. Consecutively alternating adsorption of anionic and cationic polyelectrolytes on charged surfaces. Thin Solid Films, v. 210/211, p.831835, 1992.

DECHER, G. Fuzzy Nanoassemblies: Toward Layered Polymeric Multicomposites. Science, v.277, p.1232-1237, 1997. 
DEISINGH, A. K.; STONE, D. C.; THOMPSON, M. Application of electronic noses and tongues in food analysis. International Journal of Food Science and Technology, v.39, p.587-604, 2004.

DIAS, L. A.; PERES, A. M.; VILAS-BOAS, M.; ROCHA, M. A.; ESTEVINHO, L.; MACHADO, A. A. S. C. An electronic tongue for honey classification. Microchimica Acta, v.163, p.97-102, 2008.

DIAS, L.A.; PERES, A. M.; VELOSO, A. C. A.; REIS, F. S.; VILAS-BOAS, M.; MACHADO, A. A. S. C. An electronic tongue taste evaluation: Identification of goat milk adulteration with bovine milk. Sensors and Actuators B, v.136, p.209-217, 2009.

DI NATAlE, C.; PAOleSse, R.; MACAGNANO, A.; MANTINI, A.; D'AMICO, A.; LEGIN, A.; LVOVA, L.; RUDNITSKAYA, A.; VLASOV, Y. Electronic nose and electronic tongue integration for improved classification of clinical and food samples. Sensors and Actuators B, v.64, p.15-21, 2000.

DURÁN, N.; MATTOSO, L. H. C.; MORAIS, P. C. Nanotecnologia: Introdução, preparação e caracterização de nanomateriais e exemplos de aplicação. São Paulo: Artliber, 2006.

DYMINSKI, D. S.; PATERNO, L. G.; TAKEDA, H. H.; BOLINI, H. M. A.; MATTOSO, L. H. C.; CÂNDIDO, L. M. B. Correlation between human panel and electronic tongue responses on the analysis of commercial sweeteners. Sensor Letters, v.4, p.1-6, 2006a.

DYMINSKI, D. S. Utilização potencial da Língua Eletrônica na indústria de alimentos e bebidas. 2006. 169p. Tese (Doutorado) - Universidade Federal do Paraná. Curitiba, 2006b.

EMBRAPA SOJA. Londrina. Soja na alimentação: Composição do grão. Disponível em:

<http://www.cnpso.embrapa.br/soja_alimentacao/index.php?pagina=7>. Acesso em: 21 de maio 2009.

EMBRAPA SOJA. Londrina. Cultivares 2008/2009. BRS 133. Disponível em: <http://www.cnpso.embrapa.br/cultivares/BRS133.pdf>. Acesso em: 25 de junho de 2010a. 
EMBRAPA SOJA. Londrina. Cultivares 2008/2009. BRS 257. Disponível em: <http://www.cnpso.embrapa.br/cultivares/BRS257.pdf>. Acesso em: 25 de junho de 2010b.

EMBRAPA SOJA. Londrina. Cultivares 2008/2009. BRS 258. Disponível em: <http://www.cnpso.embrapa.br/cultivares/BRS258.pdf>. Acesso em: 25 de junho de 2010c.

EMBRAPA SOJA. Londrina. Cultivares 2008/2009. BRS 267. Disponível em: <http://www.cnpso.embrapa.br/cultivares/BRS267.pdf>. Acesso em: 25 de junho de 2010d.

FURUTA, S.; NISHIBA, Y.; HAJIKA, M.; IGITA, K.; SUDA, I. DETBA Value and Hexanal Production with the Combination of Unsaturated Fatty Acids and Extracts Prepared from Soybean Seeds Lacking Two or Three Lipoxygenase Isozymes. Journal of Agricultural and Food Chemistry, v.44, p.236-239, 1996.

GALLARDO, J.; ALEGRET, S.; MUÑOZ, R.; De-ROMÁN, N.; LEIJA, L.; HERNÁNDEZ, P. R.; Del VALLE, M. An electronic tongue using potentiometric allsolid-state PVC-membrane sensors for the simultaneous quantification of ammonium and potassium ions in water. Analytical and Bioanalytical Chemistry, v.377, p.248256, 2003.

GÓES-FAVONI, S. P.; BELÉIA, A. D. P.; CARRÃO-PANIZZI, M. C.; MANDARINO, J. M. G. Isoflavonas em produtos comerciais de soja. Ciência e Tecnologia de Alimentos, v. 24, n.4, p.582-586, 2004.

GREGORUT, C.; SILVA, J. B.; WIZIACK, N. K. L., PATERNO, L. G.; PANIZZI, M. C. C.; FONSECA, F. J. Application of electronic tongue in identification of soybeans. In: INTERNATIONAL SYMPOSIUM ON OLFACTION AND ELECTRONIC NOSE, $13^{\text {th }}$, 2009, Brescia, Italia. Proceedings, Melville, NY: American Institute of Physics, 2009. p.533-534.

GUTÉS, A.; CÉSPEDES, F.; ALEGRET, S.; Del VALLE, M. Sequential injection system with higher dimensional electrochemical sensor signals Part 1. Voltammetric e-tongue for the determination of oxidizable compounds. Talanta, v.66, p.1187-1196, 2005.

IIYAMA, S.; YAHIRO, M.; TOKO, K. Measurements of soy sauce using taste sensor. Sensors and Actuators B, v.66, p.205-206, 2000. 
JANARTHANAN, C.; MOTTOLA, H. A. Enzymatic determinations with rotating bioreactors: Determination of glutamate in food products. Analytica Chimica Acta, v.369, p.147-155, 1998.

KANTOR, D. B.; HITKA, G.; FEKETE, A.; BALLA, C. Electronic tongue for sensing taste changes with apricots during storage. Sensors and Actuators B, v.131, p.4347, 2008.

KOMABA, S.; ARAKAWA, J.; SEYAMA, M.; OSAKA, T.; SATOH, I.; NAKAMURA, S. Flow injection analysis of potassium using an all-solid-state potassium-selective electrode as a detector. Talanta, v.46, p.1293-1297, 1998.

KWONG, A. W. K.; GRUNDIG, B.; HU, J.; RENNEBERG, R. Comparative study of hydrogel-immobilized L-glutamate oxidases for a novel thick-film biosensor and its application in food samples. Biotechnology Letters, v.22, p.267-272, 2000.

LAJOLO, F. M.; GENOVESE, M. I. Nutritional Significance of Lectins and Enzyme Inhibitors from Legumes. Journal of Agricultural and Food Chemistry, v.50, p.65926598, 2002.

LAMBRECHT, H. S.; NIELSEN, S. S.; LISKA, B. J.; NIELSEN, N. C. Effect of soybean storage on tofu and soymilk production. Journal of Food Quality, v.19, n.3, p.189-202, 1996.

LEGIN, A.; RUDNITSKAYA, A.; VLASOV, Y.; Di NATALE, C.; DAVIDE, F.; D'AMICO, A. Tasting of beverages using an electronic tongue. Sensors and Actuators B, v.44, p.291-296, 1997.

LEGIN, A.; RUDNITSKAYA, A.; VLASOV, Y.; Di NATALE, C.; MAZZONE, E.; D'AMICO, A. Application of Electronic Tongue for Quantitative Analysis of Mineral Water and Wine. Electroanalysis, v.11, n.10-11, p.814-820, 1999.

LEGIN, A.; RUDNITSKAYA, A.; LVOVA, L.; VLASOV, Y.; Di NATALE, C.; D'AMICO, A. Evaluation of Italian wine by the electronic tongue: recognition, quantitative analysis and correlation with human sensory perception. Analytica Chimica Acta, v.484, p.33-44, 2003.

LEGIN, A.; RUDNITSKAYA, A.; CLAPHAM, D.; SELEZNEV, B.; LORD, K.; VLASOV, $Y$. Electronic tongue for pharmaceutical analytics: quantification of tastes and masking effects. Analytical and Bioanalytical Chemistry, v.380, p.36-45, 2004. 
LIENER, I. E. Possible Adverse Effects of Soybean Anticarcinogens. In: International Symposium on the Role of Soy in Preventing and Treating Chronic Disease, 1., Arizona, 1994. American Institute of Nutrition, 1995. v.125, n.3, p.S744-S750.

LIMA, J. P. H.; ANDRADE, A. M. Morphological analysis of poly(o-methoxyaniline) thin-films deposited by spin coating technique. Journal of Materials Science: Materials in Electronics, v.17, p.593-596, 2006.

LVOVA, L.; LEGIN, A.; VLASOV, Y.; CHA, G. S.; NAM, H. Multicomponent analysis of Korean green tea by means of disposable all-solid-state potentiometric electronic tongue microsystem. Sensors and Actuators B, v.95, p.391-399, 2003.

LVOVA, L.; MARTINELLI, E.; DINI, F.; BERGAMINI, A.; PAOLESSE, R.; Di NATALE, C.; D'AMICO, A. Clinical analysis of human urine by means of potentiometric Electronic tongue. Talanta, v.77, p.1097-1104, 2009.

MARTINA, V.; IONESCU, K.; PIGANI, L.; TERZI, F.; ULRICI, A.; ZANARDI, C.; SEEBER, R. Development of an electronic tongue based on a PEDOT-modified voltammetric sensor. Analytical and Bioanalytical Chemistry, v.387, p.2101-2110, 2007.

MATOBA, T.; HIDAKA, H.; NARITA, H.; KITAMURA, K.; KAIZUMA, N.; KITO, M. Lipoxygenase-2 Isozyme Is Responsible for Generation of $n$ - Hexanal in Soybean Homogenate. Journal of Agricultural and Food Chemistry, v.33, n.5, p.852-855, 1985.

MATTOSO, L. H. C. Polianilinas: Síntese, estrutura e propriedades. Química Nova, v.19, n.4, p.388-399, 1996.

MEDEIROS, E. S.; PATERNO, L. G.; MATTOSO, L. H. C. Sensing applications of conjugated polymers. Editado por GRIMES, C. A.; DICKEY, E. C. e PISHKO, M. V. American Scientific Publishers, 2006. v.X, p.1-36. (EOS: Encyclopedia of Sensors).

MORENO, L.; MERLOS, A.; ABRAMOVA, N.; JIMÉNEZ, C.; BRATOV, A. Multisensor array used as an "electronic tongue" for mineral water analysis. Sensors and Actuators B, v.116, p.130-134, 2006.

NAKORN, P. N.; SUPHANTHARIKA, M.; UDOMSOPAGIT, S.; SURAREUNGCHAI, W. Poly(vinylferrocene)-poly(ethylene glycol) glutamate oxidase electrode for determination of L-glutamate in commercial soy sauces. World Journal of Microbiology \& Biotechnology, v.19, p.479-485, 2003. 
PATERNO, L. G. Fabricação e caracterização de filmes ultra-finos de poli(oetoxianilina) visando a aplicação em sensores de gases. 1999. Dissertação (Mestrado) - Universidade Federal de São Carlos. São Carlos, 1999.

PATERNO, L. G.; MATTOSO, L. H. C. Effect of $\mathrm{pH}$ on the preparation of selfassembled films of poly(o-ethoxyaniline) and sulfonated lignin. Polymer, v.42, p.5239-5245, 2001a.

PATERNO, L. G.; MATTOSO, L. H. C.; OLIVEIRA Jr., O. N. Filmes poliméricos ultrafinos produzidos pela técnica de automontagem: preparação, propriedades e aplicações. Química Nova, v.24, n.2, p.228-235, 2001b.

PIOGGIA, G.; Di FRANCESCO, F.; MARCHETTI, A.; FERRO, M.; AHLUWALIA, A. A composite sensor array impedentiometric electronic tongue Part I. Characterization. Biosensors and Bioelectronics, v.22, p.2618-2623, 2007a.

PIOGGIA, G.; Di FRANCESCO, F.; MARCHETTI, A.; FERRO, M.; LEARDI, R.; AHLUWALIA, A. A composite sensor array impedentiometric electronic tongue Part II. Discrimination of basic tastes. Biosensors and Bioelectronics, v.22, p.2624-2628, 2007b.

PORTAL DO AGRONEGÓCIO. Uma cultivar de soja de sabor mais adocicado que as tradicionais é a novidade da Empresa Brasileira de Pesquisa Agropecuária (Embrapa) para mercado interessado em soja para alimentação humana. 2005. Lebna Landgraf. Disponível em:

<http://www.portaldoagronegocio.com.br/conteudo.php?id=6112>. Acesso em: 25 de junho de 2010.

RIUL Jr., A. A Ciência Imitando o Corpo Humano. Revista Physicae, n.3, p.39-46, 2002.

RIUL Jr., A.; GALLARDO SOTO, A. M.; MELLO, S. V.; BONE, S.; TAYLOR, D. M.; MATTOSO, L. H. C. An electronic tongue using polypyrrole and polyaniline. Synthetic Metals, v.132, p. 109-116, 2003a.

RIUL Jr, A.; MALMEGRIM, R. R.; FONSECA, F. J.; MATTOSO, L. H. C. An artificial taste sensor based on conducting polymers. Biosensors and Bioelectronics, v.18, p.1365-1369, 2003b. 
RIUL Jr, A.; MALMEGRIM, R. R.; FONSECA, F. J.; MATTOSO, L. H. C. Nanoassembled films for Taste Sensor Application. Artificial Organs, v.27, n.5, p.469-472, 2003c.

RIUL Jr., A.; SOUSA, H. C.; MALMEGRIM, R. R.; SANTOS Jr., D. S.; CARVALHO, A. C. P. L. F.; FONSECA, F. J.; OLIVEIRA Jr., O. N.; MATTOSO, L. H. C. Wine classification by taste sensors made from ultra-thin films and using neural networks. Sensors and Actuators B, v.98, p.77-82, 2004.

RUDNITSKAYA, A.; KIRSANOV, D.; LEGIN, A.; BEULLENS, K.; LAMMERTYN, J.; NICOLAI, B. M.; IRUDAYARAJ, J. Analysis of apples varieties - comparison of electronic tongue with different analytical techniques. Sensors and Actuators B, v.116, p.23-28, 2006.

SAGIV, J. Organized Monolayers by Adsorption: I. Formation and Structure of Oleophobic Mixed Monolayers on Solid Surfaces. Journal of the American Chemical Society, v.102, n.1, p.92-98, 1980.

SCAMPICCHIO, M.; BENEDETTI, S.; BRUNETTI, B.; MANNINO, S. Amperometric Electronic Tongue for the Evaluation of the Tea Astringency. Electroanalysis, v.18, n.17, p.1643-1648, 2006.

SILVA, J. B.; PRUDÊNCIO, S. H.; FELBERG, I.; DELIZA, R.; CARRÃO-PANIZZI, M. C. Aceitabilidade de bebidas preparadas a partir de diferentes extratos hidrossolúveis de soja. Pesquisa Agropecuária Brasileira, v.42, n.12, p.1779-1784, 2007.

SILVA, J. B. Características de cultivares de soja convencionais e para consumo humano: análises físicas, químicas e sensoriais (sentidos humano e sensores eletrônicos). 2009. 187p. Tese (Doutorado) - Universidade Estadual de Londrina. Londrina, 2009.

STOCKTON, W. B.; RUBNER, M. F. Molecular-Level Processing of Conjugated Polymers. 4. Layer-by-Layer Manipulation of Polyaniline via Hydrogen-Bonding Interactions. Macromolecules, v.30, p.2717-2725, 1997.

TAYLOR, D. M.; MACDONALD, A. G. AC Admittance of the metal / insulator / electrolyte interface. Journal of Physics D: Applied Physics, v.20, p.1277-1283, 1987.

TOKO, K. Taste sensor with global selectivity. Materials Science and Engineering C, v.4, p.69-82, 1996. 
TORRES-PENARANDA, A. V.; REITMEIER, C. A.; WILSON, L. A.; FEHR, W. R.; NARVEL, J. M. Sensory Characteristics of Soymilk and Tofu Made from Lipoxygenase-Free and Normal Soybeans. Journal of Food Science, v.63, n.6, p.1084-1087, 1998.

TORRES-PENARANDA, A. V.; REITMEIER, C. A. Sensory Descriptive Analysis of Soymilk. Journal of Food Science, v.66, n.2, p.352-356, 2001.

UNITED STATES DEPARTMENT OF AGRICULTURE. World Agricultural Production Archives: Soybean Area, Yield, and Production. Disponível em:

$<$ http://www.fas.usda.gov/psdonline/psdreport.aspx?hidReportRetrievalName=BVS\& hidReportRetrievallD=906\&hidReportRetrievalTemplatelD=1>. Acesso em: 21 de maio 2009.

WINQUIST, F.; WIDE, P.; LUNDSTROM, I. An Electronic Tongue based on voltammetry. Analytica Chimica Acta, v.357, p.21-31, 1997.

WINQUIST, F.; KRANTZ-RULCKER, C.; WIDE, P.; LUNDSTROM, I. Monitoring of freshness of milk by an electronic tongue on the basis of voltammetry. Measurement Science and Technology, v.9, p.1937-1946, 1998.

WIZIACK, N. K. L. Estudo do desempenho de uma língua eletrônica baseada em materiais nanoestruturados. 2005. Dissertação (Mestrado) - Escola Politécnica, Universidade de São Paulo. São Paulo, 2005.

WIZIACK, N. K. L.; PATERNO, L. G.; FONSECA, F. J.; MATTOSO, L. H. C. Effect of film thickness and different electrode geometries on the performance of chemical sensors made of nanostructured conducting polymer films. Sensors and Actuators B, v.122, p.484-492, 2007. 